Illinois State University

ISU ReD: Research and eData

Theses and Dissertations

$5-22-2019$

\title{
The Differential Effects Of An Interspersing Procedure Among Students At Different Instructional Levels
}

Samantha DeHaan Sullivan

Illinois State University, sdehaan.sullivan@gmail.com

Follow this and additional works at: https://ir.library.illinoisstate.edu/etd

Part of the Educational Psychology Commons, and the Psychology Commons

\section{Recommended Citation}

Sullivan, Samantha DeHaan, "The Differential Effects Of An Interspersing Procedure Among Students At Different Instructional Levels" (2019). Theses and Dissertations. 1134.

https://ir.library.illinoisstate.edu/etd/1134

This Dissertation is brought to you for free and open access by ISU ReD: Research and eData. It has been accepted for inclusion in Theses and Dissertations by an authorized administrator of ISU ReD: Research and eData. For more information, please contact ISUReD@ilstu.edu. 


\section{THE DIFFERENTIAL EFFECTS OF AN INTERSPERSING PROCEDURE AMONG}

\section{STUDENTS AT DIFFERENT INSTRUCTIONAL LEVELS}

\section{SAMANTHA DEHAAN SULLIVAN}

\section{Pages}

This dissertation reports the results of a research project that examined the effects of varying rates of reinforcement on students' math performance and assignment preference. The relationship between students' instructional level and the rate of reinforcement threshold for influencing assignment preference was also explored. Participants were fourth and fifth grade elementary students who were receiving remedial math services through the school's Response to Intervention program.

Twenty elementary students (12 females, 8 males) completed all parts of the study and were included in the analyses. All participants completed a series of control-experimental assignment pairs with varying rates of interspersing at each student's instructional and frustration level. After completing each assignment pair, participants were asked to rate their perceptions of assignment time, difficulty, and effort to complete on a dichotomous and continuous rating scale. Further, participants assignment preference was assessed by asking students to choose an assignment they would like to take home for homework. Results were analyzed using visual analysis, planned comparisons, and ANOVAs. There was evidence that participants relative problem completion rates were lower on 1:1 and 2:1 instructional level assignment pairs than frustration assignment pairs at the same rate of interspersing. Moreover, a visual analysis indicated that relative problem completion rates increased as the rate of interspersing became 
denser on instructional level assignments. Total problem completion rates increased on experimental assignments as the rate of interspersing became denser; however, there was minimal to no visible difference on target problem completion rates for control and experimental assignments at the same instructional level. Total problem accuracy increased as the rate of interspersing became denser on experimental assignments at frustration level only. There was a visible difference for target problem accuracy between instructional and frustration level assignments, but there was minimal to no visible difference between experimental and control assignments at the same instructional level despite the rate of interspersing. Instructional level assignments were perceived as requiring less time, effort, and as being less difficult overall than frustration level assignments; however, participants tended to perceive control assignments at instructional level as more favorable than experimental assignments on continuous and forcedchoice rating scales. With regard to assignment preference, participants were more likely to choose experimental assignments for homework than paired controls across rates of interspersing. KEYWORDS: math interspersal; elementary students; homework; assignment modification; interspersal; matching law 
THE DIFFERENTIAL EFFECTS OF AN INTERSPERSING PROCEDURE AMONG

STUDENTS AT DIFFERENT INSTRUCTIONAL LEVELS

SAMANTHA DEHAAN SULLIVAN

A Dissertation Submitted in Partial

Fulfillment of the Requirements

for the Degree of

DOCTOR OF PHILOSOPHY

Department of Psychology

ILLINOIS STATE UNIVERSITY

2019 
(C) 2019 Samantha DeHaan Sullivan 
THE DIFFERENTIAL EFFECTS OF AN INTERSPERSING PROCEDURE AMONG STUDENTS AT DIFFERENT INSTRUCTIONAL LEVELS

SAMANTHA DEHAAN SULLIVAN

COMMITTEE MEMBERS:

Gary Cates, Chair

Craig Blum

Valeri Farmer-Dougan

Mark Swerdlik 


\section{ACKNOWLEDGMENTS}

I would like to thank all who have supported me while completing my dissertation. I would like to thank Dr. Gary Cates, my dissertation chair, for his guidance throughout the development and revision of this dissertation. In addition to Dr. Cates, I would also like to thank my dissertation committee, Drs. Swerdlik, Farmer-Dougan, and Blum, for providing me with critical feedback to improve my dissertation.

I dedicate this dissertation to all of the amazing people in my life who have provided their unwavering support and encouragement throughout my doctoral training, including my parents, Brian DeHaan and Clare Duran, my husband, Michael Sullivan, and my dear friend, Amanda Rohan. Your love, support, and advice throughout this journey has provided me the motivation I needed to complete this final step in becoming Dr. DeHaan Sullivan.

S. D. S 


\section{CONTENTS}

Page

ACKNOWLEDGMENTS

TABLES $\quad$ V

FIGURES

CHAPTER I: INTRODUCTION 1

CHAPTER II: LITERATURE REVIEW 9

$\begin{array}{ll}\text { Background } & 9\end{array}$

Response to Intervention $\quad 11$

$\begin{array}{ll}\text { Instructional Level } & 13\end{array}$

$\begin{array}{ll}\text { Academic Engagement } & 16\end{array}$

$\begin{array}{ll}\text { Matching Law } & 24\end{array}$

Mathematics Interspersing 33

$\begin{array}{ll}\text { Hypotheses } & 46\end{array}$

$\begin{array}{ll}\text { CHAPTER III: METHODS } & 50\end{array}$

$\begin{array}{ll}\text { Methods } & 50\end{array}$

$\begin{array}{ll}\text { Participants } & 50\end{array}$

$\begin{array}{ll}\text { Measures } & 50\end{array}$

$\begin{array}{ll}\text { Procedures } & 54\end{array}$

$\begin{array}{ll}\text { Experimental Design } & 57\end{array}$

$\begin{array}{ll}\text { Data Analysis } & 58\end{array}$

CHAPTER IV: RESULTS

$\begin{array}{ll}\text { Baseline Results } & 61\end{array}$ 
Instructional-Frustration Control Pair Performance Data $\quad 61$

Instructional-Frustration Control Pair Perception Data 63

Instructional-Instructional Control Pair Data $\quad 66$

$\begin{array}{ll}\text { Frustration-Frustration Control Pair Data } & 68\end{array}$

$\begin{array}{ll}\text { Results } & 70\end{array}$

$\begin{array}{ll}\text { Hypothesis } 1 & 70\end{array}$

$\begin{array}{ll}\text { Hypothesis } 2 & 73\end{array}$

$\begin{array}{ll}\text { Hypothesis } 3 & 87\end{array}$

$\begin{array}{ll}\text { Hypothesis } 4 & 99\end{array}$

$\begin{array}{ll}\text { Hypothesis } 5 & 109\end{array}$

CHAPTER V: DISCUSSION 113

$\begin{array}{ll}\text { Discussion } & 113\end{array}$

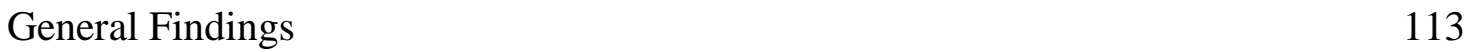

Consistency With Previous Research 114

Extension of Literature on Interspersing 116

$\begin{array}{ll}\text { Study Strengths } & 117\end{array}$

Limitations and Future Directions for Research $\quad 118$

$\begin{array}{lr}\text { Conclusions } & 120\end{array}$

$\begin{array}{ll}\text { REFERENCES } & 121\end{array}$

APPENDIX A: PARENT CONSENT 139

APPENDIX B: PARTICIPANT ASSENT FORM 140

APPENDIX C: RESEARCHER ASSENT SCRIPT 141

APPENDIX D: DEMOGRAPHICS FORM 142 
APPENDIX E: CONTROL, AT INSTRUCTIONAL LEVEL (WITHOUT CARRYING), ASSIGNMENT EXAMPLE

APPENDIX F: CONTROL, AT FRUSTRATION LEVEL, ASSIGNMENT EXAMPLE 144

APPENDIX G: 1:3 EXPERIEMNTAL ASSIGNMENT EXAMPLE 145

APPENDIX H: 1:1 EXPERIMENTAL ASSIGNMENT EXAMPLE 147

APPENDIX I: 2:1 EXPEIRMENTAL ASSIGNMENT EXAMPLE 149

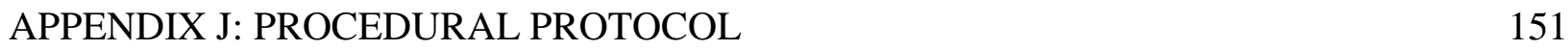

APPENDIX K: PREFERENCE AND PERCEPTION RATINGS WORKSHEET 155

$\begin{array}{ll}\text { APPENDIX L: PARTICIPANT DEBRIEFING SCRIPT } & 156\end{array}$

APPENDIX M: INTERVENTION FIDELITY CHECKLIST 157 


\section{TABLES}

Table

Page

1. Planned Comparison of Performance Measures on Baseline Control Instructional versus Control Frustration Assignment Pair

2. Planned Comparison of Performance and Perception Measures on Baseline Control Instructional versus Control Frustration Assignment Pair

3. Comparison of Total Problems Completed, Total Accuracy, and Likert Perception Ratings Between Baseline Control Instructional and Baseline Control Instructional Assignment Pair

4. Comparison of Total Problems Completed, Total Accuracy, and Likert Perception Ratings Between Baseline Control Frustration and Baseline Control Frustration Assignment Pair

5. Comparison of Relative Problem Completion Rates between Assignments at Instructional versus Frustration Level

6. Comparison of Total Problems Completed on Control versus Experimental Assignments and Assignments at Instructional versus Frustration Level

7. Comparison of Target Problems Completed on Control versus Experimental Assignments and Assignments at Instructional versus Frustration Level

8. Comparison of Total Problem Accuracy on Control versus Experimental Assignments and Assignments at Instructional versus Frustration Level

9. Comparison of Target Problem Accuracy on Control versus Experimental Assignments and Assignments at Instructional versus Frustration Level

10. Comparison of Likert Scale Ratings on Control versus Experimental Assignments and Assignments at Instructional versus Frustration Level 


\section{FIGURES}

Figure

Page

1. Sessions 2-4 assignment pairs $\quad 55$

2. Control-experimental assignment pairs 56

3. Total problems completed and total accuracy on control-instructional and controlfrustration assignment pair at baseline

4. Ratings on Likert scale for time, effort, and difficulty on control-instructional and control-frustration assignment pair at baseline

5. Percentage of participants who chose the frustration-level assignment as requiring more time and effort and being more difficult to complete than the paired instructional-level control assignment at baseline

6. Total problems completed and total accuracy on control-instructional and controlinstructional assignment pair at baseline

7. Ratings on Likert scale for time, effort, and difficulty on control-instructional and control-instructional assignment pair at baseline

8. Total problems completed and total accuracy on control-frustration and controlfrustration assignment pair at baseline

9. Ratings on Likert scale for time, effort, and difficulty on control-frustration and control-frustration assignment pair at baseline

10. Results for relative problem completion rates

11. Results for total problem completion means across conditions of each independent variable (i.e., experimental vs. control; instructional vs. frustration level)

12. Results for planned comparisons of mean total problem completion data for assignment type (experimental or control) and assignment difficulty (at instructional level or at frustration level)

13. Results for within participant total problem completion rates/across participant mean total problem completion rates across experimental and control assignments at instructional or frustration level

14. Results for comparison of mean total problem completion means for experimental assignments vs. paired controls 
15. Results for target problem completion means across conditions of each independent variable (i.e., experimental vs. control; instructional vs. frustration level)

16. Results for planned comparisons of mean target problem completion data for assignment type (experimental or control) and assignment difficulty (at instructional level or at frustration level)

17. Results for within participant target problem completion rates/across participant mean target problem completion rates across experimental and control assignments at instructional or frustration level

18. Results for comparison of mean target problem completion for experimental assignments vs. paired controls

19. Results for total problem accuracy means across conditions of each independent variable (i.e., experimental vs. control; instructional vs. frustration level)

20. Results for visual analysis of mean total problem accuracy data for assignment type (experimental or control) and assignment difficulty (at instructional level or at frustration level)

21. Results for within participant total problem accuracy and across participant mean total problem accuracy across experimental and control assignments at instructional or frustration level

22. Results for comparison of mean target problem accuracy for experimental assignments vs. paired controls

23. Results for target problem accuracy means across conditions of each independent variable (i.e., experimental vs. control; instructional vs. frustration level)

24. Results for visual analysis of mean target problem accuracy data for assignment type (experimental or control) and assignment difficulty (at instructional level or at frustration level)

25. Results for within participant target problem accuracy and across participant mean target problem accuracy across experimental and control assignments at instructional or frustration level

26. Results for comparison of mean target problem accuracy for experimental assignments vs. paired controls

27. Perception ratings from Likert scale for time across assignment conditions

28. Perception ratings from Likert scale for effort across assignment conditions 
34. Preference results for experimental and control assignments at each instructional level and ratio of interspersing

35. Preference results for experimental and control assignments with overlay of Relative Problem Completion Rate results for each instructional level and ratio of interspersing

36. Preference results for experimental and control assignments with overlay of Total Problem Completion Rates results for each instructional level and ratio of interspersing 


\section{CHAPTER I: INTRODUCTION}

In the United States, students have consistently performed lower in mathematics than students in other countries (Kenna, 2016; National Assessment of Educational Progress, 2017; Organization for Economic Cooperation and Development, 2015). Math deficits are frequent among students and are often related to difficulties with number sense, basic operations, and solving word problems. Moreover, students who experience skill deficits in the area of math are more likely to experience long-term academic difficulties, have poor perceptions of and motivation to complete math tasks, and have lower levels of academic engagement than students who do not underperform in math (Moors, Weisenburgh-Snyder, \& Robbins, 2010). In an effort to support student learning across academic areas, including math, laws have been established in an effort to outline school standards and expectations for promoting student success and providing an optimal learning environment and experience (e.g. Every Student Succeeds Act; 2015; Individuals with Disabilities Education Act, 2004). Revisions to legislation have led to an increase in school accountability, such that there is more pressure on school districts to develop effective and efficient procedures for identifying students in need of intervention. To increase efficiency, educators are encouraged to use assessment tools that can also inform intervention and curriculum modification strategies. Specifically, assessment procedures should inform ways to individualize evidence-based interventions and strategies to address each student's unique educational needs (Gresham, 2006).

Response to Intervention (RtI) is a multi-tier system of supports framework that emphasizes early identification and remediation of academic, social, and behavior concerns, as well as early intervention and regular monitoring of student progress. RtI consists of tiers that represent the intensity of support services provided. Tier 1 consists of the services and supports 
provided to all students, such as the general curriculum. Tier 2 supports include small group services that target a specific academic, social-emotional, or behavioral skill set. Finally, Tier 3 supports consist of individualized interventions provided at a higher frequency and intensity than lower-level tiers. When applying RtI to math, students’ progress through a hierarchical structure that indicates an increasing need for individualized, direct, intervention and support services. RtI has gained popularity as a guided system for educators to efficiently and effectively identify math supports at an appropriate level of intensity for individual students based on standard math assessment procedures. When a student does not demonstrate sufficient math progress at a given tier of service, the intensity of math supports increase until he or she demonstrates stable progress or the need for special education is identified (Cates, Blum, \& Swerdlik, 2011; Gresham, 2006). As RtI continues to gain momentum as a framework of service delivery in math it is important for researchers and educators to identify evidence-based instructional strategies and interventions that can be modified to address students' individual needs at various tiers of service.

Teachers often assign independent seatwork assignments to encourage students to practice new skills and to gain mastery with completing previously learned skills. However, students who choose to engage in non-academic behaviors may become disruptive to their own, as well as other students', learning and mastery of math skills through the use of independent seatwork. Although teachers may be instructed to use targeted behavioral strategies to address disruptive non-academic behaviors, this can become challenging to balance when multiple students require assistance with sustaining engagement in their work and/or assistance with understanding the material (Lane, Oakes, \& Menzies, 2014). Since progression in math requires mastery of lower-level skills prior to learning higher-level skills, students with math deficits are 
at an even higher risk of falling further behind, having more negative perceptions of math tasks, and being less motivated to be academically engaged than students with difficulties in other academic areas (Bryant, Bryant, \& Hammill, 2000; Fuchs et al., 2004). It likely that evidencebased strategies to address math concerns will prove to be ineffective if concomitant behavioral challenges that impede engagement are not adequately addressed. In fact, research has demonstrated that students who spend less time engaging in academic-related behaviors and more time engaging in non-academic behaviors, such as talking out of turn and engaging in offtask behaviors, are at a higher risk of his or her academic deficit worsening due to having fewer opportunities to respond appropriately (Greenwood, 1991; Greenwood, Delquadri, \& Hall, 1984; Reschly, Appleton, Pohl, 2014; Shapiro, 2011). Thus, it is imperative that researchers evaluate the use of evidence-based strategies that concurrently address academic engagement on math tasks and facilitate the learning and mastery of math skills through increased learning trials. One way of achieving this goal is to evaluate the use of evidence-based assignment modification strategies to improve students' perceptions of and preference for math tasks to promote optimal levels of academic engagement during math instruction and independent seatwork, particularly for those students who have math deficits.

Research has demonstrated that modifying assignments to meet individual student needs has a positive influence on student response rates (i.e., learning trials or opportunities to practice a skill), assignment preference and perceptions, and academic engagement (Denton, 2012; Gettinger \& Stoiber, 2011; Stoiber \& Gettinger, 2016; Vaughn \& Chard, 2006). Assignment modification strategies with supporting research include providing students with a legitimate opportunity to choose aspects of the academic task (e.g., sequencing of task presentation, choose a task amongst menu of similar tasks with slight variations; Dunlap et al., 1994; Dunlap \& Kern, 
1996; Kern, Mantegna, Vorndran, Bailin, \& Hilt, 2001), integrating individual student preferences into tasks (Clarke et al., 1995; Kern, Delaney, Clarke, Dunlap, \& Childs, 2001), and providing reinforcement for academic-related behaviors (Mace, Neef, Shade, \& Mauro, 1996; Martens, Lochner, \& Kelly, 1992; Neef, Mace, Shea, \& Shade, 1992; Neef, Shade, \& MIller, 1994; Skinner, Wallace, \& Neddenriep, 2002). Moreover, research on interspersing procedures suggest that completion of assignments with brief and easy problems interspersed amongst longer and more difficult target problems is related to improvements in students' academic engagement, perceptions of effort and time to complete the assignment, perceptions of assignment difficulty, work productivity, and willingness to take an assignment with more problems home for homework (Billington, Skinner, \& Cruchon, 2004; Cates \& Erkfritz, 2007; Cates \& Skinner, 2000; Logan \& Skinner, 1998; McDonald \& Ardoin, 2007; Wildmon, Skinner, Watson, \& Garrett, 2004). Studies that examine the interspersing procedure typically alter the rate of interspersing on experimental assignments (e.g., one brief problem for every five or three target problems) and pair experimental assignments with one another and/or a control assignment without interspersing. Results consistently suggest that students demonstrate more favorable perceptions of and preference for assignments with interspersing than control assignments. Further, students tend to favor and complete more problems overall on assignments with denser rates of interspersing (i.e., higher rate of reinforcement rates) than assignments with less dense rates of interspersing (Billington, Skinner, \& Cruchon, 2004; Cates \& Dalenberg, 2005; Cates \& Erkfritz, 2007; Cates \& Skinner, 2000; Logan \& Skinner, 1998; McDonald \& Ardoin, 2007; Wildmon, Skinner, Watson, \& Garrett, 2004). The Matching Law has provided one explanation as to why interspersing procedures are effective in influencing students' choice behaviors, such 
as academic engagement, problem completion rates, perceptions, and preference (Herrnstein, 1970).

The Matching Law posits that an organism will allocate its behavior between two concurrent alternatives as proportionate to the ratio of reinforcement between the two behaviors. In other words, organisms are more likely to choose to spend more time or responses engaging in a behavior alternative that has the higher proportion of reinforcement, and less time or responses for the behavior alternative that provides a lower proportion of reinforcement (McDowell, 2013; Herrnstein, 1970). Researchers who examine interspersing procedures often assess participants’ relative problem completion rates (i.e., the number of problems completed on experimental assignments divided by the number completed on control assignments) and have demonstrated that assignment preference, perceptions of time, difficulty and effort, and academic engagement varies as a function of the relative problem completion rates in accordance with the matching law (See Skinner, 2002 for a full review). However, this assumption forces one to presume that the completion of a discrete problem serves as a reinforcing event. The discrete task completion hypothesis was thus developed to propose the idea that completion of a discrete problem or task acts as a reinforcing event due to principals of operant conditioning. Specifically, completion of a discrete task may reinforce academic-related behaviors by signaling to the student that they are closer to completing the assignment and having access to a preferred task (e.g., earning a break, reading a preferred book, talking to peers). Conversely, completion of a discrete task may negatively reinforce a student's academic-related behavior due to indicating that the student is closer to completing the assignments and thus escaping a potentially unfavorable consequence, such as missing recess (Skinner, 2002; Skinner, Hurst, Teeple, \& Meadows, 2002). 
Researchers have examined whether the completion of a task acts as a reinforcing event and results have demonstrated support for the discrete task completion hypothesis (Logan \& Skinner, 1998; Skinner, 2002; Skinner, Hurst et al., 2002). Thus, students are more likely to prefer academic assignments that result in high problem completion rates relative to academic assignments that results in low problem completion rates; in other words, discrete problem completion acts as a signal that the completion of the assignment is or is not forthcoming and influences preference. Moreover, students are more likely to choose assignments that produce higher rates of problem completion because completing a discrete task is indicative of being closer to completing the entire assignment and having access to a preferred reinforcer or escaping a negative consequence. Although, researchers have consistently demonstrated that students choose to engage in math assignments that include brief problems interspersed and that students vary in the level of reinforcement required for him or her to begin demonstrating preference for a task (Cates \& Skinner, 2000; Cates \& Dalenberg, 2005; Cates \& Erkfritz, 2007; Logan \& Skinner, 1998). Thus, understanding the unique characteristics of students that account for the level of reinforcement required to evoke changes in engagement, as well as preference for and perceptions of academic tasks, is important in developing individualized assignments with interspersing to target specific groups of students.

The ratio of mastered tasks and newly or unlearned tasks, or instructional load of assignments, is one factor that has been shown to impact academic performance, engagement, and skill development. Specifically, tasks that include problems that are too advanced relative to a student's skill level, or at the student's frustration level, increase the likelihood that he or she will choose to engage in non-academic behaviors that result in more reinforcement than the assigned task. Moreover, when assignments are appropriate for a student's skill level, such that it 
provides an appropriate level of challenge without eliciting frustration, the student is more likely to choose to engage in and have more motivation to complete the assignment. Considering that students who receive remedial math services likely vary with regard to skill level, it is important to modify assignments by matching a student's instructional level to the instructional load of the assignment. McDonald and Ardoin (2007) attempted to account for instructional level when examining the relationships between interspersing procedures and assignment engagement, preference, and perceptions. However, participants were grouped based on arbitrary math fluency criteria, rather than each individual student's instructional level. Results mimicked those of other interspersing studies in that some participants demonstrated changes in problem completion rates and perceptions of and preference for assignments while other participants did not follow this trend, as the matching law would predict. Although there was an attempt to control for instructional level, the inconsistent results were partially attributed to students' varying skill levels within each group. Thus, experimental assignments were at an appropriate instructional for some students within a group but were still at frustration level for other students. These results led to the recommendation that future research examine the interaction between instructional level for individual students and interspersing procedures on academic engagement, problem completion rates, and assignment preference and perceptions.

The current study sought to examine whether participants' rate of responding, problem accuracy, and preference for and perceptions of assignments vary as a function of the rate of interspersing and instructional level of the assignment. Further, this study made use of a curriculum-based measurement tool to evaluate each participant's skill level that is commonly used to make educational decisions regarding movement along tiers of service delivery within an RtI framework. Results from this study contribute to the current interspersal literature, as well as 
expand on current research, by examining whether matching a student's instructional level to the assignment influences performance, as well as preference and perception ratings. Further, the current study may have applied implications for educators responsible for developing math tasks for remedial math students at varying skill levels. 


\section{CHAPTER II: LITERATURE REVIEW}

\section{Background}

The primary goal of education in the United States is to provide all students with an equal opportunity to be successful in school. However, the United States Department of Education reports that a large percentage of students continue to struggle in math. In $2015,40 \%$ of fourthgrade students were at or above and 18\% were below proficiency in basic math skills (Kenna et al., 2016; National Assessment of Educational Progress, 2015). These results highlight the dire need for improvements in the early identification of students with math difficulties and evidencebased intervention and instructional practice for such students.

In an effort to increase accountability in the educational process, data-based decision making (i.e., systematic collection, analysis, and interpretation of data to make informed educational decisions) has been integrated within various state and federal education laws and resulting educational policies. The reauthorization of the Individuals with Disabilities Education Act (2004) mandates that every student has the right to a "free and appropriate education" regardless of a person's disability status, which includes meeting his or her individual educational needs. Further, the Every Student Succeeds Act (2015), which represents a reauthorization of No Child Left Behind (2002), requires local education agencies to develop a plan for using systematic and data-driven approaches to identify students in need of educational supports in addition to assessing student progress toward state academic standards. With the heavy emphasis on data-based decision making and supporting individual student needs, schools must identify and use reliable and valid assessment methods that inform instructional practices and increase the likelihood for a student's academic success (Gresham, 2006; Shapiro, 2011). Further, Every Student Succeeds Act has increased schools’ accountability for identifying 
evidence-based interventions that are effective for remediating individual student's unique learning difficulties. This study partially focused on the use of effective and efficient procedures for evaluating a student's instructional level and modifying assignments based on these data in an effort to improve student’s performance on, perceptions of, and preference for math assignments.

Past practices for identification of students' educational needs focused on determining whether there was a discrepancy between a student's performance on standardized measures of aptitude (i.e., cognitive ability) and achievement. Observed discrepancies between scholastic aptitude and achievement were inferred to indicate a within the student problem, thus justifying a label of a specific learning disability and indicating a need for intensive educational supports and/or interventions. Further, it was assumed that once a student's aptitude was identified an intervention targeting his or her specific aptitude deficit could be identified that would indirectly result in improved academic performance. If a discrepancy was not observed the student would continue to be educated in the general education classroom, typically with limited support for their specific academic difficulties. Without the proper supports in place, students who are not observed to have a discrepancy between aptitude and academic achievement are likely to continue to struggle and their academic deficits would continue to impact academic progress or overall success. The discrepancy approach has been characterized as a "wait-to-fail” model and, given its limited support in empirical literature, is no longer the required method of identifying learning problems in many states (Burns, Codding, Boice, \& Lukito, 2010; Cronbach, 1957; Cronbach \& Snow, 1977; Gresham, 2006; Kenna et al., 2016; Moors et al., 2010; Shapiro, 2011). Other methods of identifying a specific learning disability include documenting a lack of response to intervention implemented with fidelity and a significant discrepancy in performance 
from same-grade peers in an academic skill area. Although some school districts may require the documentation of a cognitive processing deficit for the identification of specific learning disabilities, research does not support the utility of cognitive testing in informing recommendations for modifications to instructional practices or interventions in academic settings. This discovery, along with recent legislation placing more accountability for the early implementation of evidence-based assessment and intervention strategies to meet the unique needs of students on schools, further supports the need for alternative methods for identifying student's in need of remedial services and determining appropriate modifications and interventions for a student's unique needs. RtI is a data-based decision making framework that is used in educational systems to promote the early identification of students with learning difficulties, prevention of persistent or worsening learning difficulties, and the use of data to identify effective and individualized intervention strategies (Bradley, Danielson, \& Doolittle, 2005; Burns, VanDerHeyden, \& Zaslofsky, 2014; D. Fuchs, Mock, Morgan, \& Young, 2003).

\section{Response to Intervention}

RtI in math refers to a team-based approach to data-based decision-making practices for the identification of students struggling to achieve success when only receiving the core math curriculum. RtI emphasizes the standard implementation of math interventions at varying levels of intensity to remediate students’ skill deficits (Gresham, 2006; Moors et al., 2010). Thus, a major component of RtI is the provision of evidence-based math practices (e.g., structured or semi-structured programs, supports, and interventions) based on individual needs to optimize each students' opportunity to succeed. Evidence-based practices are those that integrate researchbased strategies and programs with clinical judgment to provide services that are appropriate for students within their learning and living context, individual characteristics, and cultural 
background (Cates et al., 2011; Sugai \& Horner, 2009). With an increased emphasis on identifying appropriate intervention methods for individual students, educators should seek to improve current practice with prescribing interventions and recommendations at the individualstudent level.

Tiered approaches to math services delivery, such as RtI, help to ensure that students are receiving adequate supports and services if the universal math curriculum is not meeting his or her needs (Stoiber \& Gettinger, 2016). A major advantage of using an RtI model with math is that it focuses on a risk versus deficits model through the early identification of students at risk for math failure rather than waiting for students to fall so far behind that the likelihood of successful remediation of specific math skill deficits would be unlikely. Standard RtI frameworks involve a three-tiered system with universal instruction/programming at the lowest tier (i.e., tier 1), programs and strategies to supplement the core curriculum in each area of concern at the middle tier (i.e., tier 2), and highly intensive, individualized, intervention services at the highest tier (i.e., tier 3; Stoiber, 2014; Stoiber \& Gettinger, 2016). Understanding how to assign students to tiers may be better understood by understanding variables related to positive outcomes. These include matching student instruction to his or her skill level, providing the correct ratio of learned to mastered material, and increasing academic engagement.

There is increasing focus on the use of efficient and effective assessment procedures to identify students' skill deficits and to assist in the development and monitoring of individualizedinterventions as students move through the RtI tiers of math service delivery. Therefore, it is important for school personnel involved in making educational decisions for individual students to have effective and efficient procedures to evaluate students' math skill deficits and link the results to standard modification techniques and/or interventions; thus, promoting increased 
opportunity for academic growth (Gresham, 2006; Kelley, Hosp, \& Howell, 2008; Stoiber, 2014;

Stoiber \& Gettinger, 2016; Ysseldyke et al., 2003). Further, with schools having more accountability for ensuring that the current instructional and intervention procedures are appropriate for students, it is important for educators to understand the factors influencing students' engagement in, motivation to complete, and performance on math tasks. Understanding such factors can also assist educators in modifying academic tasks and/or interventions to improve the student's academic engagement and learning experience. Instructional level of academic-tasks is one factor that has been shown to influence student's learning and academic engagement (Bramlett et al., 2010; Burns et al., 2014; Gravois \& Gickling, 2008). This research focused on the use of pre-established identification procedures to determine remedial math students' (i.e., students in tiers 2 or 3 ) current instructional level in math computation to inform the development of math assignments using an instructional modification technique (i.e., additive interspersing procedure) demonstrated to improve student engagement in and acceptability of academic tasks.

\section{Instructional Level}

Research has demonstrated the importance of controlling for instructional load to enhance intraindividual factors that are known to impact academic performance and skill development. When an academic task is matched to the student's skill level, such that it provides an appropriate level of challenge without increasing frustration, students tend to be more academically engaged, experience less anxiety about attempting the task, and are more motivated to respond (DiPerna \& Elliott, 2002; DiPerna, Volpe, \& Elliott, 2005; Gickling \& Armstrong, 1978; Gottfried, 1982; Shapiro, 2011). Thus, it is important to recognize that, in addition to assessment data being used to make decisions about movement along RtI tiers of service delivery 
(i.e., referral, screening, and classification of specific learning problems and behavioral concerns), data may also be used to make important educational decisions for students, such as progress monitoring, creating individualized interventions and accommodations, and prescribing individualized modification based on a student's current level of performance. Given the utility of assessment data in informing educational practices, it is imperative that standard assessment and data-based decision-making procedures are established and used in schools to collect data that can inform curriculum and intervention modifications (Shapiro, 2011). Assessment procedures commonly used or emphasized in educational research or school systems are curriculum based measurement (CBM) and curriculum based evaluations (CBE) (Skinner, 2004). Given that focusing on changes in academic performance over time requires more frequent assessment, curriculum-based measurements (CBM) were developed as a standardized progress monitoring tool to regularly assess a student's performance in the core areas of reading, mathematics, spelling, and written expression relative to grade-level standards while also considering the time constraints of school personnel (Ardoin et al., 2005; Deno, 1985; Lichtenstein, 2014). Both CBM and CBE can be used to evaluate a student's current level of performance in a given academic area; however, CBE, unlike CBM, provides information regarding a student's performance relative to same-grade peers in addition to an error-analysis of basic skill probes and other evaluation measures to assist in the problem-solving process. The CBE process employs a problem-solving approach that includes identifying the problem and potential causes, developing an intervention to target the specific causes, and evaluating whether the intervention is effective and, if necessary, why it may not be effective (Howell \& Hosp, 2014; Shapiro, 2011). Thus, CBE can be useful in assisting educators in the development of 
individualized interventions and curriculum modification strategies, such as adjusting instructional level of the task, that targets a student's identified area of concern.

Academic tasks are thought to be at one of three levels for students: frustration, instructional, or mastery/independent. If the demands of a task are too great for a student in comparison with his or her skills, the task it said to be at the frustration level for that student. When the ratio of known and unknown material is at an appropriate level to where it promotes student engagement and reduces the likelihood of the student becoming frustrated when completing the assignment, the task is said to be at an instructional level. The most learning occurs when the academic material is at a student's instructional level. When the demands of the task do not provide sufficient challenge, which can potentially decrease student engagement or fail to promote further academic progress, the task is said to be at mastery, or independent, level. CBE has been demonstrated to provide an indication of instructional load by evaluating a student's current performance ratio of unknown to known material. This information can then be used to compare a student's current skill level and the level of skill required to be successful on a particular task (i.e., instructional level; Burns et al., 2010; Gravois \& Gickling, 2008).

The suggested overall performance on an academic task to be categorized as a frustration, instructional, or mastery level varies across skill areas. Generally, it is suggested that tasks at frustration level include $70 \%$ or less known material, instructional level includes $70 \%$ to $85 \%$ known material, and mastery level includes $90 \%$ to $100 \%$ known material (Deno \& Mirkin, 1977; Gickling \& Thompson, 1985; Gravois \& Gickling, 2008; Shapiro, 2011). In mathematics, calculating digits correct per minute has also been determined to be an effective procedure for examining the identification of instructional levels of math tasks and correlates with overall math achievement. Digits correct per minute has been shown to be a more accurate and reliable 
method of determining whether a single skill math probe is at frustration (e.g., 0-19 DCPM), instructional (e.g., 20-39 DCPM), or mastery (e.g., 40+ DCPM) level (Burns et al., 2010; Burns, VanDerHeyden, \& Jiban, 2006). DCPM norms for identifying instructional level vary by gradelevel. Moreover, the assessments from which these data are gathered, such as CBM probes, can be further analyzed using CBE procedures to examine the types of problems the student often gets incorrect and/or the types of errors that the student frequently makes, develop interventions targeting the specific skill deficit, and then evaluate whether the intervention was effective (Burns et al., 2010; Kelley et al., 2008). It is clear that the instructional load of a task and matching tasks with a student's skill level has an impact on student learning (Bramlett et al., 2010; Burns et al., 2014; Gickling \& Armstrong, 1978; Ysseldyke et al., 2003). It is therefore important to investigate the variables that may contribute to learning that are inherent within instructional load, such as increasing student response rates, academic engagement, and acceptability of instructional tasks.

\section{Academic Engagement}

Educators work to develop teacher-led, student-led, and independent seatwork activities that promote students' acquisition, fluency, and generalization of academic material. Research has demonstrated that the degree to which a student is actively engaged through actively responding during academic tasks (i.e., academic engagement) influences learning rate and is a strong predictor of academic achievement and performance on CBMs (Gettinger \& Miller, 2014; Greenwood et al., 1984; Logan \& Skinner, 1998; Shapiro, 2011). Identifying methods to increase academic engagement and decrease nonacademic related behaviors (i.e., disruptive behaviors or passive engagement in unrelated tasks) is key in maximizing a student's educational experience and performance (Billington, Skinner, Hutchins, \& Malone, 2004; Skinner, Pappas, \& Davis, 
2005). Studies have examined ways of increasing academic engaged time and decreasing engagement in alternative behaviors by providing students with task-related choices (Dunlap et al., 1994; Dunlap \& Kern, 1996; Kern, Mantegna, Vorndran, Bailin, \& Hilt, 2001), modifying curricular activities to match student preference and interests (Clarke et al., 1995; Kern, Delaney, Clarke, Dunlap, \& Childs, 2001), and providing reinforcement for engaging in appropriate behaviors (Mace, Neef, Shade, \& Mauro, 1996; Martens, Lochner, \& Kelly, 1992; Neef, Mace, Shea, \& Shade, 1992; Neef, Shade, \& MIller, 1994; Skinner, Wallace, \& Neddenriep, 2002). Identifying appropriate methods to increase academic engagement is a challenge since, at any point during the school day, students choose how to allocate their time. It is therefore critical to understand the variables that increase student's engagement particularly for modification procedures aimed at students with math skill deficits. This study specifically addresses student engagement by evaluating assignment modification procedures to increase student response rates (i.e., problem completion rates).

Providing task-related choices. One method for improving student engagement is providing choices. Researchers have demonstrated that providing students with the opportunity to choose various aspects of an assigned task increases the likelihood that he or she will engage in appropriate, rather than undesired, behaviors. Dyer, Dunlap, and Winterling (1990) evaluated the impact of choice on aggressive, self-injurious, and disruptive behaviors, and the rate of correct task responding of three students with developmental disabilities. Students were presented with puzzle tasks and performance and behavioral observation data were collected. During the no-choice condition the students were provided with a teacher directed task and provided with edible reinforcement afterward. During the choice condition students were allowed to choose the task and reinforcer they would receive upon completion. Results 
demonstrated a clear reduction in problematic behaviors during the choice condition and a higher frequency of problematic behaviors in the no-choice condition. Rate of responding was not influenced by choice in this study, which may have been partially related to reinforcement being present in both conditions. This study demonstrated that students engage in less non-task related behaviors when provided with legitimate control, or choice, over aspects of the task (Dyer, Dunlap, \& Winterling, 1990).

Dunlap and colleagues (1994) further researched the effects of choice on engagement in academic and non-academic behaviors. Two elementary students with emotional and behavioral disorders participated in the study, which took place in a self-contained classroom at a public elementary school. Academic behaviors were described as actively working on an assigned task, engaging in behaviors in accordance with teacher-provided instructions, and having eyes on the task materials or teacher when appropriate. Non-academic behaviors consisted of behaviors that were disruptive to the assigned task (e.g., talking out of turn, noise making, out-of-seat behaviors, not complying with instructions within a 5-second interval). Each student participated in two conditions, a choice condition and a no-choice condition. Students alternated between a no-choice condition, in which the assignments were selected by the teachers and the students were instructed to complete them independently, and a choice condition, in which the students were provided a teacher-developed menu of assignment options and were instructed to choose a pre-specified number of assignments to complete throughout the day. A third no-choice condition involved a teacher-assigned task list based on the assignments the student chose during the choice condition; in other words, teachers selected preferred tasks for the student and presented the tasks on the blackboard. Results indicated that students engaged in higher rates of 
academic-related behaviors and lower rates of non-academic behaviors in the choice condition than both of the no-choice conditions.

Results from the studies described above demonstrate the positive influence that choice has on students' engagement in academic behaviors; thus, lending credit to the hypothesis that antecedent manipulations of academic tasks to include choice could positively influence engagement, and therefore learning (Dunlap et al., 1994; Dunlap \& Kern, 1996; Dyer et al., 1990). These results are consistent with other studies that have found that giving student's legitimate control over aspects of their assigned tasks may be an effective method for increasing the likelihood that said student will choose to actively engage in an academic task over an alternative behavior (Bambara, Ager, \& Koger, 1994; Dunlap et al., 1994; Dunlap, Kern-Dunlap, Clarke, \& Robbins, 1991; Fisher, Thompson, Piazza, Crosland, \& Gotjen, 1997; Kern et al., 1998; Kern, Delaney, et al., 2001; Kern, Mantegna, et al., 2001). Further, studies suggest that integrating student preference into tasks, with or without direct manipulation of task-related choice, has a similar effect on student's academic engagement (Bambara et al., 1994). This study specifically addresses choice and preference as it relates to assignment modifications.

Modifying instructional tasks. Another method of increasing academic engagement is modifying instructional tasks to meet a student's individual needs. Some researchers have also explored modifying curricular activities to integrate a student's preferred activity or interests in an effort to increase the likelihood of the student's active engagement (Clarke et al., 1995; Kern, Delaney, et al., 2001). Kern, Delaney, and colleagues (2001) conducted a study in which they exposed two elementary school students to conditions in which instructions were to either complete a written assignment by handwriting their response in a notebook (i.e., traditional presentation condition) or to use a student-selected method of completing the assignment (i.e., 
preferred presentation condition), such as using a typewriter, speech-to-text software, or typing on a computer. In the traditional presentation condition Student A engaged in significantly more problem behaviors than he did in the preferred presentation condition. Further, Student A's rate of academic engagement significantly increased during the preferred presentation condition. Only the rate of Student B's engagement was measured across traditional and preferred presentation conditions. Data demonstrate that engagement significantly increased during the preferred presentation condition. Although this study consisted of only two participants, data demonstrated that allowing a student to use a preferred method of completing an assignment significantly increases academic engagement and productivity and decreases disruptive behaviors.

Clark and colleagues (1995) conducted student preference assessments to identify students' interests and then instructed students to complete an unmodified "problematic", or challenging, assignment and a modified problematic assignment that incorporated the individual student's interests. Results indicate that not only did students' academic productivity and engagement increase and problematic behaviors decrease, but these methods were highly accepted and viewed as effective by teachers and students. Skinner and colleagues (2002) attempted to decrease problem behaviors and increase academic engagement of four students with emotional and behavioral disorders by using an interspersing technique that has been shown to improve perceptions and preference for academic tasks. Experimental assignments were modified to include brief, easy, problems interspersed amongst challenging problems. Results demonstrated that this procedure was an effective approach for improving academic engagement amongst participants. These studies support other findings that suggest that modifying assignments to increase preference for certain academic tasks and/or integrating students' 
preferences into the curriculum increase the likelihood that they will actively engage in the assignment (Billington \& Skinner, 2002; Billington, Skinner, \& Cruchon, 2004; Dunlap \& Kern, 1996; Logan \& Skinner, 1998; McCurdy, Skinner, Grantham, Watson, \& Hindman, 2001; Skinner, Hurst, et al., 2002). This study sought to examine the influence of modifying rates of interspersing mastery level material amongst more difficult materials and modifying the skill level of assignments on student preference and perceptions of math assignments.

Reinforcement of academic engagement. It is apparent that student preferences for assignments may influence student engagement. Therefore, it is important to understand how to optimize this affect. A basic way to understand preferences of one academic task to another is to simply have students choose between them. Understanding variables that influence students' choice behaviors can inform student- and classroom-level practices that teachers and school psychologists can use to optimize academic performance (Skinner et al., 2005). Reducing assignment length is one method of increasing the likelihood that students will engage in work, given that the briefer assignment will require less effort; however, this method may result in lower rates of learning due to the decreased number of learning trials that a student is exposed to. Researchers have examined a variety of factors that may influence a student's choice behavior to identify additional strategies that do not include reducing learning trials. For instance, studies have demonstrated that students' choice behavior is influenced by actual or perceived effort required to complete a task or engage in a behavior, with a preference for engaging in a task that requires the least effort (Billington \& DiTommaso, 2003; Billington \& Skinner, 2002; Billington, Skinner, \& Cruchon, 2004; Billington, Skinner, Hutchins, \& Malone, 2004; Cates \& Skinner, 2000; Dunlap \& Kern, 1996; Roberts, Turco, \& Shapiro, 1991). Thus, identifying assignment 
alteration methods that limit or eliminate the reduction of target problems would be best to reduce the negative impact of the chosen approach on a student's learning.

Reinforcement qualities, such as rate, quality, timing (e.g., immediate or delayed), and effort required to obtain reinforcement have been shown to influence student choice behavior, as well as perceptions of effort required to complete assignments (Fisher et al., 1997; Horner \& Day, 1991; Mace et al., 1996; Martens \& Houk, 1989; Martens et al., 1992; Neef \& Lutz, 2001; Neef et al., 1994). Neef and colleagues (1994) examined the effects of reinforcement rates, quality, and timing on student's response behavior. The study consisted of six students with known learning and behavioral difficulties. Each student was provided two sets of math problems with varying rates and types of reinforcement. Across various conditions, participants either received high quality reinforcement (e.g., nickels or highly preferred items based on a preference assessment) or low quality reinforcement (e.g., tokens to be used with school-based token economy or least preferred items based on a preference assessment). Reinforcement rate was examined by presenting reinforcement on a variable-interval schedule (i.e., 30 seconds, 60 seconds, 90 seconds) and timing of reinforcement was examined by either presenting reinforcement at the end of the session or the following day. Results indicated that many subjects $(n=4)$ demonstrated a preference for problem sets that required low effort and low reinforcement rates or high effort problem sets with high reinforcement rates. The two participants in the study that did not respond as expected required either immediate reinforcement for engaging in desirable behaviors or engaging in undesirable response behaviors was more reinforcing than that available throughout the study. Another study examined the effects of reinforcement rate using a variable-interval reinforcement schedule on fourth-graders' choice behavior using verbal praise. They found that as reinforcement rates increased the 
frequency of disruptive behaviors decreased and academic engagement increased (Martens et al., 1992). These experimental approaches, along with many others, have demonstrated that the rate of reinforcement governs student choice behavior (Mace, Neef, Shade, \& Mauro, 1994; Martens et al., 1992, 1992; Neef, Mace, \& Shade, 1993; Neef et al., 1992, 1994; Skinner, Robinson, Johns, Logan, \& Belfiore, 1996; Wallace, Cox, \& Skinner, 2003).

In addition to variable-interval schedules, studies have examined the positive effects of variable- and fixed-ratio schedules on student choice behaviors (Hawkins, Skinner, \& Oliver, 2005; Logan \& Skinner, 1998; Mace, McCurdy, \& Quigley, 1990). For example, Mace and colleagues (1990) compared the effects of reinforcement rate and quality on student preference for multiplication or division assignments. Conditions consisted of: (1) a baseline condition with no reinforcement for problem completion; (2) social praise reinforcement for every two problems completed (i.e., VR-2 schedule) during multiplication and division assignments; (3) edible reinforcement (i.e., a piece of a candy bar) on a VR-2 schedule during multiplication and division assignments; (4) token reinforcement on a continuous schedule (i.e., after each problem completed) during a multiplication assignment and VR-2 schedule during division assignments; and (5) token reinforcement on a continuous schedule during a division assignment and VR-2 schedule during multiplication assignments. They found that when the reinforcement type and schedule were the same for both assignments, the student demonstrated no preference for one assignment over another; however, when a continuous reinforcement schedule was paired with a VR-2 schedule the student demonstrated more engagement and a faster work rate on the assignment that was paired with the denser reinforcement schedule (e.g., continuous schedule).

It is important to understand how this research can be effectively used in educational settings to increase the likelihood that students will engage in academic tasks and reach optimal 
levels of learning. Taken together, these studies demonstrate that modifying assignments to integrate reinforcement and/or student preferences can positively influence academic engagement. Further, understanding how and why the rate at which reinforcement is provided within an academic task influences student's response behavior and preference for a task is imperative given the strong role that preference plays in a student's choice to respond appropriately. One way of integrating reinforcement into independent seatwork is with the use of an interspersing procedure. Using such procedures involves integrating brief problems that reflect mastered academic material within assignments that contain newly learned material (Skinner, 2002; Skinner, Robinson, et al., 1996). Interspersing procedures have been shown to have a positive influence on factors important to student learning. Specifically, mathematics interspersing research has shown to increase academic engagement and productivity, decrease problematic behaviors, and positively influence perceptions of and preference for academic tasks (Cates et al., 1999; Cates \& Dalenberg, 2005; Cates \& Skinner, 2000; Logan \& Skinner, 1998; Robinson \& Skinner, 2002; Skinner et al., 1999; Skinner, Fletcher, Wildmon, \& Belfiore, 1996a). One theory that directly relates to the efficacy of interspersing procedures is the theory of matching law (Herrnstein, 1961, 1970), which posits that the rate at which a student engages in a particular behavior is governed by the rate at which the chosen behavior is reinforced over alternative behaviors. This study sought to examine whether participant's problem completion rates, and preference for and perceptions of math assignments varies as a function of the rate of interspersing, in accordance with the matching law.

\section{Matching Law}

Researchers have sought out mathematical equations to assist in explaining and predicting organisms' choice behavior when concurrently presented with two operant 
alternatives (i.e., response options). Early experiments provided pigeons with opportunities to peck on two keys that were concurrently available. Reinforcement (i.e., brief exposure to food) upon pecking the keys was provided on variable-interval schedules that were independent of one another. Studies have repeatedly found that the frequency of behavioral responding and/or time allocated to an operant alternative is proportionate to the relative rate of reinforcement available for each operant alternative (Baum, 1974a; Baum \& Rachlin, 1969; Catania, 1963a, 1963b; Chung \& Herrnstein, 1967; Herrnstein, 1961, 1970, 1974; Neuringer, 1967).

Herrnstein (1961, 1970, 1974) developed a mathematical equation that provides a precise, quantitative, explanation of organisms' choice behavior when two operant alternatives are available. Specifically, he found that the choice to engage in one operant alternative over another matched the relative rate of reinforcement available for each response option. The mathematical equation is as follows: $B_{1} / B_{1}+B_{2}=r_{1} / r_{1}+r_{2}$; where $B$ denotes operant alternatives concurrently available and $\mathrm{r}$ denotes the reinforcement available for each operant alternative. The numerical subscript differentiates between the two operant alternatives (i.e., B1, B2) or available rate of reinforcement for each response option. This equation, also known as the matching law, posits that, when given the choice between two, concurrently available, behavioral response options, an organism will choose to engage in the behavior that will result in the higher rate of reinforcement (Herrnstein, 1961, 1970). Moreover, the theory underlining the matching law suggests that organisms operate in environments with concurrent response options of varying reinforcement values that influence the response an organism chooses to engage in. Thus, understanding how and under what conditions reinforcement influences alterations in choice behavior is imperative in accurately predicting and explaining behavior across a variety of settings (Billington \& DiTommaso, 2003) including academic engaged time during independent seatwork. 
Herrnstein (1961) further explored the utility of the matching law equation in predicting and explaining the pecking behavior of pigeons in a laboratory setting. Specially, he examined the relationship between relative rates of responding (i.e., pecking at one key over another) and relative rates of reinforcement. During a training period, three food-deprived pigeons were placed in a cage with two response keys and reinforcement was provided for pecking at each key only when the pigeon alternated pecking behavior. In other words, reinforcement for pecking at key 1 was contingent on obtaining reinforcement for pecking at key 2. Upon completion of the training period, the three pigeons participated in four experimental conditions in which reinforcement for pecking at each key was placed on variable-interval (VI) schedules that were independent of one another. The average interval of reinforcement for the two keys was held constant at 1.5 minutes across all conditions and a changeover delay (i.e., a brief pause in responding) of 1.5 seconds, during which no reinforcement was available, occurred when a pigeon alternated between keys to prevent the reinforcement schedules of each key from influencing one another. Results showed that the frequency at which the pigeons allocated pecking behavior toward one key relative to total pecking behavior (i.e., $\mathrm{B}_{1} / \mathrm{B}_{1}+\mathrm{B}_{2}$ ) matched the rate of reinforcement received for that key relative to the total amount of reinforcement received (i.e., $r_{1} / r_{1}+r_{2}$ ). That is, the rate at which a pigeon pecked at a single key increased as the rate of reinforcement for pecking at that key increased. Herrnstein (1961) was the first to provide empirical support for the utility of the matching law equation in quantitatively explaining an organism's choice behavior in single-alternative response environments and set the stage for future studies to extend this research across behaviors, settings, species, reinforcement, and multi-alternative response environments. 
The standard matching law equation fails to account for deviations from matching law that may occur in laboratory or natural settings, such as overmatching, undermatching, and response bias (Baum, 1974b, 1979). Baum (1974a, 1979) introduced the reinforcer sensitivity, or matching parameter, defined as "a". The reinforcer sensitivity parameter will be 1.0 is the student adjusts their response ration to changes in the reinforcement ratio over several schedule changes. Overmatching and undermatching occurs when an organism fails to respond to, or adjust, their response ratio as reinforcement ratios change. Overmatching is defined as reinforcer sensitivity greater than one; undermatching is defined as reinforcer sensitivity less than one (Baum, 1974b; McDowell, 1989).

Bias may occur when an organism demonstrates a preference for one response over another based on extraneous variables that are uncontrolled by the experimenter. In the pigeon pecking experiments, one key was white, and one key was red. If a pigeon had a color preference of red, responding to the red key would hold a high response value for that pigeon, thus resulting in biased response ratios regardless of the reinforcement ratio. Further, differences in the duration of exposure to reinforcement, as well as the qualitative properties of and prescribed value to the reinforcement, may influence response ratios. Continuing with the pigeon pecking example, if a pigeon was unintentionally exposed to the food during reinforcement for one key for a slightly longer period of time the pigeon may demonstrate a preference for that key, regardless of changes in reinforcement ratio between the two keys. Qualitative differences between reinforcement may vary across organisms as well. For instance, when provided the option between qualitatively different reinforcement options (i.e., bird seed versus bread), one pigeon may show a preference in responding due to attributing a higher value or preference for specific reinforcement option, regardless of reinforcement rate (Baum, 1974b, 1979). 
Although some research has shown occasional deviations in matching, studies have consistently demonstrated that the matching equation can be generalized to choice behavior in a wide variety of animal species and across a variety of choice behaviors, reinforcement type (e.g., tangible, social, sensory), and in single- and multiple-alternative response environments (Anderson, Velkey, \& Woolverton, 2002; Baum, 1974a; Baum \& Rachlin, 1969; Catania, 1963a, 1963b; de Villiers \& Herrnstein, 1976; Dougan \& McSweeney, 1985; Hollard \& Davison, 1971; McDowell, 1988, 1989; Neuringer, 1967; Reynolds, 1963; Shull \& Pliskoff, 1967). For example, Baum and Rachlin (1969) conducted an experiment with six pigeons to examine the generalization of matching law to choice behaviors other than pecking at keys. Pigeons were individually placed in a reinforcement-producing apparatus that emitted food through a chamber dependent on which side of the cage the pigeon was standing on (i.e., right, left, or middle). The food chambers on the left and right sides of the cage were released on independent variableinterval schedules and the middle of the cage provided no reinforcement. The pigeon was required to be to be standing on the proper side of the cage when the food chamber was released for the food to become available to the pigeon. Results demonstrated that the pigeons spent more time on the side of the cage the emitted higher rates of reinforcement than the side of the cage that emitted lower rate of reinforcement. Thus, the time that the pigeon allocated to a behavior over operant alternatives (i.e., standing on the left versus right side) was governed by the rate of reinforcement produced by each response.

Researchers have also examined the use of the matching law to explain human behavior in laboratory (Baum, 1975; Bradshaw, Szabadi, \& Bevan, 1976; Conger \& Killeen, 1974; Mace et al., 1994; Schroeder \& Holland, 1969) and applied settings (C. Borrero et al., 2010; J. C. Borrero \& Vollmer, 2002; Mace et al., 1990; Martens et al., 1992; McCurdy et al., 2001; Shriver 
\& Kramer, 1997). Shroeder and Holland (1969) conducted a study during which undergraduate students were asked to track needle movements on four dials and "reset" a needle by pressing the respective switch if the needle moved. Each dial was placed on a concurrent, independent variable-interval schedules and the frequency with which participants looked in the vicinity of each dial were tracked with an eye-movement camera. Results were consistent with studies of animal behavior in that the rate at which participants looked at a dial matched the relative rate of reinforcement (i.e., needle movements) for that dial. Further, the researchers found that the presence of a changeover delay strengthened the matching relationship, whereas the absence of a changeover delay weakened this relationship (Herrnstein, 1961; Shull \& Pliskoff, 1967).

Conger and Killeen (1974) were among the first to measure human choice behavior in a social setting. Seven participants were told that they would be part of a discussion group that focused on attitudes toward drug abuse. Discussion groups consisted of one subject and three confederates who were first acquainted in a waiting room and then brought into the experimental room to begin the "discussion". Two of the confederates were signaled on variable-interval schedules to provide verbal approval following a statement made by the participant. The amount of time the participant spent talking to the two confederates was measured. During phase one, confederate A was placed on a denser schedule of reinforcement (i.e., higher rate of reinforcement rates) and confederate B was placed on a lean schedule of reinforcement (i.e., lower rate of reinforcement); the inverse occurred during phase two. As expected, the time participants spent talking to each confederate matched the proportion of reinforcement (i.e., verbal praise) provided by that confederate. Specifically, participants spent more time talking to confederate A during phase one and switched to talking to confederate B more frequently during phase two; thus, participants consistently engaged in more social interaction with the confederate 
who provided them with more praise, even when it required them to switch their pattern of responding across phases. This study was among the first to demonstrate the utility of manipulating reinforcement rates to influence social behavior of humans.

Borrero and colleagues (2010) conducted a study that examined the application of the matching law equation to children's engagement in problems behaviors versus appropriate behavior. Three students with developmental disabilities served as participants and each were identified as engaging in disruptive problem behaviors, such as screaming and physical aggression. During condition one and two, problem behaviors and appropriate behaviors were defined for each student individually and placed on concurrent variable-interval schedules of reinforcement. During condition one, problem behaviors were placed on a denser schedule of reinforcement and condition two consisted of a denser schedule of reinforcement for appropriate behaviors. Condition three consisted of no reinforcement for problem behaviors and a treatment condition that used a continuous reinforcement schedule for appropriate behavior. They found that children's problems behaviors worsened in the condition that involved a denser schedule of reinforcement for those behaviors. Further, the children's engagement in appropriate behaviors increased in the condition that involved a denser schedule of reinforcement for appropriate behaviors, as well as the treatment condition. Therefore, manipulating reinforcement rates is a useful approach to alter student choice behavior.

Taken together, the matching law provides a quantitative explanation of human choice behavior, as it does animal choice behavior, and suggests that humans tend to choose to engage in the behavioral response that results in higher rate of reinforcement (J. C. Borrero \& Vollmer, 2002; Conger \& Killeen, 1974; McDowell, 1988; Schroeder \& Holland, 1969). Since students spend much of their time in school working on academic tasks, it is important to understand the 
causal mechanisms responsible for student's choice behaviors; that is, understanding the motivating forces behind students' choice to engage in academic tasks or alternative behaviors (e.g., off-task talking to peers, out-of-seat behavior, engaging in disruptive or problematic behaviors) can assist educators in identifying appropriate approaches to increase the likelihood that students will choose to be academically engaged. Findings from matching law research suggest that one way of influencing student choice behavior may be to increase the rate of reinforcement provided within academic tasks (Billington \& DiTommaso, 2003).

Many researchers have explored the application of the matching law to academic settings with students at various grade-levels and levels of functioning (Billington \& DiTommaso, 2003; Dunlap et al., 1994; Mace et al., 1990, 1994, 1996; Martens et al., 1992; McCurdy et al., 2001). Mace and colleagues (1994) sought to apply the matching law in an applied setting by exploring whether participants would adjust the amount of time they allocated to a particular set of math problems in proportion to the rate of reinforcement (i.e., nickels) that was received for responding in each problem set. The participants were three teenage students identified as having behavioral and learning difficulties. Each participant was presented with sets of math problems that were developed based on teacher-identified arithmetic problems that the student could complete with $80 \%$ accuracy. Participants were able to choose which problem set to work on and each set was placed on concurrent variable interval schedules of reinforcement. Results indicated that the time participants allocated to a problem set matched the rate at which they received nickels while completing that set when reinforcement ratios for operant alternatives were held constant. Various studies support these findings, while also extending them by demonstrating that reinforcement frequency, timing, and effort required to engage in a response choice also influence choice behavior (Mace et al., 1996; Neef \& Lutz, 2001; Neef et al., 1993, 1992, 1994). 
Although these studies provide evidence for the generalization of the matching law to applied settings, it does not consider the ever-changing operant alternatives and concurrent reinforcement schedules present in natural settings. However, these studies do suggest that the theoretical underpinnings of the matching law imply that if all behavior is considered choice behavior and if choice can be influenced through manipulating reinforcement rate, then academic tasks that incorporate reinforcement may influence student’s choice to be academically engaged versus engaging in non-academic tasks. Teacher behavior, such as verbal praise or acknowledgement, has been shown to influence students' choice behavior in the classroom in accordance with matching law (Martens, Halperin, Rummel, \& Kilpatrick, 1990; Martens et al., 1992; Martens \& Houk, 1989; Shriver \& Kramer, 1997). However, teachers are often required to respond to the needs of many students at a given point in time. This may lead to some students receiving more reinforcement for engaging in appropriate academic behaviors than others and increasing the likelihood that students will seek out other ways of obtaining reinforcement, such as talking to peers, obtaining peer attention through disruptive behaviors, or engaging in passive non-related academic tasks. Moreover, teacher-led activities provide only a subset of students the opportunity to respond due time limitations in the classroom. Independent seatwork is one method that has been used by educators to provide students with more opportunities to practice academic skills and receive written and/or verbal feedback; the challenge is to identify methods that integrate reinforcement into independent seatwork and increase the likelihood that students will choose to engage in the task independently (Hawthorn-Embree, Skinner, Parkhurst, \& Conley, 2011; Hawthorn-Embree, Skinner, Parkhurst, O’Neil, \& Conley, 2010).

It has been suggested that the completion of a discrete task may act as a reinforcing event when completing independent seatwork due to students' learning histories (e.g., receiving a high 
grade and/or positive feedback, accessing preferred activities upon task completion; Skinner, Hurst, et al., 2002). Thus, as the matching law suggests, increasing the rate at which a student completes discrete tasks within an assignment will inherently increase the rate of reinforcement they receive and positively influence students' choice behavior toward choosing to engage in the task. One way of integrating reinforcement into independent seatwork is with the use of an interspersing procedure, which integrates brief problems that reflect mastered academic material within assignments that contain newly learned material (Skinner, 2002; Skinner, Robinson, et al., 1996). This study examined whether participants' rate of responding, assignment preference, and assignment perceptions varied as a function of the rate of interspersing mastery level materials amongst target material at instructional level or at frustration level for each participant.

\section{Mathematics Interspersing}

Independent seatwork provides students with the opportunity to practice previously developed skills for the purpose of improving or maintaining fluency and/or generalizing a skill to different types of problems. By interspersing mastery level brief problems among instructional level target problems researchers have been able to demonstrate improvement in student perceptions of math assignments. Student perceptions play an important role in the degree to which a student is academically engaged in a task (Dunlap et al., 1994). When tasks are perceived to be too difficult or time-consuming, a student may opt to engage in non-academic behaviors that are more reinforcing in that moment and to escape the frustration that may be associated with completing the assignment (Dunlap et al., 1994; Dunlap \& Kern, 1996; Kern et al., 1998; Kern, Delaney, et al., 2001). Therefore, it is important that modifications to academic tasks that facilitate student engagement and increase acceptability of the task be considered. 
By applying Herrnstein's matching law to academic engagement, we can propose that students will be more likely to choose to engage in an assignment during which their engagement is reinforced. Studies have examined and supported the use of teacher directed reinforcement (i.e., verbal praise, tangible reinforcement) for student engagement (Mace et al., 1990; Martens \& Houk, 1989; Neef et al., 1994). However, it can be difficult and time consuming for educators to monitor all students' behaviors and disperse reinforcement continuously, systematically, and equally across all students (Logan \& Skinner, 1998).

Modifying independent seatwork tasks to decrease student frustration and increase acceptability of the task is one way of increasing academic engagement. These approaches can enhance learning rates and decrease engagement in behaviors that are incompatible with learning without requiring the teacher to consistently track and distribute reinforcement (Calderhead, Filter, \& Albin, 2006). One method commonly used by educators is reducing assignment length or the number of target problems the student must complete. Studies have also demonstrated the effectiveness of using task variation procedures (i.e., alternating preferred or simple tasks with unlearned or target skills) to facilitate learning, increase motivation to engage in a task, and decrease inappropriate behaviors across a variety of student populations (Dunlap \& Egel, 1982; Dunlap, 1984; Dunlap \& Koegel, 1980; L. K. Dunlap \& Dunlap, 1987; Winterling, Dunlap, \& O’Neill, 1987). Substitutive interspersal is one type of task variation procedure that involves replacing newly learned/unmastered material (i.e., target problems) with mastered material that is perceived as brief or easy to the student. Research on substitutive interspersal has been plentiful and results have consistently demonstrated that it has positive effects on acquisition of various academic skills (Cates, 2005; Dunlap, 1984; Dunlap \& Koegel, 1980; Neef, Iwata, \& Page, 1980; Roberts et al., 1991). However, approaches that reduce the length of the assignment or number of 
target problems that student is exposed to may impair the student's learning rate due to decreasing the number of learning trials for the target skill (Cates, 2005; Logan \& Skinner, 1998). Additive interspersing procedures addresses these limitations by enhancing engagement and acceptability of tasks by interspersing brief and easy items amongst target problems without reducing assignment length or the number of target problems the student is exposed to. Although matching law would suggest that students would continue to prefer standard assignments, without additional brief problems, due to there being less problems and requiring less effort, research has consistently demonstrated that students prefer longer assignments that include the same number of target problems as standard assignments, but with interspersed brief and easy problems (Billington \& Skinner, 2002; Billington, Skinner, Hutchins, et al., 2004; Cates \& Skinner, 2000; Hawkins et al., 2005; Skinner, Hurst, et al., 2002; Skinner et al., 2005; Skinner, Robinson, et al., 1996). The discrete task completion hypothesis provides an explanation as to why a student would prefer or choose an assignment that quantitatively requires more effort, and it is related to the completion of a discrete task being a reinforcing event (Skinner, 2002).

Discrete task completion hypothesis. The discrete task completion hypothesis (Skinner, 2002) assumes that the completion of a task is a reinforcing event. The discrete task completion hypothesis posits that, due to previous learning experiences, completion of a discrete task acts as positive or negative reinforcement for students. Completion of a discrete task may act as positive reinforcement for a student's active engagement due to its indication of being closer to accessing free time or receiving positive feedback or praise from teachers or as negative reinforcement due to avoiding negative consequences of not completing one's work (i.e., avoiding having to miss recess due to not completing assignment). Further, based on the matching law theory and the discrete task completion hypothesis, students should allocate more time to assignments that 
provide higher rates of reinforcement (i.e., problem completion rates) and student preference, engagement, and perceptions should vary as a function of reinforcement rate. Thus, integrating brief, discrete, tasks into assignments with target problems may be a way to influence student perceptions of and level of academic engagement when completing assignments due to increasing problem completion rates (Skinner, Wallace, et al., 2002).

Skinner (2002) compiled data from published interspersal experiments to conduct a metaanalysis for the purpose of examining the relationship between relative problem completion rates and student choice behavior. A second purpose of this meta-analysis was to examine the predictability of choice behaviors using relative problem completion rates based on the theory of matching law. In order to be included in the meta-analysis, studies were (a) required to be published or accepted for publication in nationally refereed journals, (b) employed group design and analysis procedures, (c) assigned percentage of students choosing one assignment over another (i.e., control assignment with only target problems vs. experimental with interspersed problems) as a dependent variable, (d) involved participant completion of assignments with discrete tasks, (e) altered problem completion rates using additive interspersing procedures, (f) collected data on relative problem completion rates, and (g) used target problems on control and experimental assignments that were equated. A total of seven experiments were included in the analysis after being evaluated using the aforementioned guidelines. Despite evidence of overmatching (i.e., more students choosing the assignments with interspersing than what would be predicted), relative problem completion rate accounted for over $97 \%$ of the variance; thus, demonstrating a strong correlation between relative problem completion rate and student choice and supporting the discrete task completion hypothesis. Further, results also demonstrated a clear linear relationship between relative problem completion rates and student choice behavior in 
accordance with matching law. Researchers have since worked toward examining the influence of adjusting reinforcement rates within assignments by manipulating problem completion rates to improve academic engagement and alter assignment choice and preference (Billington \& Skinner, 2002, 2006; Billington, Skinner, \& Cruchon, 2004; Billington, Skinner, Hutchins, et al., 2004; Calderhead et al., 2006; Cates et al., 1999; Cates \& Skinner, 2000; McCurdy et al., 2001). Reinforcement rate. A significant amount of research has been conducted on the use of interspersing procedures to influence student perceptions of assignment difficulty, perceptions of effort and time required to complete an assignment, assignment acceptability, and academic engagement (e.g., on-task behavior; problem completion rates; see Cates [2005] for review of addiitonal studies; Cates \& Dalenberg, 2005; Cates \& Erkfritz, 2007; Clark \& Rhymer, 2003; Hawkins et al., 2005; Jaspers, Skinner, Williams, \& Saecker, 2007; McDonald \& Ardoin, 2007; Montarello \& Martens, 2005; Rhymer \& Cates, 2006; Rhymer \& Morgan, 2005; Robinson \& Skinner, 2002; Skinner, 2002; Skinner et al., 1999, 2005; Skinner, Fletcher, Wildmon, \& Belfiore, 1996; Skinner, Hurst, et al., 2002; Skinner, Robinson, et al., 1996; Wildmon, Skinner, Watson, \& Garrett, 2004). Standard procedures in research on interspersing procedures involve providing the student with assignment pairs consisting of a control assignment (i.e., consisting of target problems only) and an assignment with interspersing (i.e., consisting of target problems and integrated brief, easy, problems) to complete in its entirety or within a pre-specified time limit. Upon completing the assignment pairs the students may be asked a series of questions to assess assignment perceptions (i.e., difficulty, time and effort required to complete) and preference (i.e., which they would like to take for homework). Further, performance variables are often examined to gather information on accuracy and engagement (e.g., on-task behavior while 
completing the assignment; relative problem completion rates calculated upon assignment completion).

Skinner, Robinson, and colleagues (1996) conducted a study examining the influence of additive interspersing procedures on student perceptions of assignments, problem completion rates, and target problem accuracy. Students were provided a packet with an assignment pair: a control (i.e., containing 16, 3x2 multiplication “target” problems) and experimental (i.e., containing 16 target problems and 6, 1x1 "brief” multiplication problems) assignment. The brief problems on the experimental assignment were set on a fixed-ratio schedule consisting of one brief problem for every three target problems (i.e., FR3 schedule). Target problems on each assignment were equated and problems were presented in an unbalanced manner to reduce the chance that students' perceptions would be influenced by counting the number of problems on each assignment. Students were provided 5 minutes and 5 seconds to complete each assignment to the best of his or her ability. Upon completion of both assignments, students were asked to answer three, forced-choice response, questions to indicate which assignment they believed required the most time to complete, required the most effort to complete, and which assignment would be the most difficult to complete. Students were also asked to indicate which assignment they preferred by choosing an assignment to complete in its entirety. Although the experimental assignment contained six additional problems, more students indicated favorable ratings for the assignment with interspersing on measures of time, effort, difficulty, and assignment preference.

A second experiment was conducted to account for novelty effects of the assignment with interspersing. Undergraduate students $(N=30)$ were exposed to control and Experimental assignments similar to those used in experiment 1 , as well as a third assignment consisting of 3x2 multiplication and 3/2 division problems to represent assignment novelty. The students 
completed assignments using the same procedure as Experiment 1 and indicated assignment preference and rankings of time, effort and difficulty (e.g., most and least). Similar to Experiment 1, significantly more students ranked the $1 \mathrm{x} 1$ assignments with interspersing more favorably across all perception and preference ratings. Further, students completed significantly more problems on experimental assignments than control assignments, without negatively impacting problem accuracy. These results were among the first to demonstrate that problem completion rates could be manipulated using an additive interspersing procedure, which then positively influences students' perceptions and assignment acceptability without hindering performance on target problems (i.e., problem accuracy).

These experiments (Skinner, Robinson, et al., 1996) provided the groundwork for a multitude of future studies to examine the influence of math interspersing procedures on student perceptions, assignment preference, and performance variables. Studies have been completed with a variety of student populations, including college, school-age, and remedial math students with results consistently favoring assignments with interspersing on rating of effort, time, difficulty, and assignment preference (Cates et al., 1999; Cates \& Dalenberg, 2005; Cates \& Erkfritz, 2007; Cates \& Skinner, 2000; Hawkins et al., 2005; Skinner et al., 1999; Skinner, Fletcher, et al., 1996; Wildmon et al., 2004). Research on the interspersing procedure continues to function based on the theoretical foundations set by Herrnstein's (1961) matching law as well as the belief that interspersing procedures inherently contain reinforcing properties (i.e., completion of discrete tasks) that influence student perceptions, preference, and engagement in academic tasks. Researchers have also focused on the systematic manipulation of relative problem completion rates by adjusting interspersing ratios to influence student perceptions, 
preference, and academic engagement (Billington \& Skinner, 2006; Cates \& Dalenberg, 2005;

Cates \& Erkfritz, 2007; Hawkins et al., 2005).

For example, Cates and Dalenberg (2005) manipulated relative problem completion rates by varying the rate at which brief items were interspersed amongst target items on math assignments. It was hypothesized that if student choice is reinforced by the completion of a discrete task, they will tend to choose assignments with denser rates of interspersing that result in a higher relative problem completion rate. Undergraduate students $(N=60)$ across various majors were presented with four control-experimental assignment pairs. Each control assignment contained fifteen 3x2 multiplication problems and each experimental assignment contained fifteen 3x2 multiplication problems with 1x1 problems interspersed on three different fixed-ratio schedules: every other problem (FR1), every third problem (FR3), and every fifth problem (FR5). After completing each assignment pair, participants were asked to rate each assignment pair based on perceptions of time, effort, and difficulty and which assignment they would prefer for homework. The following performance variables were also examined: total problems completed, total target problems completed, accuracy of target problems completed, and relative problem completion rates. Results demonstrated that interspersing procedures significantly increased target problem completion without negatively impacting accuracy on target problems. Further, participants who completed more problems on assignments with interspersing rated the assignment as more acceptable on all perception and preference dimensions. In other words, acceptability ratings of the assignment favored the assigned that contained more reinforcement (i.e., assignment with interspersing) thus providing further support for the matching law. Additionally, results suggested that relative problem completion rates increase as a function of the rate of interspersing. 
Cates and Erkfritz (2007) sought out to replicate the findings of Cates and Dalenberg (2005) while improving ecological validity by exposing school-age students to various schedules of interspersing. Students $(N=70)$ across grades six, seven, and eight were asked to complete four control-experimental assignment pairs. Procedures mimicked those in the Cates and Dalenberg (2005) study, in that students were asked to complete each assignment pair and subsequently complete forced-choice ratings of perception (i.e., time, effort, difficulty) and assignment preference. Performance data, such as total and target problem completion rates and accuracy, were also collected. Although interspersing assignments did not affect accuracy, the procedure to increase the number of target problems that were completed within each control-experimental assignment pair. Further, data replicated that of previous studies such that preference and assignment perception ratings were favorable toward interspersing assignments (Billington \& Skinner, 2006; Billington, Skinner, Hutchins, et al., 2004). These studies demonstrate the implications for manipulating relative problems completion rates to enhance assignment acceptability. Research has demonstrated that when students view assignments as more acceptable, they tend to engage in less behaviors that are disruptive and incompatible with learning (Cates \& Dalenberg, 2005; Dunlap \& Kern, 1996; McCurdy et al., 2001; Skinner, Hurst, et al., 2002). Moreover, students tend to become more engaged in the assigned academic task, which is important when striving to enhance learning rates and improve academic skill deficits (Cates \& Skinner, 2000; Hawkins et al., 2005; Logan \& Skinner, 1998). Thus, researchers have examined the influence of manipulating relative problem completion rates (i.e., reinforcement rates) on student behavior and academic engagement (Calderhead et al., 2006; Logan \& Skinner, 1998; McCurdy et al., 2001; Montarello \& Martens, 2005; Skinner et al., 2005). 
For example, McCurdy and colleagues (2001) used an alternating treatments design to evaluate the percentage of on-task behavior exhibited by an elementary student when completing control (i.e., unmodified) assignments and assignments modified using the additive interspersing procedure. This student was identified as frequently exhibiting off-task behaviors that were disruptive to the classroom setting. The study consisted of 16 sessions that were integrated into the typical classroom independent seatwork activities. Control assignments were worksheets with approximately 15 target problems that were taken directly out of a math workbook aligned with the teacher's math curriculum. Experimental assignments containing interspersed items were developed by modifying math worksheets that were part of the pre-established math curriculum. During the study, control and experimental assignments were alternated each day and the student's on-task behavior (i.e., head oriented to the assignment, asking teacher relevant questions, raising her hand) was evaluated. Results showed that the student's on-task (i.e., academically engaged) behaviors was $17 \%$ higher when completing experimental assignment than when completing control assignments. This study demonstrated that assignments with interspersing was an effective intervention in reducing a student's engagement in behaviors that could disrupt her completion of math assignments. Other researchers have found similar results supporting the theory that additive interspersing procedures positively influence on-task behavior, as well as problem completion rates on math assignments (Calderhead et al., 2006; Montarello \& Martens, 2005; Skinner, Hurst, et al., 2002). Another common theme across these studies lay in the suggested directions for future research. These studies recognize that varying levels of math performance and fluency and whether the assignment is at frustration, instructional, or mastery level for the individual student may influence the rate of reinforcement required to alter perceptions, problem completion rates, and on-task behaviors. Although 
interspersing procedures have been demonstrated to have a positive influence on student's perceptions of, preference for, and performance on academic tasks, such research has yet to evaluate how modifying instructional level on assignments with interspersing can impact these variables. Understanding how the instructional level of academic tasks influence students' engagement, learning, and acceptance of the task is imperative to appropriate individualization of assignment modifications techniques to meet the unique needs of students struggling in mathematics, such as those receiving tier 2 and 3 supports. Thus, the current study sought to examine the interaction between the rate of interspersing and instructional level on relative problem completion rates, total and target problem accuracy and completion, as well as assignment perceptions and preference.

McDonald and Ardoin (2007) attempted to determine whether interspersing procedures would be effective when administered to an entire classroom. Recognizing that each student would likely be at a different instructional level in math computation, the researchers attempted to group the fourth-grade students into "fluent" or "less fluent" categories based on performance on a math CBM consisting of only target problems that was developed with teacher-input on the item difficulty. Students in the fluent group $(N=42)$ consisted of students who performed with at least 45 challenging digits and 16 challenging problems correct, with the remaining students in the less fluent group $(N=34)$. Therefore, another goal of this study was to evaluate whether intervention results differed for students identified as fluent vs. less fluent. Further, the researchers conducted the procedures across four session to determine whether the effects of an interspersing procedure could withstand multiple treatment administrations (McDonald \& Ardoin, 2007). Control and experimental assignments were developed based on curriculumbased evaluation performance and teacher input on item-level difficulty and all experimental 
assignments included interspersed items after every third target problems (i.e., FR3). Results support previous research such that the effects of interspersing procedures positively influenced student perceptions of assignment effort, time to complete, difficulty level, and assignment preference. Researchers suggested that a reason for this may be due to whether the challenging and interspersed items were at mastery, instructional, or frustration level for each student. It was noted that the interspersed items were not at mastery level for all of the students who participated in the study; thus, these items may have acted as a barrier to completing target problems, influencing overall problem completion. Further, if all items were at a frustration level for the student, the interspersed items may have not acted as a reinforcing event. Also, if the target problems were at frustration level rather than instructional level, the time to reach interspersed items may have been delayed further.

These results demonstrate the importance of identifying individual student's skill level of determining how to appropriately apply assignment modification techniques to meet his or her academic needs. The current study seeks to examine the differential effects of assignment difficulty based on a student's instructional level on student performance on assignments with interspersing and assignment perceptions and preference. Further, McDonald and Ardoin (2007) suggested the use of a continuous rating scale to gather information regarding student perceptions and preference for assignments to assess incremental changes that may be associated with the rate of interspersing and/or difficulty level of the assignment, as indicated by problem completion rates and problem accuracy. Thus, the current study used a continuous rating scale for gathering data on participant's perceptions of time to complete, effort to complete, and difficulty of assignments at different rates of interspersing and instructional levels. 
The purpose of the current study was to examine the effects of varying rates of reinforcement on math performance, perceptions of math assignments, and relative problem completion rates in a sample of school-aged students receiving remedial math services (i.e., tier 2 or tier 3). This was accomplished by recruiting a sample of students across fourth and fifth grade classrooms who were receiving tier 2 or tier 3 services for math due to computation difficulties. Participating students were asked to complete a series of math assignment pairs consisting of a control assignment with no reinforcement and an experimental assignment with varying rates of reinforcement (i.e., 1:3, 1:1, 2:1). Control and experimental assignments were constructed at two different difficulty levels (i.e., target problems at instructional level or at frustration level). Upon completion of each control-experimental assignment pair, participants were asked to rate the difficulty level and time and effort required to complete each assignment on a continuous rating scale (i.e., 4-point Likert scale) to assess incremental changes in perception, as well as a dichotomous (i.e., forced-choice) rating scale. Forced-choice rating scales were used to ask the students to choose which assignment was more difficult and would take more time or effort to complete. Assignment preference was evaluated by asking participants to indicate which assignment they would rather complete for homework on a forced-choice rating scale. The following performance variables were also examined: (a) total problem accuracy, (b) target problem accuracy, (c) total problems completed, (d) target problems completed, and (e) relative problem completion rates. Specifically, this study examined whether a functional relationship exists between fixed rates of reinforcement on math assignments at two different difficulty levels and academic performance, assignments preferences, and assignment perceptions of effort, difficulty and completion time. Further, this study explored whether performance, perception and preference change as a function of the instructional level and rate of interspersing. 


\section{Hypotheses}

The hypotheses of the current study addressed the relation between fixed rates of reinforcement (i.e., ratio of interspersed brief problems) on math assignments at two different difficulty levels (i.e., at instructional level and at frustration level) and academic performance, assignment preference, and assignment perceptions within a sample of fourth and fifth grade students who were enrolled in Tier 2 or Tier 3 services for mathematics. This was completed in four ways: (a) examining the relation between the rate of interspersing and academic performance variables (i.e., accuracy and problem completion rates), (b) examining the relation between the rate of interspersing and student perceptions of the math assignments (i.e., ratings of difficulty, effort, and time for completion), (c) examining the relation between the rate of interspersing and student preference for a math assignment (i.e., choosing an assignment to take home for homework), and (d) examining whether performance, perception, and preference change as a function of instructional level and rate of interspersing. Hypotheses related to each of the dependent variables are outlined below.

1. Relative Problem Completion Rates: It was hypothesized that the number of problems completed on assignments with interspersing would differ relative to the number of problems completed on the paired control assignments (i.e., relative problem completion rate). Specifically, it was expected that as the rate of interspersing becomes denser the relative problem completion rate would increase. For example, the relative problem completion rate for a 2:1 assignment pair (i.e., an experimental assignment with a 2:1 interspersing ratio and a paired control assignment) would be greater than the relative problem completion rate for control-1:3 and control-1:1 assignment pairs. It was expected that relative problem completion rates would be 
higher for 1:1 interspersing ratio assignment pairs than 1:3 assignment pairs and higher for the 1:3 assignment pairs relative to the control-control assignment pairs. Further, it was hypothesized that, during baseline conditions, relative problem completion rates would be higher on control assignments at instructional level than paired control assignments at frustration level.

2. Total and Target Problem Completion: It was hypothesized that participants will complete more target problems and more problems overall on experimental assignments (i.e., assignments containing brief problems interspersed among longer target problems) than control assignments. Further, it was expected that participants would complete more total and target problems on assignments at instructional level than assignments at frustration level, regardless of the assignment being a control or experimental assignment. It was also expected that participants would complete more problems overall on assignments with the same rate of interspersing at instructional level than similar assignments at frustration level. For example, the researchers proposed that participants would have higher problem completion rates on a 1:3 assignment at instructional level than a 1:3 assignment at frustration level. Finally, it was hypothesized that there would be minimal differences for the total number of problems completed across control assignments at the same instructional level since assignments should be equivalent in terms of difficulty level and reinforcement was not integrated into either assignment. Thus, problem completions rates were not expected to vary across assignment pairs with two controls at instructional level or two controls at frustration level. 
3. Accuracy: It was hypothesized that participants would demonstrate minimal to no improvement on overall accuracy and accuracy on target problems during the control assignment consisting of only target problems or the experimental assignments. In other words, when using specific visual analysis parameters (Kratochwill et al., 2010; Monahan, Kratochwill, \& Lipscomb, 2011) data were expected to show minimal differences in level and variability across phases and a relatively flat trend. This is consistent with previous research that has found that the use of an interspersing procedure was not effective with improving accuracy on math problems (e.g., Calderhead, Filter, \& Albin, 2006; Cates \& Dalenberg, 2005; Cates \& Erkfritz, 2007). It was expected that total problem accuracy would be higher on experimental assignments and assignments at instructional level than control assignments and assignments at frustration level, respectively. Further, it was hypothesized that total problem accuracy would increase as the rate of interspersing increases but would remain stable on control assignments.

4. Perception: It was hypothesized that participant perceptions of difficulty, effort, and time to complete the task would vary as function of the instructional level and the rate of interspersing. Participants were expected to indicate that the control assignments were more difficult, took more effort to complete, and took more time to complete than the paired experimental assignment, regardless of instructional level. Further, it was hypothesized that participants would rate control and experimental assignments at instructional level more favorably across perception ratings than control and experimental assignments at frustration level. Regarding the rate of interspersing, it was expected that ratings would be more favorable for assignments with denser rates 
of interspersing than paired control assignments and assignments with less dense rates of interspersing.

5. Preference: It was hypothesized that participants would be more likely to choose experimental assignments with a denser rate of interspersing for a homework assignment than assignments with a less dense rate of interspersing or control assignments. Additionally, it was expected that assignment choice would change as function of relative problem completion rates on the math assignments. That is, participants who completed more problems on assignments with a 2:1 ratio of interspersing than on paired control assignments would be more likely to choose the experimental assignment for homework. Similar trends in the data were expected for participants who completed more problems on assignments with a 1:3 and 1:1 ratio of interspersing than the paired control assignments. Regarding instructional level, it was hypothesized that participants would choose assignments at instructional level over assignments at frustration level. 


\section{CHAPTER III: METHODS}

\section{Methods}

\section{Participants}

A total of 38 parent consent forms (Appendix A) were sent to the parents/ legal guardians of fourth and fifth grade students from two Midwestern elementary schools who were currently receiving tier two or three remedial math services. Once signed parent consent was received, students were scheduled for an initial assessment session of approximately 20 minutes and nine subsequent 15- to 20-minute sessions. An assent form was collected, and a script was read explaining what the participants were assenting to (Appendices B and C). A total of 28 parents and students provided consent and assent, respectively.

Eight participants were excluded due to one of the following reasons: not finding instructional level during the assessment session $(n=1)$, choosing the frustration level assignment at baseline $(n=2)$, participant could not read preference/perception rating form $(n=1)$, participant indicated that he guessed on each item and wrote the same answer repeatedly $(n=1)$, accuracy on instructional assignments at baseline was $\leq 50 \%(n=2)$, only participant in instructional/ frustration level group ( $n=1)$. Thus, the final sample size included 20 participants (12 females, 8 males) who were enrolled in fourth- $(n=3)$ or fifth-grade $(n=17)$. The participants in this sample self-identified as the following: 18 White/Caucasian, 1 Black/African American, 1 Biracial. The average age of the sample was 10.55 years $(S D=.605)$. Sixteen participants were currently receiving tier 2 math services, and 4 students were receiving tier 3 remedial math services.

\section{Measures}

Math instructional level. During session one, participants were asked to complete a series of single-skill and multiple-skill multiplication CBM probes created on 
interventioncentral.org. The following worksheet types were created using this online resource and completed by participants to assess instructional level: (a) single-skill 2-digit by 1-digit multiplication problems with or without regrouping; (b) single-skill 2-digit by 2-digit multiplication problems with or without regrouping; (c) multiple-skill 2-digit by 1-digit multiplication problems with and without regrouping; (d) multiple-skill 2-digit by 2-digit multiplication problems with and without regrouping. Students had 1 minute to complete each CBM probe and the number of digits-correct per-minute (DCPM) was calculated to determine instructional level based on grade-level norms. Grade-level norms were developed using 1minute CBM probes by using a digits-correct per-minute approach, which is a more sensitive approach to identifying students' instructional level than calculating problem accuracy per minute (Burns, VanDerHeyden, \& Jiban, 2006). For fourth and fifth grade, mastery level is more than 49 DCPM, instructional level is 24 to 49 DCPM, and frustration level is less than 24 DCPM. The number of digits incorrect were also assessed and the following criteria were used, $\geq 8$ errors is frustration level, 3 to 7 errors is instructional level, and $\leq 2$ errors is mastery level. Error criteria, rather than DCPM criteria, were used as a guide to inform instructional level for students who meet criteria for two different levels on one CBM. Standard directions for administration are available on interventioncentral.org and were used when administering each probe.

Math assignments. All participants were exposed to 16 math assignments that were developed by the researcher based on each participant's instructional level, as described above. Two types of control assignments were developed, each consisting of 20 target problems: (1) control assignments at instructional level (CI; See Appendix E for example) and (2) control assignment at frustration level (CF; See Appendix F for example). During baseline, participants 
completed control assignment pairs to demonstrate assignment equivalence for assignments at instructional level (i.e., CI vs. CI) and at frustration level (i.e., CF vs. CF).

Each assignment displayed one-digit by one-digit or two-digit by two-digit multiplication problems, with or without carrying, on an 8.5 x 11 inch sheet of white paper. Control math worksheets consisted of only target problems (i.e., 2x2 digit multiplication with or without carrying). Baseline performance data for each participant was used to determine whether 2x2 multiplication problems with or without carrying are at instructional or at frustration level for each individual student. Experimental math assignments consisted of 20 target problems with additional brief problems that were at mastery level (i.e., 1x1 digit multiplication) interspersed at varying rates (See Appendices G through I for examples). Math problems were interspersed with one brief problem for every three target problems (i.e., 1:3 ratio), one brief problem after each target problem (i.e., 1:1 ratio), and two brief problems after each target problem (i.e., 2:1 ratio).

Each assignment with interspersing (i.e., 1:3, 1:1, 2:1) was paired with a control assignment with target problems at the same instructional level (e.g., CI vs. 1:3 at instructional level; CF vs. 1:3 at frustration level). Assignments were equated for difficulty using similar procedures to those in previous research (e.g., Cates et al., 1999; Cates \& Dalenberg, 2005; Cates \& Erkfritz, 2007; Cates \& Skinner, 2000; Hawkins et al., 2005; Skinner et al., 1999). Specifically, digits greater than four were used for target problems with carrying, 2 digits greater than 4 and 2 digits lower than four were used for target problems without carrying, and digits lower than four for the brief problems were used. Also consistent with previous methods (e.g., Cates et al., 1999; Cates \& Dalenberg, 2005; Cates \& Erkfritz, 2007; Cates \& Skinner, 2000; Robinson \& Skinner, 2002; Skinner et al., 1999), assignments were created without a numbering system for the problems and without equal spacing between problems to decrease the ease of 
participants counting the number of problems per assignment. This method was used to reduce the likelihood that participants would choose a preferred assignment based on the number of problems on the assignment.

Assignment perceptions and preference. A sheet of paper following each assignment pair contained the questions developed to gather data on students' perceptions of and preferences for assignments (See Appendix J). Forced-choice perception and preference questions are similar to those that have been used in previous studies (e.g., Billington \& Skinner, 2002; Billington, Skinner, \& Cruchon, 2004; Billington, Skinner, Hutchins, et al., 2004; Cates et al., 1999; Cates \& Dalenberg, 2005; Cates \& Erkfritz, 2007; Logan \& Skinner, 1998; Skinner et al., 1999). To gather data on incremental changes in assignment perceptions, a Likert scale was also used to evaluate these dependent variables. A 4-point Likert scale was used due to studies indicating that scales with less than four points still represent a forced-choice response due to one degree of freedom being present in between each response option. Researchers have also suggested that differences in reliability and validity between scales with four or more response options do not significantly differ in terms of reliability and validity and scales above 6-points may result in less consistent responding (Chang, 1994; Garland, 1991; Matell \& Jacoby, 1971).

To gather information on assignment perceptions, participants were asked to rate each assignment based on time, difficulty, and effort on both a dichotomous (i.e., forced-choice between assignment I vs. assignment F) and continuous (i.e., Likert scale 1 to 4) rating scale. The following questions were used to measure participant perceptions: (a) "On a scale of 1 to 4 , how difficult was assignment (I/F)?” (b) “On a scale of 1 to 4, how much effort would it take to complete assignment (I/F)?” (c) “On a scale of 1 to 4, how much time would it take to complete the (I/F) assignment?” Further, participants were asked to rate assignment perceptions on a 
dichotomous rating scale (e.g., Which assignment would take more effort to complete from start to finish? I or F). Participants were asked to indicate assignment preference on a dichotomous rating scale as well (i.e., Which assignment would you like to take for homework: I or F). Letters were assigned to each assignment to aid the participants in differentiating between the two assignments while answering perception and preference questions. Participants were allowed to briefly reference the letter corresponding to each assignment while completing the rating scale.

Intervention fidelity checklist. All researchers, which included 3 doctoral students and the co-PI, who participated in data collection were instructed to follow a procedural protocol and script (Appendix L). Training included direct instruction for administering each procedure, modeling procedures for trainees by the co-PI, and the trainee practicing administration in a roleplay practice session. Direct feedback was given and trainees were asked to role-play procedure administration until she was able to do so with $100 \%$ procedural fidelity by using accurate timing procedures and reading all instructions verbatim. An intervention fidelity checklist (Appendix K) was developed by the researcher to evaluate the extent to which the protocol was consistently followed throughout the study. The integrity of the implementation of $30 \%$ of intervention phases was evaluated during baseline and intervention conditions by directly observing the researchers implementing the protocol with participants and using the intervention fidelity checklist; procedural protocol was follow $100 \%$ of all fidelity checks.

\section{Procedures}

The following procedures were carried out in an available room within a school setting, which was pre-determined by the researcher and school principal. At one school, research was carried out in an empty classroom and at another school one of three rooms were used as available: the art room, conference room, or the social worker's office. The school was asked to 
send home a parent/guardian consent form (Appendix A) to all fourth and fifth grade students who were currently receiving remedial math services. All students who returned signed parent/guardian consent forms providing permission to participate in the study were enrolled as participants and asked to complete a total of 10 sessions. During session one, participants read an informed assent script (Appendix C) and were asked to review and sign an informed assent form (Appendix B). Participants who provided assent to participate were asked to complete a demographics form (Appendix D) and pre-data were gathered by administering a series of single-skill and multiple-skill curriculum-based measurement probes to assess current performance levels in math. During sessions two through four, participants met with a researcher in small groups of two to seven students to complete control assignment pairs (i.e., CI vs. CI; CF vs. CF; and CI vs. CF). A CI-CI and CF-CF assignment pair were administered to demonstrate equivalence. A CI and CF assignment was paired to gather baseline performance, perception, and preference data when assignments at instructional level and at frustration level are paired.

\begin{tabular}{|l|c|c|}
\hline & Assignment 1 & Assignment 2 \\
\hline Session: Control Pair 1 & Control Instructional & Control Instructional \\
\hline Session: Control Pair 2 & Control Frustration & Control Frustration \\
\hline Session: Control Pair 3 & Control Instructional & Control Frustration \\
\hline
\end{tabular}

Figure 1. Sessions 2-4 assignment pairs.

During sessions five through ten, participants were provided a packet that contained a paired control (i.e., CI or CF) and experimental assignment, at instructional (I) or at frustration (F) level, with interspersing at different fixed ratios (e.g., 1:3; 1:1; 2:1). The six controlexperimental assignment pairs are as follows: (a) CI vs. 1:3I; (b) CF vs. 1:3F; (c) CI vs. 1:1I; (d) CF vs. 1:1F; (e) CI vs. 2:1I; (f) CF vs. 2:1F. Researchers followed outlined procedures and read 
instructions from the procedural protocol (Appendix L). Participants were instructed that they had 4-minutes to complete each math assignment as best as they could. They were also instructed to work the problems in order, from left to right, and to not skip any problems. A stop sign was been placed at the end of each assignment to provide a visual reminder for participants to stop when they reached the end of the assignment and to prevent them from moving on to the next assignment too early. Once directions were provided, the researcher prompted the students to begin working and started a stop-watch for 4-minutes. At the end of the 4-minute period, the researcher instructed the students to "stop" and turn to the next page to begin the next assignment. After each assignment in the pair was complete, the participants were instructed to flip to and complete the next page, which contained the assignment perceptions and preference rating sheet (Appendix J). During the last session, participants were debriefed (Appendix M) after completion of the final assignment pair and any questions that the participants, or their parents, had for the researcher(s) were answered. After completing each phase of the study, participants chose a prize from a treasure chest/prize box. Assignment Pairs

\begin{tabular}{rll}
\hline Control Assignment Type & Experimental Assignment Type \\
\hline Control Instructional & $1: 3$ Instructional \\
\hline Control Frustration & $1: 3$ Frustration \\
\hline Control Instructional & $1: 1$ Instructional \\
\hline Control Frustration & $1: 1$ Frustration \\
\hline Control Instructional & $2: 1$ Instructional \\
\hline Control Frustration & $2: 1$ Frustration \\
\hline
\end{tabular}

Figure 2. Control-experimental assignment pairs. 


\section{Experimental Design}

A brief experimental analysis was used to evaluate the differential effects of assignment alteration based on instructional level and an interspersing procedure on the chosen dependent variables (i.e., task performance, assignment preference, assignment perceptions). An alternating treatments design was used within the brief experimental analysis to compare results of outcome measures on math assignments with different rates of interspersing and different instructional levels. Experimental conditions were as follows: assignments with an interspersing ratio of 1 brief problem for every 3 target problems that are at instructional (1:3I) or frustration level (1:3F), assignments with an interspersing ratio of 1 brief problem for every 1 target problem that are at instructional $(1: 1 \mathrm{I})$ or frustration level $(1: 1 \mathrm{~F})$, and assignments with an interspersing ratio of 2 brief problems for every 1 target problem that are at instructional (2:1I) or frustration level $(2: 1 F)$.

When implementing single-case research designs (SCRDs), such as the one used in this study, researchers must be aware of and work toward decreasing the impact of threats to internal validity (Kratochwill et al., 2010, 2013). SCRDs should demonstrate experimental control through effect replication at three different points in time, either across participants or within a single participant, and methodological soundness (i.e., the structure of the design). The current study sought to recruit a minimum of 10 participants to demonstrate effect replication across participants. Within participant replications were also completed to demonstrate the effects of manipulating instructional level and rate of interspersing on each outcome measure. With regard to methodological soundness, the current study addressed concerns regarding potential sequencing and carryover effects by counterbalancing the presentation of intervention phases and randomly assigning participants to a particular phase order. Further, participants received one 
intervention condition per day of data collection to reduce the chance of carryover effects. To improve the researchers' confidence that changes in a dependent variable were directly related to the systematic manipulation of the independent variables, outcome measures were administered immediately following the manipulation. Attrition is a major concern in SCRDs, as it was in the current study, due to data collection being conducted in a school setting and the likelihood that students would miss days due to being sick and/or having required academic tasks to complete at the schedule data collection time. The researchers achieved $0 \%$ attrition by having "make-up days” at another scheduled day/time to maintain the pre-assigned order of session materials administered to each participant. Data were analyzed using visual inspection procedures outlined in the What Works Clearinghouse, Procedures and Standards Handbook for Single Case Experimental Designs (Monahan et al., 2011) and Single-Case Design Technical Documentation (Kratochwill et al., 2010). Visual inspection procedures and statistical analyses were completed for each set of dependent variables.

\section{Data Analysis}

Visual analysis procedures. Visual inspection of the data were conducted according to the What Works Clearinghouse, Procedures and Standards Handbook (Monahan et al., 2011) and Technical Documentation (Kratochwill et al., 2010) for Single Case Experimental Designs. Visual inspection procedures involve four steps for evaluating six features: (1) level, (2) trend, (3) variability, (4) immediacy of the effect, (5) overlap, and (6) consistency of data in similar phases. The first step in conducting a visual inspection is to determine a baseline pattern that can be used to compare the effects of the interventions. In the current study, baseline data were collected using control assignments at instructional level and at frustration level. Further, each control assignment type was paired with one another (i.e., CA vs. CF; CF vs. CF; CA vs. CF) to 
demonstrate equivalence between assignments of the same instructional level and to collect baseline performance, perception, and preference data.

The second step in conducting a visual analysis is to assess the level, trend, and variability of the data within and across each intervention phase. Assessing the level and trend refers to calculating the mean score and the slope for data within a condition, respectively. Evaluating the variability of the data refers to determining the range of data within and across phases. Level and trend of the data were evaluated by graphing each of the dependent variables on the $y$-axis, rate of interspersing on the $\mathrm{x}$-axis, and categorizing data points based on whether assignments are at instructional or at frustration level. The level and trend of data derived from assignments at instructional level was compared to data derived from assignments at frustration level across all participants (e.g., evaluating the mean relative problem completion rate on each assignment type across all participants). To evaluate the variability of the data the researcher compared the data in each phase with data in adjacent phases to determine if the manipulation of the independent variables (i.e., instructional level and rate of interspersing) was associated with predicted changes in each of the dependent variables.

The third step involved completing an evaluation of the overlapping data points for assignments at instructional versus at frustration level and data points for control assignments versus assignments with interspersing. The smaller the proportion of overlapping data points in each phase the more compelling the argument for demonstrating an effect is. Further, immediacy of effect was assessed by examining the extent to which data for each of the dependent variables fluctuates between control assignments and assignments with interspersing, and between assignments at instructional versus at frustration level. 
The final step in conducting a visual analysis was to determine if the dependent variable data follow hypothesized data patterns. Specifically, researchers analyzed data to evaluate whether preference for and perceptions of math assignments varies as a function of the rate of interspersing and instructional level in a manner that would be predicted by the matching law. In addition to conducting the visual inspection procedures, $100 \%$ of assignments at assessment, baseline, and intervention phases were scored by two researchers prior to data entry. 


\section{CHAPTER IV: RESULTS}

\section{Baseline Results}

\section{Instructional-Frustration Control Pair Performance Data}

During baseline, control assignments consisting of target problems at instructional level (CI) and at frustration level (CF) were paired and administered across sessions two through four. Across two of the baseline sessions, two CI assignments and two CF assignments were paired together to gather baseline data on control assignments at instructional and frustration level, as well as to demonstrate equivalence between the two assignment types. Further, CI and CF assignments were paired during one of the three baseline sessions to demonstrate a baseline preference for assignments at instructional level that have no interspersing. Participants were expected to complete more target problems and have higher target problem accuracy on control assignments at instructional level than frustration level. Preference and perception ratings were also expected to favor control assignments at instructional level. Further, assignment pairs at the same instructional level were not expected to significantly vary with regard to performance, preference, or perception data. Thus, a relatively flat trend line in the CI-CI and CF-CF conditions were expected.

There was a statistically significant difference between the number of problems completed on control assignments at instructional level and control assignments at frustration level at baseline, $t(d f=19)=5.66, p<.000$, which represented a large effect size, $d=1.81$. At baseline, students completed more problems on the control assignment at instructional level $(M=$ $19.95, S E=.05)$ than on the control assignment at frustration level $(M=12.10, S E=1.37)$. With regard to problem accuracy, there was a statistically significant difference between problem accuracy on control assignments at instructional level and control assignments at frustration level 
at baseline, $t(d f=19)=5.85, p<.000$, which represented a large effect size, $d=1.66$.

Specifically, participants' accuracy was higher on control assignment at instructional level $(M=$ 93.05, $S E=2.73)$ than on control assignment at frustration level $(M=43.75, S E=8.99)$. Visual analysis of the data (See Figure 3) illustrate similar results. Specifically, there was a visible difference in the level of the data between assignments at instructional and frustration level in the expected direction, such that participants’ performance was more optimal on instructional level assignments.

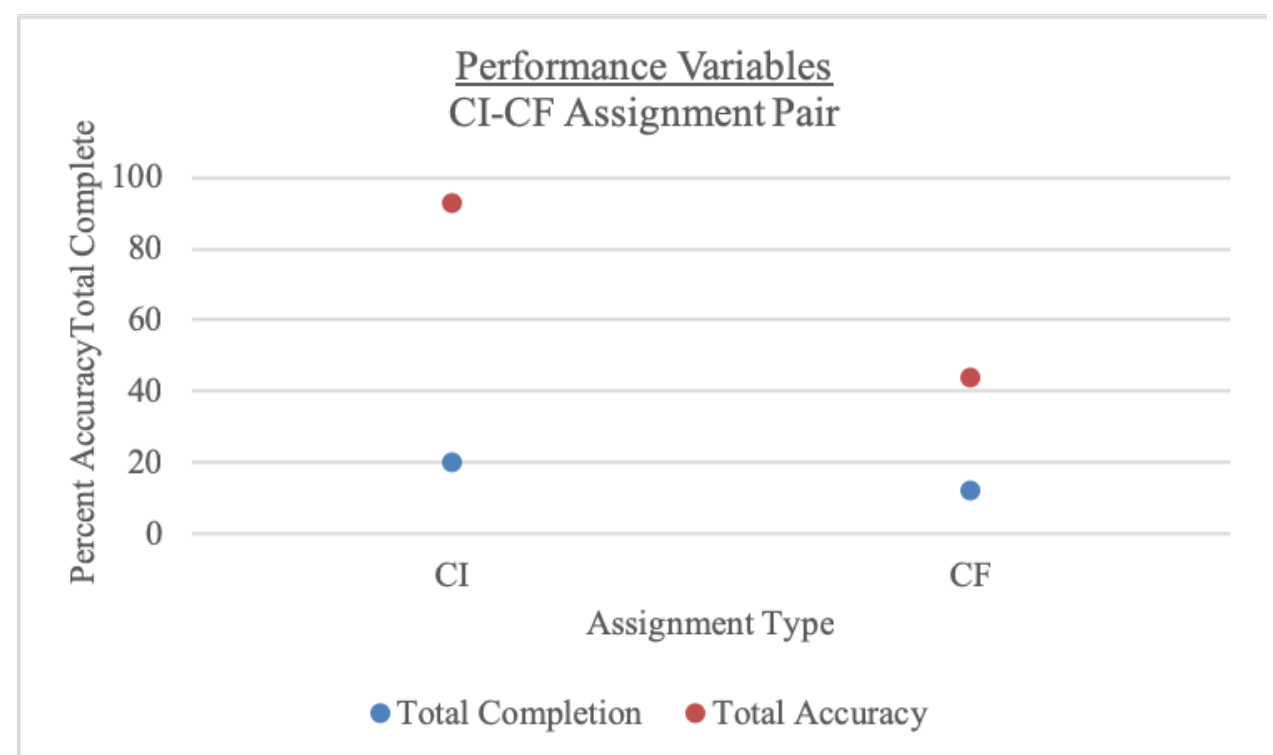

Figure 3. Total problems completed and total accuracy on controlinstructional and control-frustration assignment pair at baseline.

Table 1.

Planned Comparison of Performance Measures on Baseline Control Instructional versus Control Frustration Assignment Pair

\begin{tabular}{lccccc}
\hline \multicolumn{1}{c}{ Planned Comparison } & $t$ & $d f$ & Sig. & $M$ & $S D$ \\
\hline Total Problems Completed & 5.66 & 19 & $.000^{*}$ & 7.85 & 6.20 \\
Total Accuracy & 5.85 & 19 & $.000^{*}$ & 49.30 & 37.71 \\
\hline
\end{tabular}

*denotes statistically significant $p$-value 


\section{Instructional-Frustration Control Pair Perception Data}

Baseline data on perception and preference ratings were also gathered. At baseline, there was a statistically significant difference between participant perceptions of control assignments at instructional level and control assignments at frustration level for time $[t(d f=19)=-6.31, p<$ $.000, d=2.04]$, difficulty $[t(d f=19)=-8.46, p<.000, d=2.71]$, and effort $[t(d f=19)=-2.59$, $p=.018, d=.94]$, which represented a large effect size. Participants were more likely to rate the control assignment at instructional level as taking less time $(M=1.80, S E=.14)$ than the control assignment at frustration level $(M=3.35, S E=.20)$. The control assignment at instructional level was also perceived as being less difficult $(M=1.25, S E=.10)$ than the assignment at frustration level $(M=3.05, S E=$.19). Finally, participants perceived the control assignment at instructional level as requiring less effort $(M=2.25, S E=.23)$ to complete than the control assignment at frustration level $(M=3.15, S E=.20)$. The visual analysis of Likert perception data (See Figure 4) reveal visible differences in preference ratings between control assignments at instructional and frustration level at baseline in the expected direction. Specifically, participants rated the frustration level control assignment as requiring more time and effort and as being more difficult to complete than the paired control assignment. 


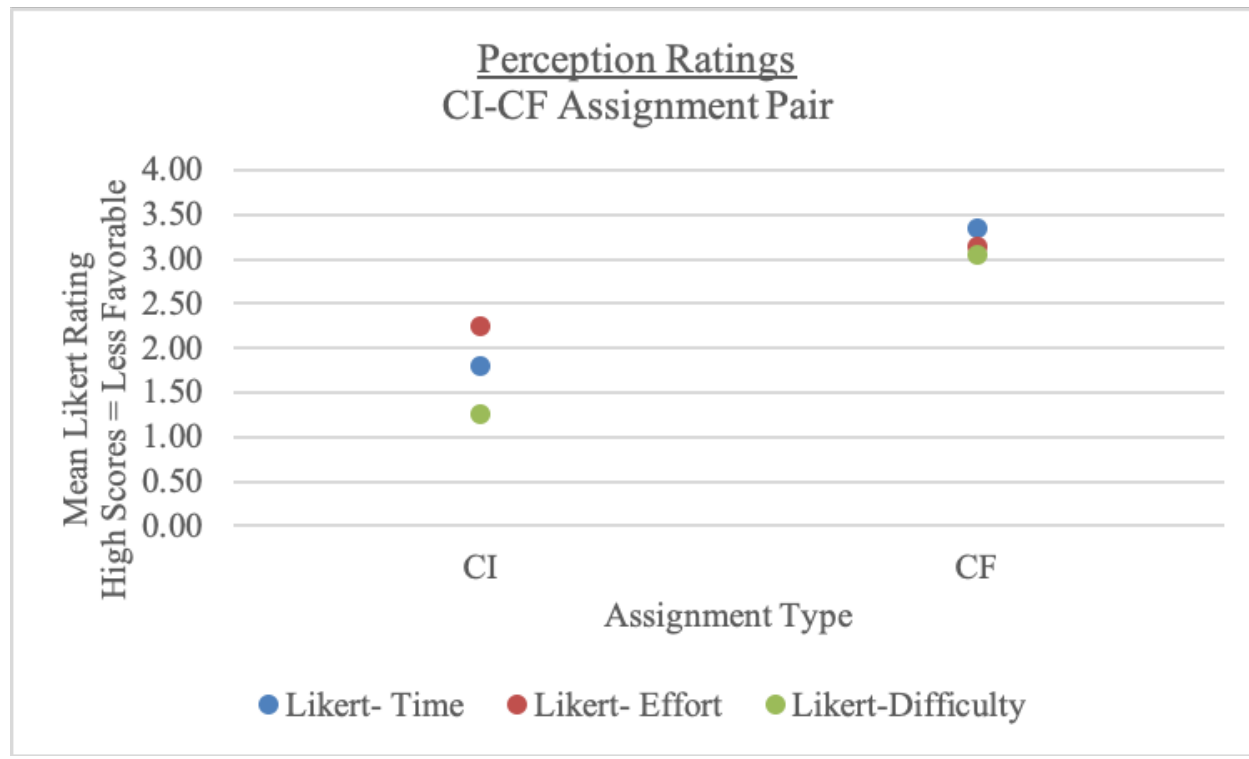

Figure 4. Ratings on Likert scale for time, effort, and difficulty on controlinstructional and control-frustration assignment pair at baseline.

Participants also completed forced-choice questions regarding which assignments seemed to take more time, be more difficult, and take more effort to complete. When asked Which assignment would take the most time to complete from start to finish, statistically significantly more participants indicated that the assignment at frustration level would take more time to complete than the control assignment at instructional level, $t(d f=19)=13.08, p<.000$. Specifically, 90\% ( $n=18)$ of participants indicated that the frustration level assignment would take more time and $10 \%(n=2)$ of participants indicated that the instructional level assignment would take more time to complete.

When asked Which assignment was most difficult, 100\% $(n=20)$ of participants rated the control assignment at frustration level as being more difficult than the instructional level assignment. When asked Which assignment would take the most effort to complete from start to finish, statistically significantly more participants indicated that the assignment at frustration level would take more effort to complete than the control assignment at instructional level, $t$ $(d f=19)=10.38, p<.000$. Specifically, $85 \%(n=17)$ of participants indicated that the frustration 
level assignment would take more effort and 15\% $(n=3)$ of participants indicated that the instructional level assignment would take more time to complete. Out of the three participants who rated the instructional assignment as taking more effort than the frustration assignment, two participants rated the frustration level assignment as one point higher than the instructional level assignment, indicating that they rated the frustration level assignment as requiring more effort than the instructional assignment on the Likert scale. Since participants who did not choose the instructional level assignment were eliminated from the final sample, $100 \%(n=20)$ of participants chose to take the instructional level control assignment for homework. Figure 5 provides a representation of the perception of participants that chose the frustration level control assignment as requiring more time and effort and as being more difficult than the paired instructional level control assignment

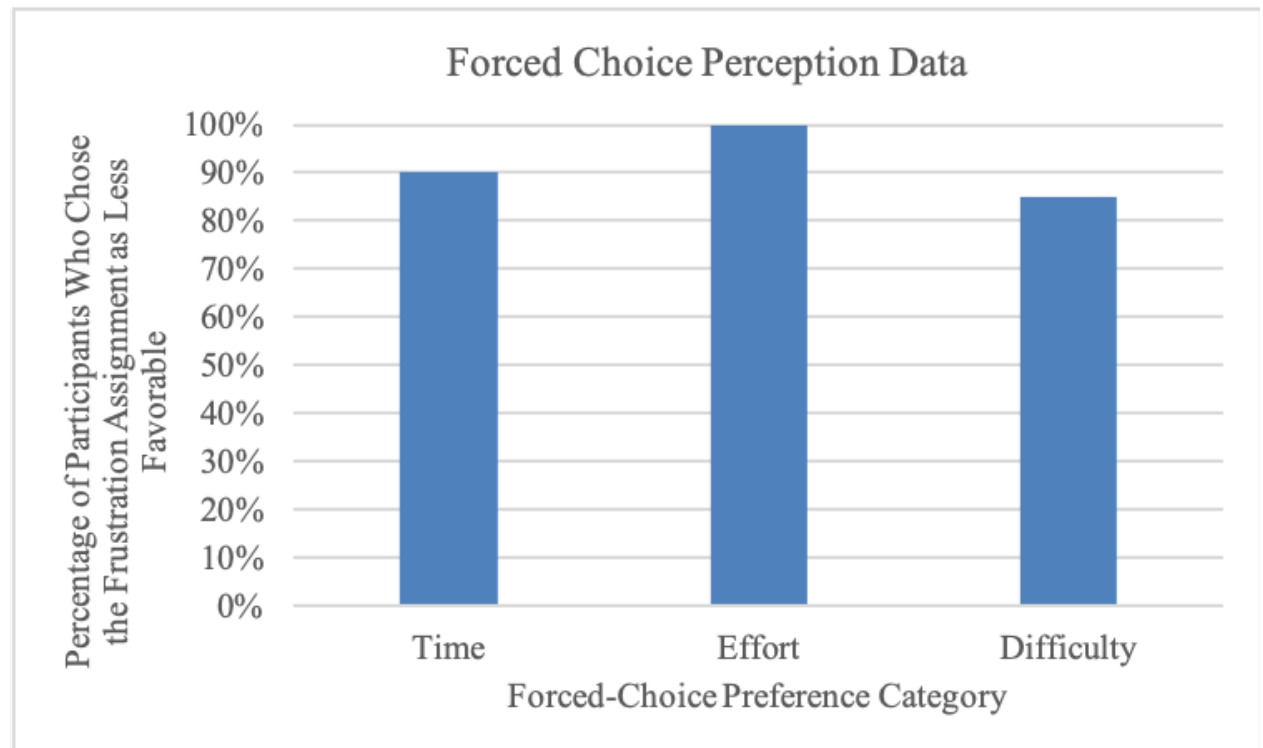

Figure 5. Percentage of participants who chose the frustration-level assignment as requiring more time and effort and being more difficult to complete than the paired instructional-level control assignment at baseline. 
Table 2.

Planned Comparison of Performance and Perception Measures on Baseline Control Instructional versus Control Frustration Assignment Pair

\begin{tabular}{lccccc}
\hline \multicolumn{1}{c}{ Planned Comparison } & $t$ & $d f$ & Sig. & $M$ & $S D$ \\
\hline Likert - Time Rating & -6.31 & 19 & $.000^{*}$ & -1.55 & 1.10 \\
Likert - Difficulty Rating & -8.46 & 19 & $.000^{*}$ & -1.80 & .95 \\
Likert- Effort Rating & -2.59 & 19 & $.018^{*}$ & -.90 & 1.55 \\
Forced-Choice Time Rating & 13.08 & 19 & $.000^{*}$ & .90 & .31 \\
Forced-Choice Difficulty Rating * & - & - & - & 1.00 & .00 \\
Forced-Choice Effort Rating & 10.38 & 19 & $.000^{*}$ & .85 & .37 \\
\hline
\end{tabular}

Note: $t$ cannot be computed for Forced-Choice difficulty because the standard deviation is 0 . *denotes statistically significant $p$-value

\section{Instructional-Instructional Control Pair Data}

When control instructional assignments were paired with one another, there was no statistically significant difference between the number of problems completed, $t(d f=19)=$ $1.19, p=.249$, total problem accuracy, $t(d f=19)=-.26, p=.802$, or Likert perception ratings of time $[t(d f=19)=1.37, p=.186]$, difficulty $[t(d f=19)=1.00, p=.330]$, or effort $[t(d f=19)=$ $.72, p=.418]$. Thus, participant performance and ratings of perception on instructional level assignments were equivalent. This also suggests that the assignments themselves were equivalent assignments. Further, a visual analysis of the data (See Figures 6 and 7) demonstrates that there is no visible difference between instructional level control assignments at baseline across dependent variables. 


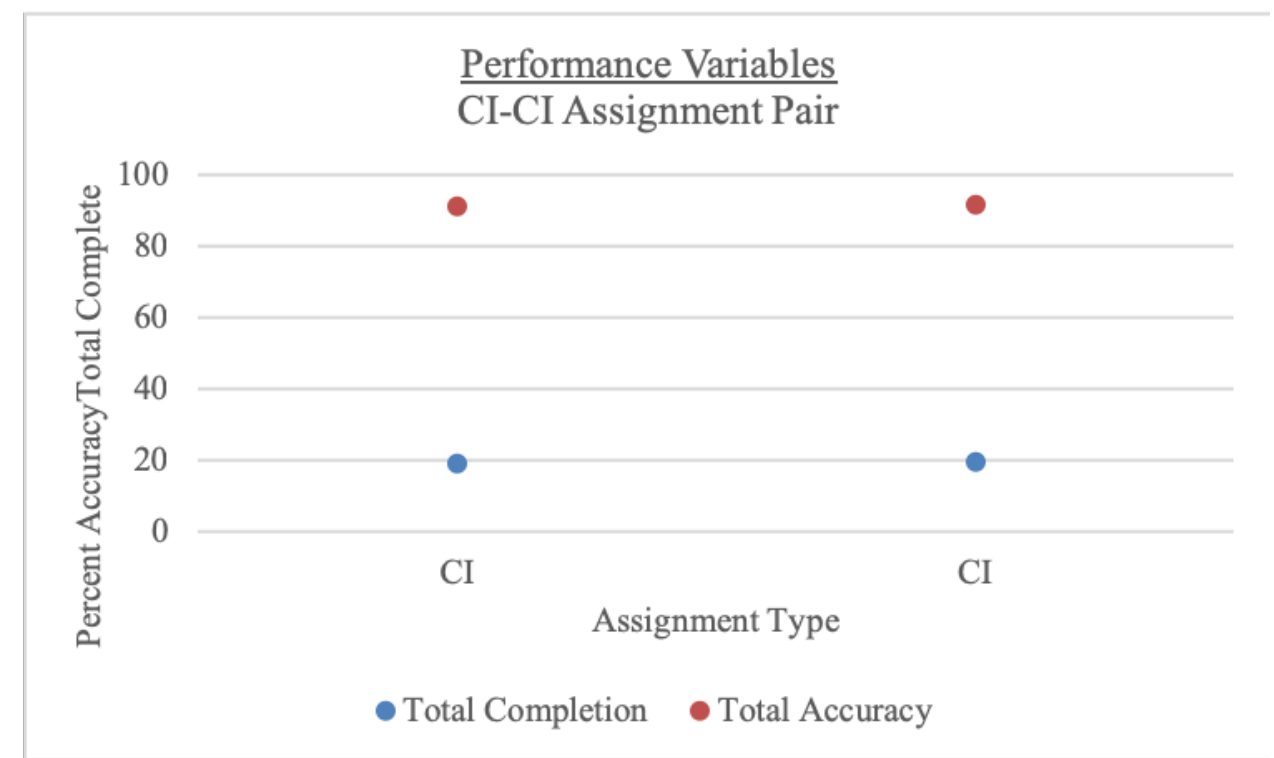

Figure 6. Total problems completed and total accuracy on controlinstructional and control-instructional assignment pair at baseline.

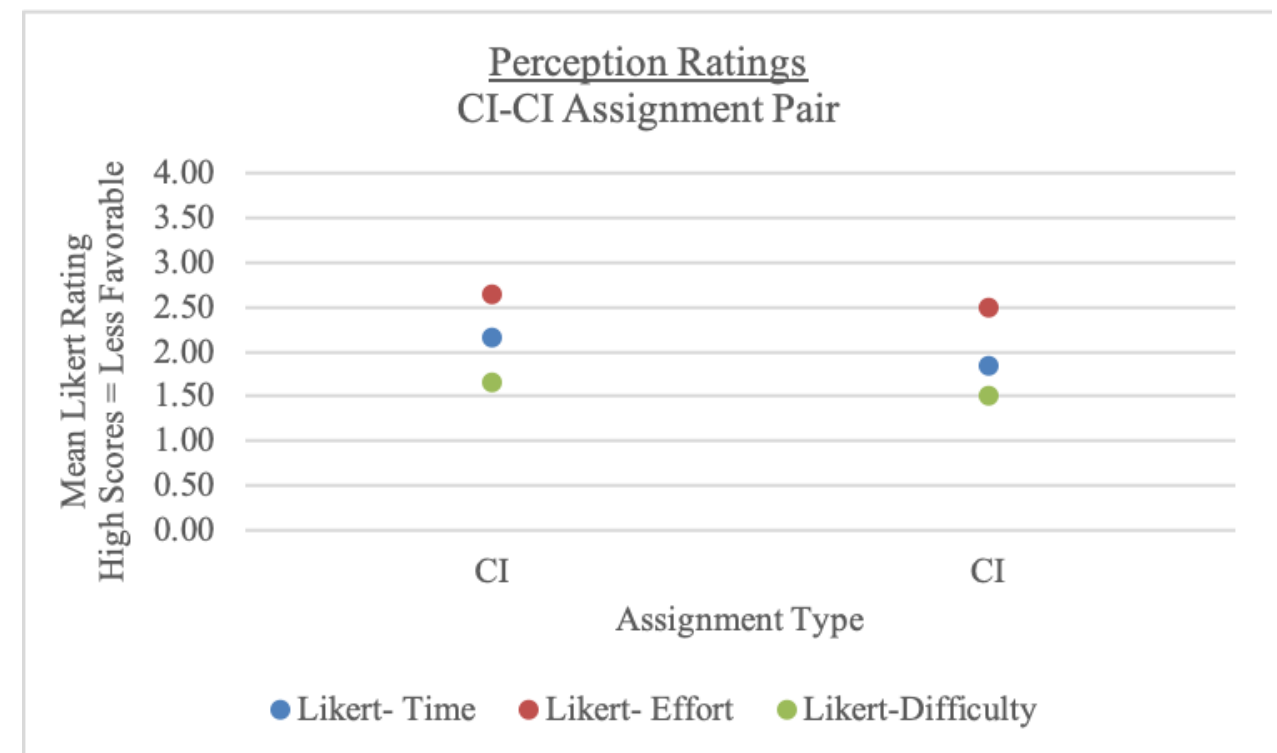

Figure 7. Ratings on Likert scale for time, effort, and difficulty on control-instructional and control-instructional assignment pair at baseline. 
Table 3.

Comparison of Total Problems Completed, Total Accuracy, and Likert Perception Ratings Between Baseline Control Instructional and Baseline Control Instructional Assignment Pair

\begin{tabular}{lccccc}
\hline \multicolumn{1}{c}{ Planned Comparison } & $t$ & $d f$ & $\begin{array}{c}\text { Sig. } \\
\text { (2-tailed) }\end{array}$ & $M$ & $S D$ \\
\hline Total Problems Completed & -1.19 & 19 & .249 & -.30 & 1.13 \\
Total Accuracy & -.26 & 19 & .802 & -.45 & 7.90 \\
Time Rating & 1.37 & 19 & .186 & .30 & .98 \\
Difficulty Rating & 1.00 & 19 & .330 & .15 & .67 \\
Effort Rating & .72 & 19 & .481 & .15 & .93 \\
\hline
\end{tabular}

*denotes statistically significant $p$-value

\section{Frustration-Frustration Control Pair Data}

When control frustration assignments were paired with one another, there was no statistically significant difference between the number of problems completed, $t(d f=19)=.28$, $p=.783$, total problem accuracy, $t(d f=19)=.24, p=.812$, or Likert perception ratings of time $[t(d f=19)=1.56, p=.135]$, difficulty $[t(d f=19)=.57, p=.577]$, or effort $[t(d f=19)=.24, p$

$=.815$. Thus, participant performance measures and perception ratings of frustration level assignments were equivalent. This also suggests the assignments themselves were equivalent assignments. Further, a visual analysis of the data (See Figures 8 and 9) demonstrates that there is no visible difference between frustration level control assignments at baseline across dependent variables. 


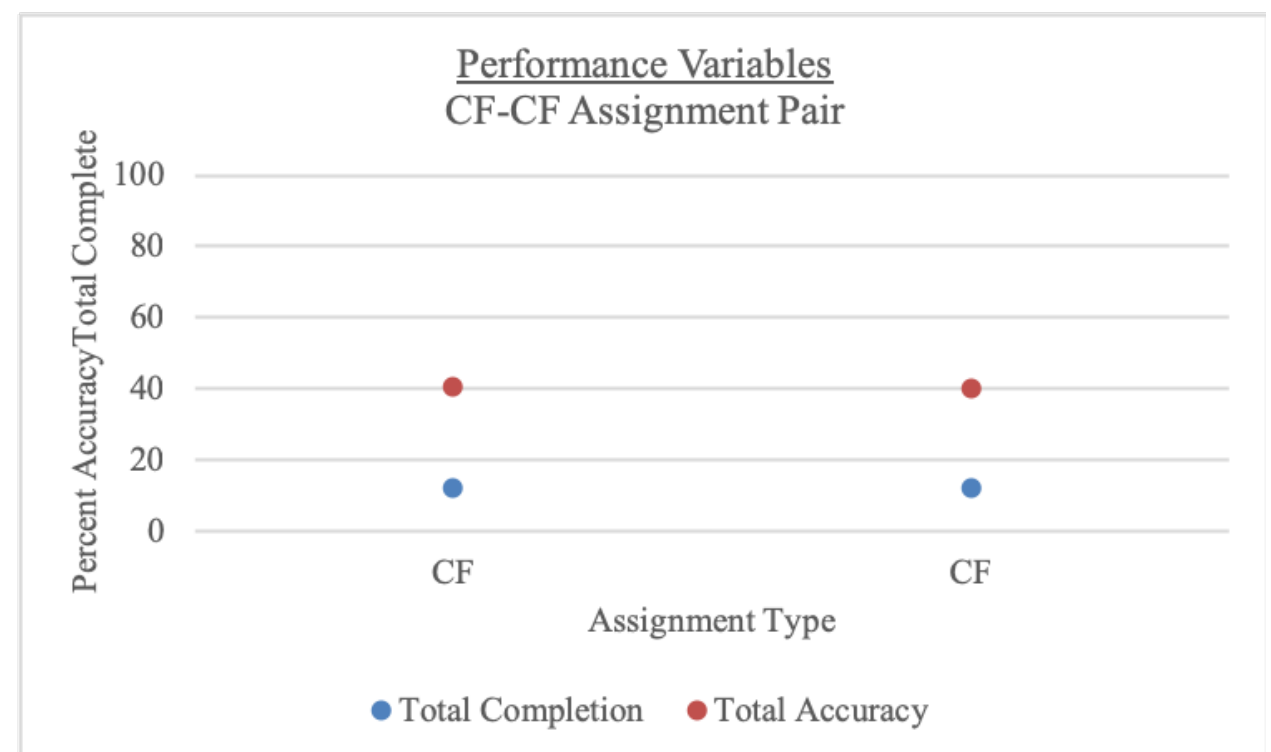

Figure 8. Total problems completed and total accuracy on controlfrustration and control-frustration assignment pair at baseline.

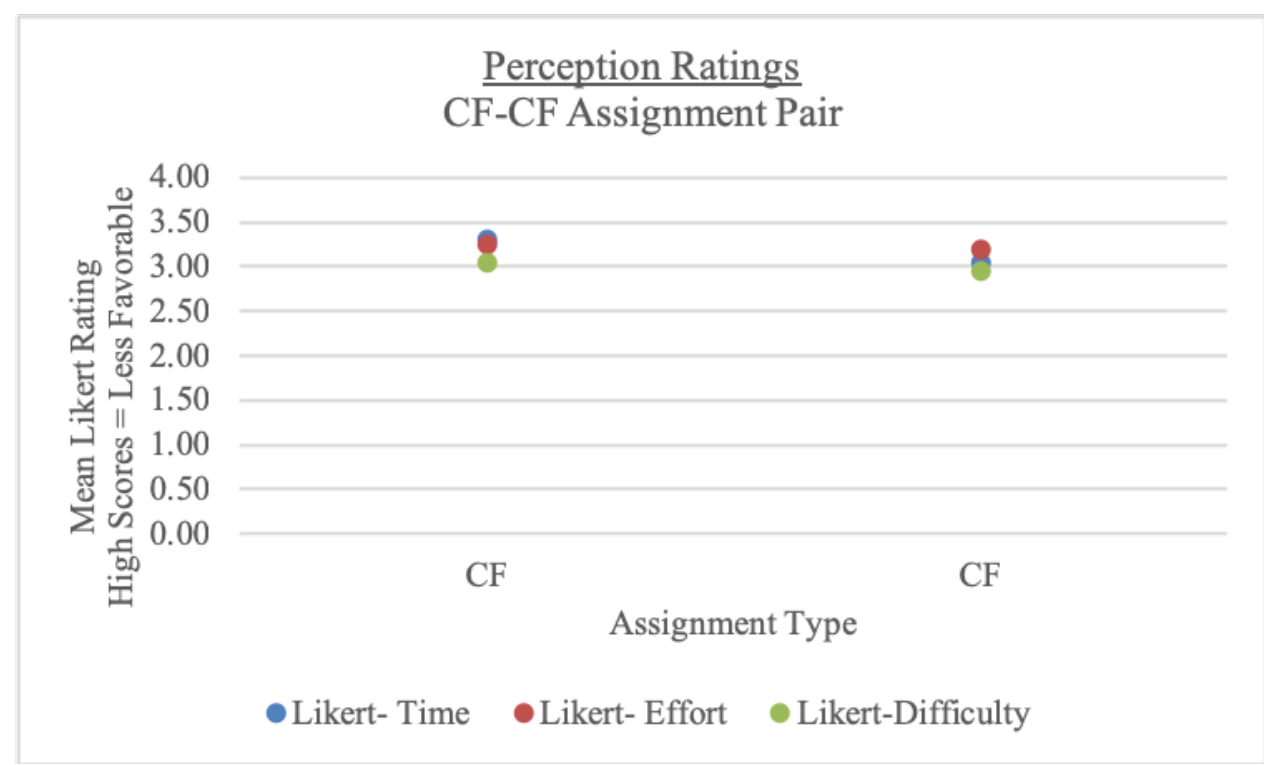

Figure 9. Ratings on Likert scale for time, effort, and difficulty on controlfrustration and control-frustration assignment pair at baseline. 
Table 4.

Comparison of Total Problems Completed, Total Accuracy, and Likert Perception Ratings

Between Baseline Control Frustration and Baseline Control Frustration Assignment Pair

\begin{tabular}{lccccc}
\hline \multicolumn{1}{c}{ Planned Comparison } & $t$ & $d f$ & $\begin{array}{c}\text { Sig. } \\
\text { (2-tailed) }\end{array}$ & $M$ & $S D$ \\
\hline Total Problems Completed & .28 & 19 & .783 & .20 & 3.21 \\
Total Accuracy & .24 & 19 & .812 & .55 & 10.20 \\
Time Rating & 1.56 & 19 & .135 & .25 & .72 \\
Difficulty Rating & .57 & 19 & .577 & .10 & .79 \\
Effort Rating & .24 & 19 & .815 & .05 & .95 \\
\hline
\end{tabular}

*denotes statistically significant $p$-value

\section{Results}

\section{Hypothesis 1}

Relative problem completion rate. Relative problem completion rates were calculated by dividing the total number of problems completed on a control assignment by the total number of problems completed on a matched experimental assignment. A visual analysis of the data were completed to evaluate whether the level, trend, variability, and immediacy of effect of the data follow predicted patterns in accordance with matching law. It was hypothesized that the number of problems completed on assignments with interspersing would differ relative to the number of problems completed on the paired control assignments. Specifically, relative problem completion rates were expected to increase as the rate of interspersing increased. Moreover, the trend of the data was expected to be steeper and the relative problem completion rate would be higher for assignments at instructional level than for assignments at frustration level.

Figure 10 illustrates that results for relative problem completion rate across interspersing ratios and assignment types. The data demonstrate variability across interspersing ratios and assignment instructional levels. As predicted, relative problem completion rate increased as the 
rate of interspersing increased for assignments at instructional level. Although a similar pattern is demonstrated for assignments at frustration level, relative problem completion rates appear to have dipped during the highest rate of interspersing for frustration level assignments. The trend of the data were steeper for frustration level assignments but leveled off at the most dense rate of interspersing, whereas the trend consistently increased with the density of interspersing for instructional level assignments. The level of the data indicates a visible difference between relative problem completion rates on all assignments at instructional versus frustration level.

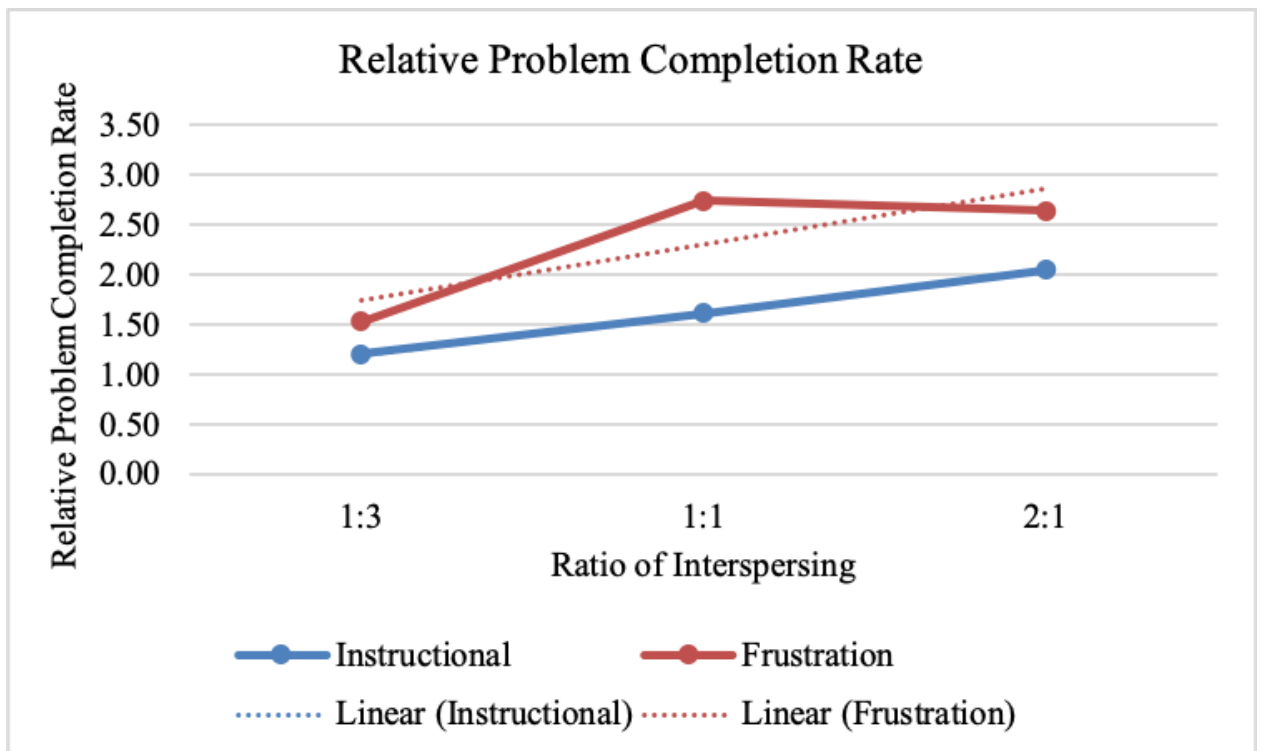

Figure 10. Results for relative problem completion rates.

Paired-sample t-tests were conducted to compare differences between the relative problem completion rates on instructional and frustration level assignments for each assignment ratio. The difference of relative problem completion rates between 1:3 Instructional assignments and 1:3 Frustration assignments was not significant, $t(d f=19)=-1.57, p=.133$. Statistically significant differences were found between 1:1 Instructional and 1:1 Frustration assignments, $t$ $(d f=19)=-3.26, p=.004$, which represented a large-sized effect, $d=1.01$. Relative problem completion rates were significantly lower on 1:1 Instructional assignments $(M=1.6145, S E=$ 
.06) than 1:1 Frustration assignments $(M=2.75, S E=.35)$. Further, the difference of relative problem completion rates between 2:1 Instructional and 2:1 Frustration assignments was statistically significant, $t(d f=19)=-3.13, p=.005$, which represented a large-sized effect, $d=$ .97. Relative problem completion rates were significantly lower on 2:1 Instructional assignments $(M=2.05, S E=.07)$ than 2:1 Frustration assignments $(M=2.64, S E=.18)$.

Table 5.

Comparison of Relative Problem Completion Rates between Assignments at Instructional versus Frustration Level

\begin{tabular}{lccccc}
\hline \multicolumn{1}{c}{ Planned Comparison } & $t$ & $d f$ & $\begin{array}{c}\text { Sig. } \\
\text { (2-tailed) }\end{array}$ & $M$ & $S D$ \\
\hline $\begin{array}{l}\text { Relative Problem Completion Rate } \\
\text { 1:3 Instructional vs. 1:3 }\end{array}$ & -1.57 & 19 & .133 & -.33 & .94 \\
$\quad \begin{array}{l}\text { Frustration } \\
\text { 1:1 Instructional vs. 1:1 }\end{array}$ & -3.26 & 19 & $.004^{*}$ & -1.13 & 1.55 \\
$\begin{array}{l}\text { Frustration } \\
\text { 2:1 Instructional vs. 2:1 }\end{array}$ & -3.13 & 19 & $.005^{*}$ & -.59 & .84 \\
Frustration & & & & &
\end{tabular}

*denotes statistically significant $p$-value

A supplemental, 3 (1:3 vs. 1:1 vs. 2:1) x 2 (at instructional level vs. at frustration level) repeated measures ANOVA for assignment type and ratio of interspersing was used to analyze differences in relative problem completion rates across assignment pairs and to determine if an interaction exists between relative problem completion rates, instructional level, and ratio of interspersing. It was hypothesized that a significant interaction would exist between relative problem completion rates, instructional level, and assignment type. Although relative problem completion rates increased as the rate of interspersing increased, this interaction was not significant, $\mathrm{F}=.74(\mathrm{df}=1,19), M S E=.346, p=.401$. 


\section{Hypothesis 2}

Total problem completion rates. Two scores were derived to evaluate problem completion rates: (1) the total number of problems completed, which included completion of brief interspersed problems and the number of target problems completed, and (2) the number of target problems completed on control or experimental assignments. Problems were considered complete if a final answer, either correct or incorrect, was provided. With regard to comparing means across assignment types, it was hypothesized that participants would complete more problems overall on experimental assignments than control assignments. The number of total problems completed was expected to increase as the rate of interspersing increased. Further, participants were expected to complete more total problems on assignments at instructional level than assignments at frustration level, regardless of being a control or experimental assignment. It was also expected that participants would complete more problems overall on assignments with the same rate of interspersing at instructional level than similar assignments at frustration level. Finally, control assignments at the same instructional level were not expected to differ due to the assignments being more equivalent in terms of difficulty level and reinforcement not being integrated into the assignment.

Figure 11 demonstrates that the level of total problem completion rate data were visibly higher on experimental assignments than control assignments and higher on assignments at instructional level than assignments at frustration level when means across each independent variable was compared. Figure 12 illustrates a visible difference in the level of the data when comparing the means for total problem completion rates. Specifically, the data demonstrate that total problem completion rates were higher on experimental assignments at instructional level than all other assignment conditions, including paired control assignments at instructional level. 
Further, the level of total problem completion rate data were higher on experimental assignments at frustration level than all control assignment types, including paired control assignments at frustration level.

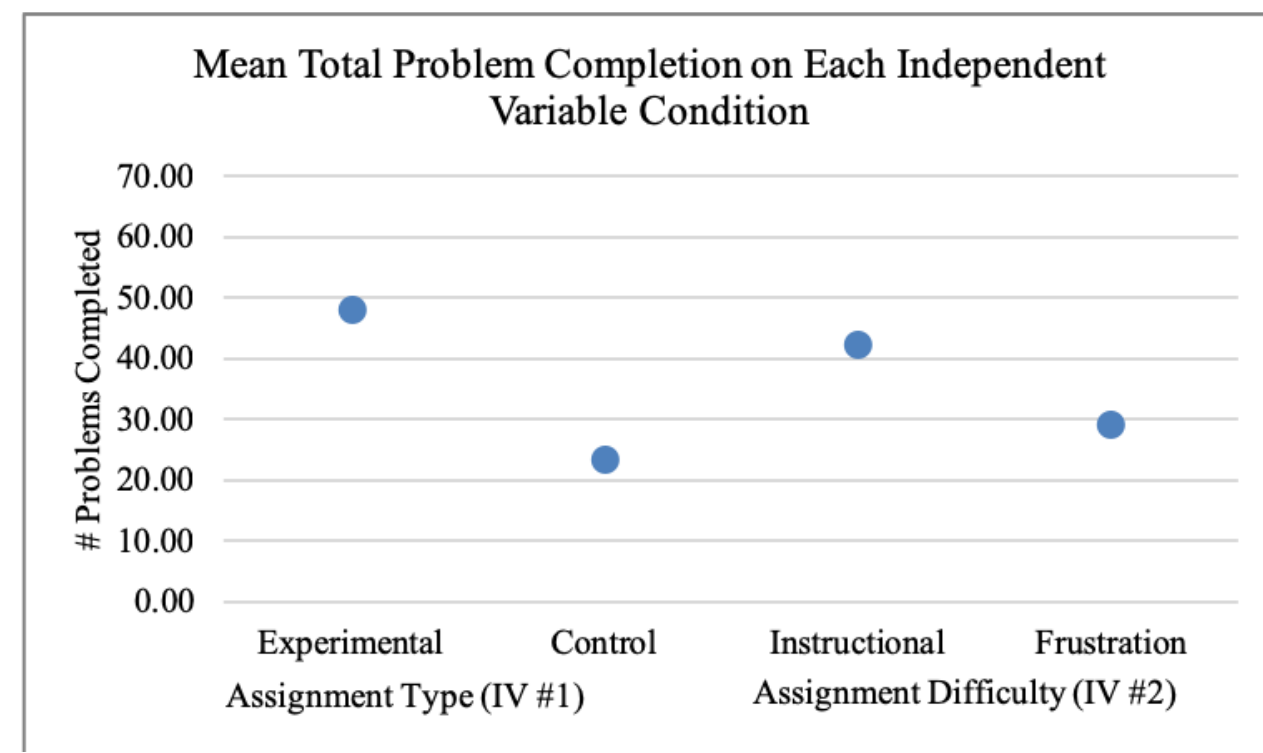

Figure 11. Results for total problem completion means across conditions of each independent variable (i.e., experimental vs. control; instructional vs. frustration level).

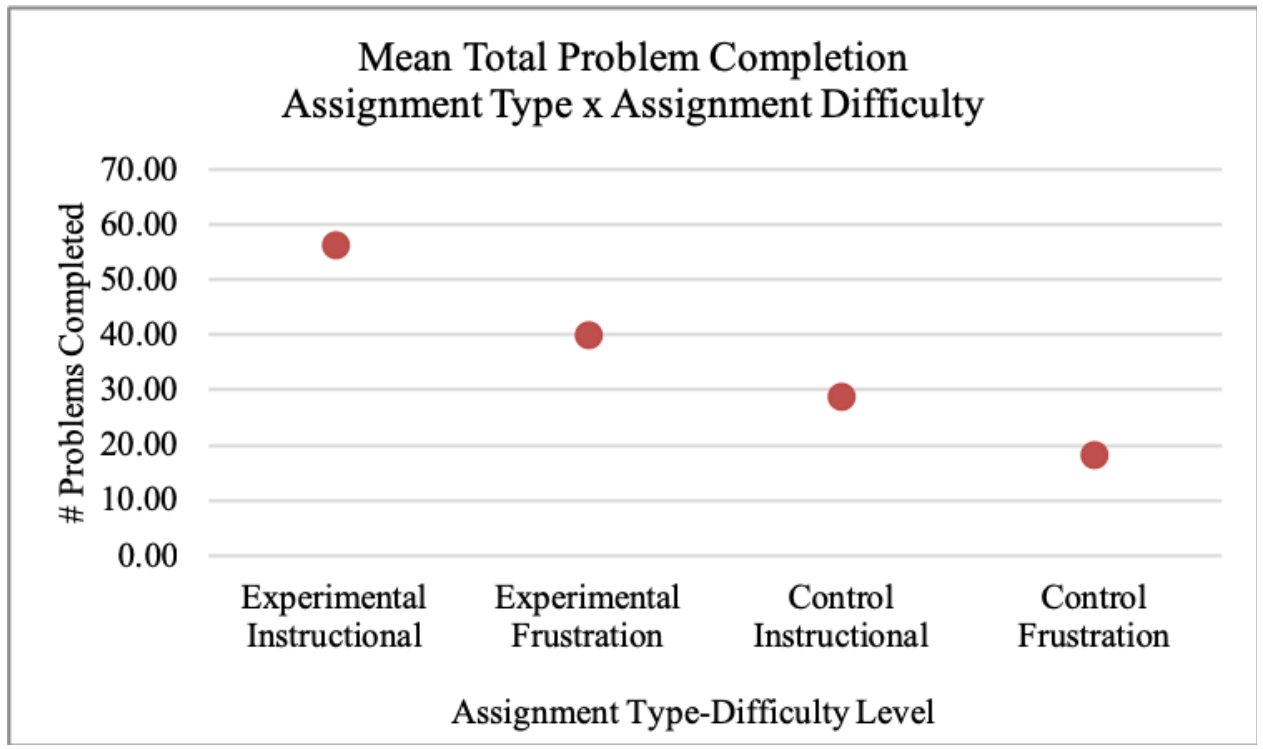

Figure 12. Results for planned comparisons of mean total problem completion data for assignment type (experimental or control) and assignment difficulty (at instructional level or at frustration level). 
Each control assignment was paired with an experimental assignment at the same instructional level. Data were collapsed across participants for each condition and a visual inspection of trend, level, and variability of the data were conducted to evaluate differences between total problem completion on assignments at instructional level and at frustration level across each experimental condition (i.e., 1:3; 1:1; 2:1). It was hypothesized that total problem completion rates would increase as a function of the rate of interspersing within an assignment and mean total problem completion rates on control assignments were expected to stay relatively stable. Thus, it was expected that an increasing trend would be present when comparing total problem completion rates across experimental assignments at varying levels of density. Further, the trend for experimental assignments at instructional level was expected to be steeper than the trend for experimental assignments at frustration level.

Figure 13 illustrates that total problem completion rates increased as a function of the rate of interspersing within an assignment type, whereas mean total problem completion rates on control assignment were relatively stable. Thus, an increasing trend is present when comparing total problem completion rates across experimental assignments at varying rates of interspersing, ranging from least dense at the left to most dense at the right. Further, the trend for experimental assignments at instructional level was steeper than the trend for experimental assignments at frustration level and there was a visible difference between the data for assignments at instructional and frustration level, regardless of interspersing rate. 


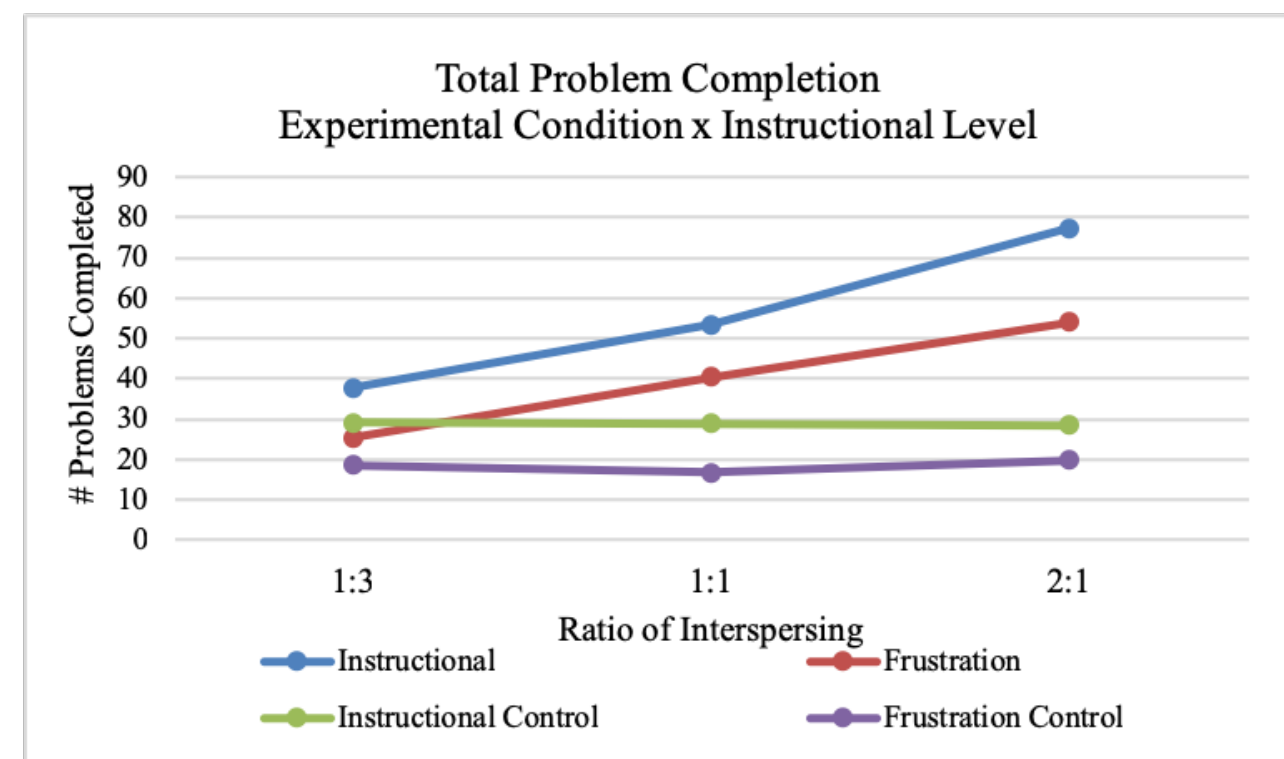

Figure 13. Results for within participant total problem completion rates/across participant mean total problem completion rates across experimental and control assignments at instructional or frustration level.

Figure 14 illustrates results when data are collapsed within experimental conditions and paired controls. It was expected that the mean total problem completion rates would increase as the assignments became denser, while the mean total problem completion rates would remain relatively stable on paired control assignments. The variability of the data were also expected to present visible differences in total problem completion across experimental conditions. As the data demonstrate, the mean total problem completion rate increased as the assignments became denser, while the mean total problem completion rates remained relatively stable on paired control assignments. The variability of the data were evaluated and a visibly significant difference between data across experimental conditions is present. Specifically, a visible difference in total problem completion is present across experimental conditions, indicating that manipulation of the independent variables (i.e., experimental conditions/rates of interspersing, and instructional level) results in changes in total problem completion rates. Further, a visible 
difference between the level of data for experimental and paired control assignments, indicating an immediate effect of altering the assignment type.

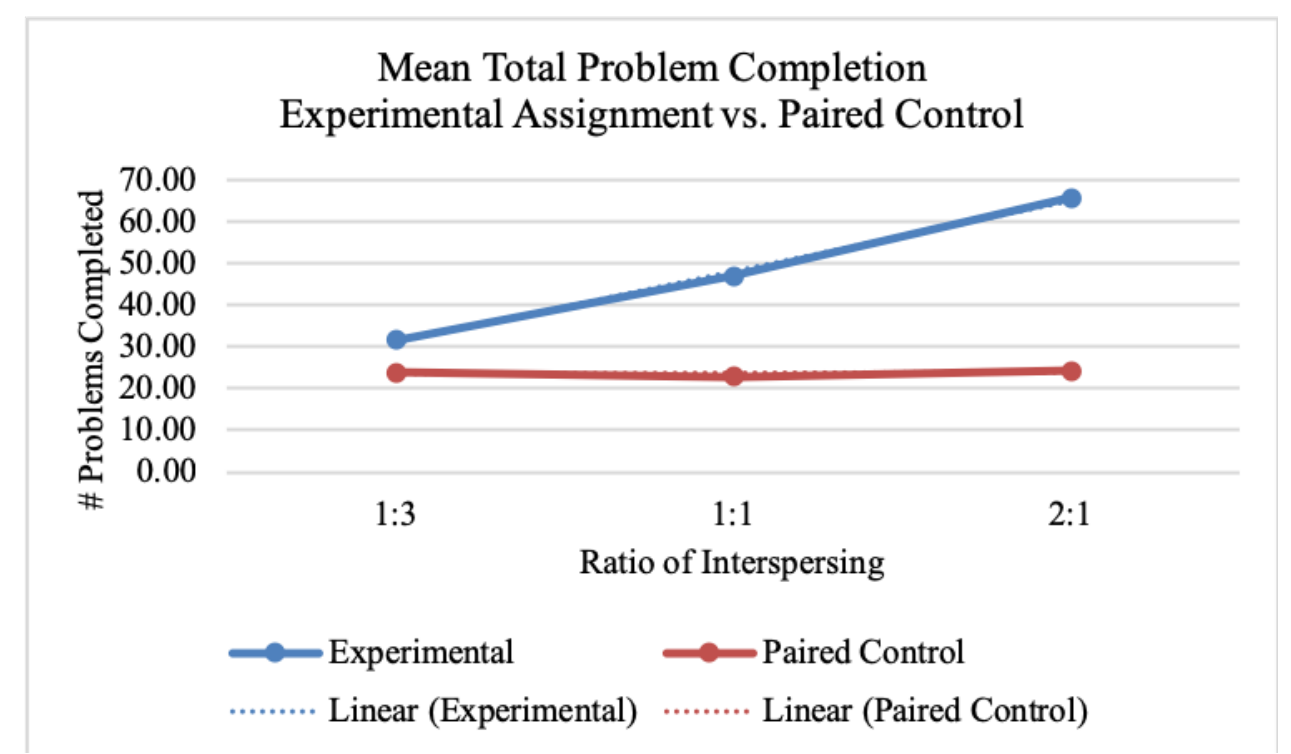

Figure 14. Results for comparison of mean total problem completion means for experimental assignments vs. paired controls.

Additional planned comparisons were completed by conducting a series of paired-sample t-tests to compare differences between the mean number of total problems completed on control and experimental assignments for each assignment type. There was a statistically significant difference between the total number of problems completed on 1:3 Control Instructional and 1:3 Experimental Instructional assignments, $t(d f=19)=-12.91, \mathrm{p}<.000$, which represented a large effect size, $d=2.35$. At instructional level, participants completed more problems overall on the 1:3 Experimental Instructional assignment $(M=37.80, S E=1.06)$ than a paired control $(M=$ 29.15, $S E=.48)$. On average, participants completed more problems overall on the 1:1 Experimental Instructional $(M=53.50, S E=2.48)$ than a paired control $(M=28.90, S E=.73)$. This difference was significant, $t(d f=19)=-12.36, p<.000$, which represented a large effect size, $d=3.01$. Finally, participants completed more problems overall on the 2:1 Experimental Instructional assignment $(M=77.40, S E=4.12)$ than the paired control $(M=28.55, S E=.75)$ 
This difference was significant, $t(d f=19)=-13.64, p<.000)$, and represented a large effect size, $d=3.68$.

There was a statistically significant difference between the total number of problems completed on 1:3 Control Frustration and 1:3 Experimental Frustration assignments, $t(d f=19)=$ $-5.19, p<.000$, which represented a medium- to large-sized effect, $d=.61$. Specifically, participants completed more problems overall on the 1:3 Experimental Frustration ( $M=25.50$, $S E=2.84)$ than the paired control assignment $(M=18.60, S E=2.21)$. On average, participants completed more problems on the 1:1 Experimental Frustration assignment $(M=40.50, S E=$ 3.97) than the paired control $(M=16.85, S E=1.83)$. This difference was significant, $t(d f=19)$ $=-8.18, p<.000$, and represented a large-sized effect, $d=1.71$. Finally, participants completed more problems overall on the 2:1 Experimental Frustration assignment $(M=54.10, S E=5.68)$ than the paired control $(M=19.95, S E=2.12)$. This difference was significant, $t(d f=19)=$ 8.36, $p=.000$, and represented a large-sized effect, $d=1.78$.

The number of total problems completed on instructional and frustration level experimental assignments at each rate of interspersal were compared. There was a statistically significant difference between the total number of problems completed on 1:3 Experimental Instructional and 1:3 Experimental Frustration assignments, $t(d f=19)=4.21, p=.000$, which represented a large effect size, $d=1$.28. Specifically, participants completed more problems overall on the 1:3 Experimental Instructional $(M=37.80, S E=1.06)$ than the 1:3 Experimental Frustration $(M=25.50, S E=2.84)$ assignment. Participants completed more problems overall on the 1:1 Experimental Instructional $(M=53.50, S E=2.48)$ than the 1:1 Experimental Frustration $(M=40.50, S E=3.97)$ assignment. This difference was significant, $t(d f=19)=2.67, p=.015$, and represented a large effect size, $d=.88$. Finally, participants completed significantly more 
problems overall on the 2:1 Experimental Instruction $(M=77.40, S E=4.12)$ than the 2:1

Experimental Frustration $(M=54.10, S E=5.68)$ assignment. This difference was significant, $t$

$(d f=19)=3.07, p=.006$, and represented a large-sized effect, $d=1.05$.

Table 6.

Comparison of Total Problems Completed on Control versus Experimental Assignments and Assignments at Instructional versus Frustration Level

\begin{tabular}{llllll} 
Planned Comparison & $t$ & $d f$ & $\begin{array}{c}\text { Sig. } \\
\text { (2-tailed) }\end{array}$ & $M$ & $S D$ \\
\hline
\end{tabular}

Total Problem Completion -

Experimental vs. Control

1:3 Control Instructional vs.

$-12.91$

19

$.000 *$

$-8.65$

2.99

1:3 Experimental Instructional

1:3 Control Frustration vs. 1:3

19

$.000^{*}$

$-6.90$

Experimental Frustration

1:1 Control Instructional vs.

$-12.36$

19

$.000 *$

$-24.60$

8.90

1:1 Experimental Instructional

1:1 Control Frustration vs. 1:1

$-8.18$

19

$.000^{*}$

$-23.65$

Experimental Frustration

2:1 Control Instructional vs.

$-13.64$

19

$.000^{*}$

$-48.85$

16.02

2:1 Experimental Instructional

19

$.000^{*}$

$-34.15$

18.27

Experimental Frustration

Total Problem Completion -

Instructional vs. Frustration

\begin{tabular}{lccccc} 
1:3 Experimental Instructional & 4.21 & 19 & $.000^{*}$ & 12.30 & 13.06 \\
vs. 1:3 Experimental & & & & & \\
$\begin{array}{l}\text { Frustration } \\
\text { 1:1 Experimental Instructional } \\
\text { vs. 1:1 Experimental }\end{array}$ & 2.67 & 19 & $.015^{*}$ & 13.00 & 21.76 \\
$\begin{array}{l}\text { Frustration } \\
\text { 2:1 Experimental Instructional } \\
\text { vs. 2:1 Experimental }\end{array}$ & 3.07 & 19 & $.006^{*}$ & 23.30 & 33.93 \\
Frustration & & & & & \\
\hline
\end{tabular}

*denotes statistically significant $p$-value 
Target problem completion rates. A visual analysis was used to evaluate differences between the mean number of target problems completed across each assignment condition (e.g., CI-1:3I; CI-1:1I; CI-2:1I; CF-1:3F; CF-1:1F; CF-2:1F). It was hypothesized that participants would complete more target problems on experimental assignment than control assignments. Further, it was expected that participants would complete more target problems on assignments at instructional level than assignments at frustration level. Specifically, it was expected that a small visible difference would be present between mean target problem completion rates between experimental and control assignments. and a larger visible difference would be present between mean target problem completion rates between instructional level and frustration level assignments. It was also hypothesized that participants would complete more target problems on assignments at instructional level and experimental assignments than controls and assignments at frustration level.

As displayed in Figure15, there was no visible difference between mean target problem completion rates between experimental and control assignments and a small visible difference between assignments at instructional level and assignments at frustration level. Specifically, participants completed slightly more target problems on assignments at instructional level assignments at frustration level. 


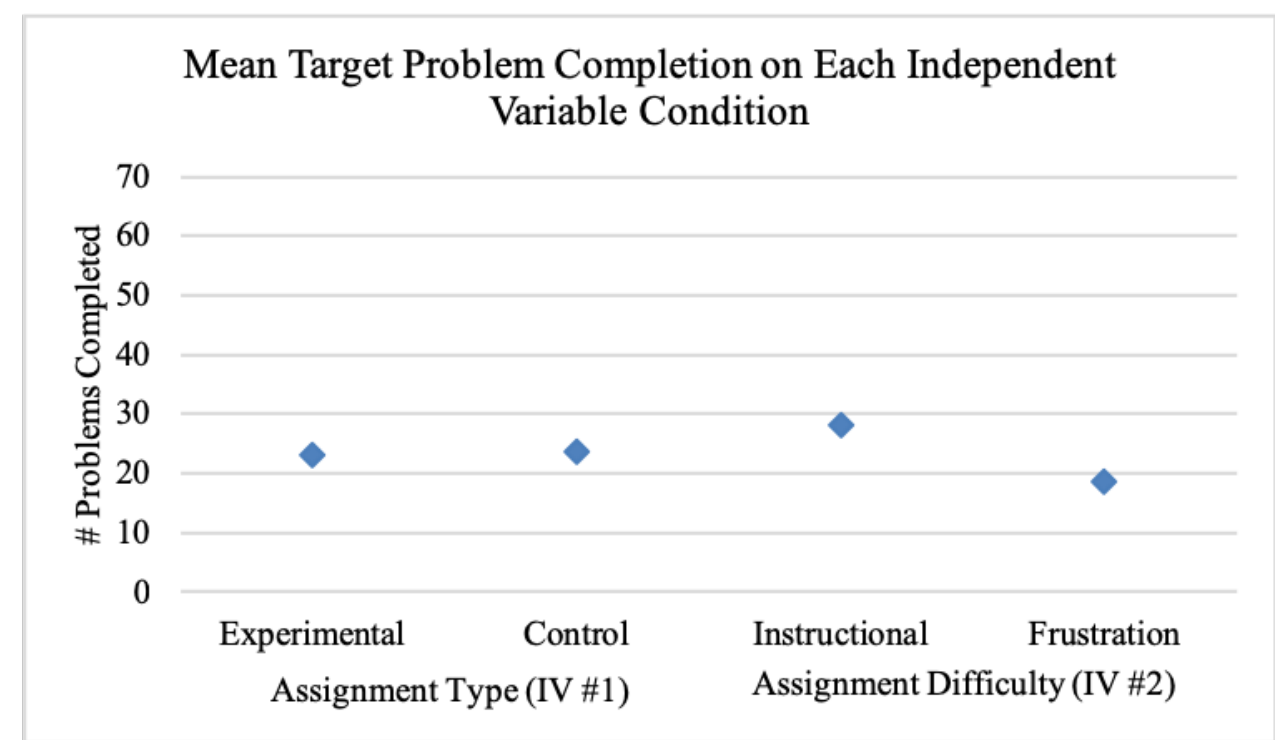

Figure 15. Results for target problem completion means across conditions of each independent variable (i.e., experimental vs. control; instructional vs. frustration level).

Mean target problem completion rates on experimental and control assignments at varying assignment difficulty levels were compared. It was expected that mean target problem completion rates would be visibly higher on experimental assignments at instructional level than all other assignment conditions, as well as paired control assignments at instructional level. Further, target problem completion rates were expected to be visibly higher on experimental assignments at frustration level than all control assignments at frustration level, but visible lower than control assignments at instructional level.

As displayed in Figure 16, there was minimal to no visible difference between mean target problem completion rates on experimental assignments and paired control assignments at instructional level. Target problem completion rates were visibly higher on assignments at instructional level than assignments at frustration level. There was no visible difference between experimental and control assignments at frustration level. 


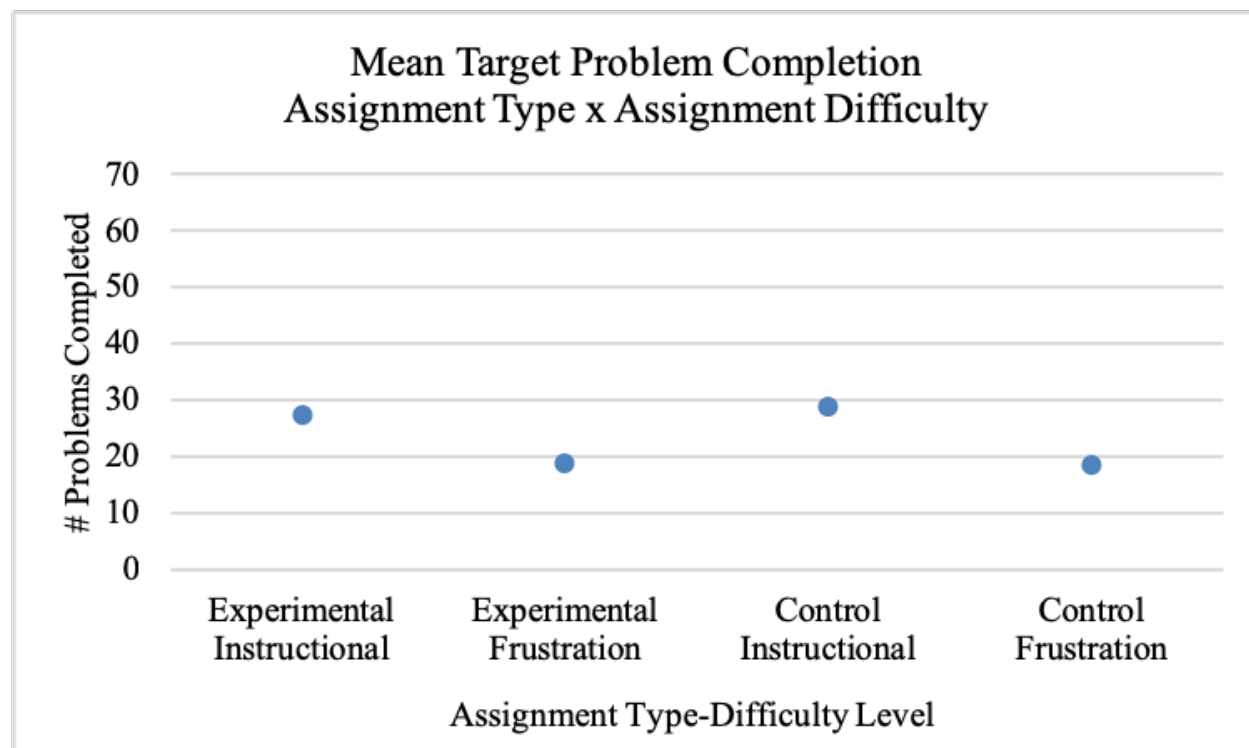

Figure 16. Results for planned comparisons of mean target problem completion data for assignment type (experimental or control) and assignment difficulty (at instructional level or at frustration level).

Visual analysis of data were also used to compare target problem completion rates on assignments at instructional level versus at frustration level across each experimental condition (i.e., 1:3; 1:1; 2:1) and to evaluate differences between experimental-control assignment pairs. Each control assignment was paired with an experimental assignment at the same instructional level. It was hypothesized that a slight visible difference between target problem completion rates on experimental assignments and paired control assignments would be present. Specifically, participants were expected to complete visibly more target problems on experimental assignments than control assignments at the same instructional level. Limited variability was expected across experimental conditions, meaning that participant' mean target problem completion data would remain fairly stable on assignments at varying rates of interspersing that were at the same instructional level. A visible difference in level was expected to be present between mean target problems completed on assignments at instructional level and mean target problems completed on assignments at frustration level. 
As displayed in Figures 17, there was no visible difference in the level between target problem completion rates on experimental assignments and paired control assignments as the rate of interspersing increased. Thus, interspersing did not impact the target completion rates. There was limited variability in the data across experimental conditions, meaning that participants' mean target problem completion data were fairly stable (i.e., flat, or non-significant trend) on assignments at varying rates of interspersing that were at the same instructional level. However, a visible difference in level was present between mean target problems completed on assignments at instructional level and means target problems completed on assignments at frustration level. Specifically, a visible difference was present indicating that participants completed more target problems on experimental or control assignments at instruction level than similar assignments at frustration level. Figure 18 illustrates results when data are collapsed within experimental conditions and paired controls. As the data demonstrate, participants' mean target problem completion is stable across assignments (i.e., minimal to no variability), even as they become denser, and there is minimal to no difference in the level of the data. 


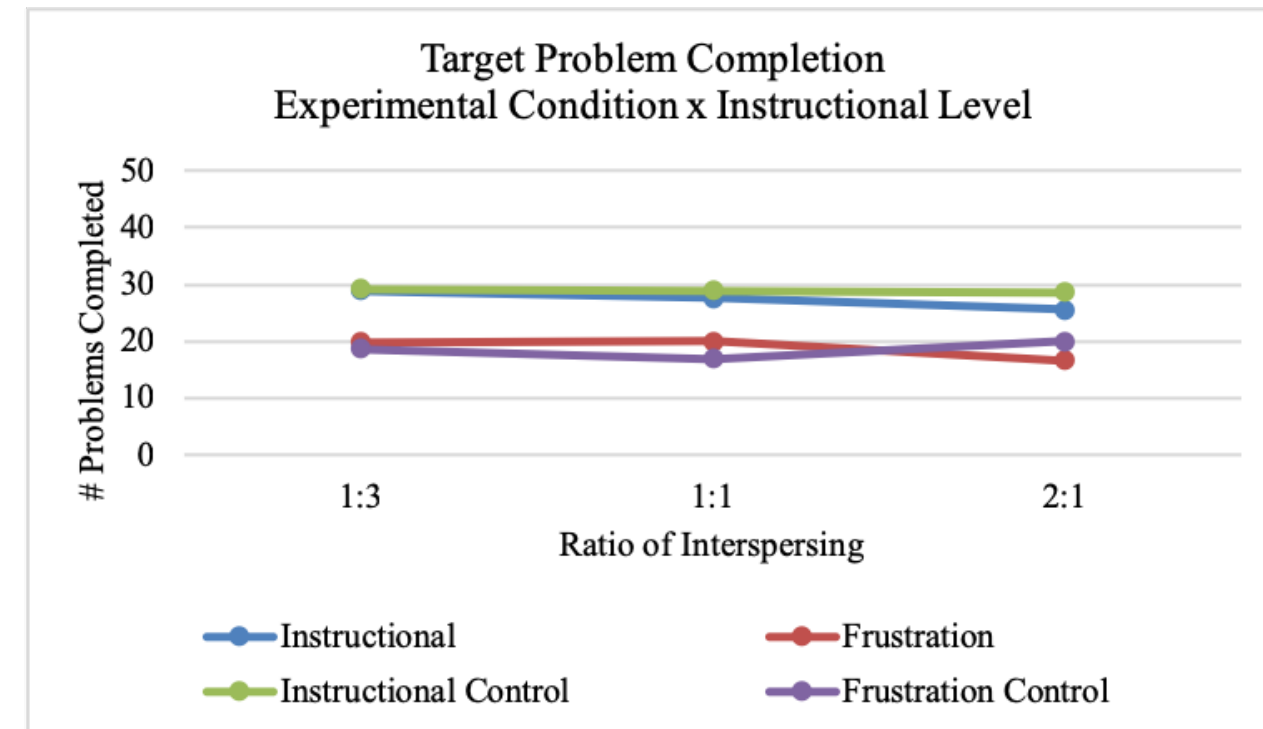

Figure 17. Results for within participant target problem completion rates/across participant mean target problem completion rates across experimental and control assignments at instructional or frustration level.

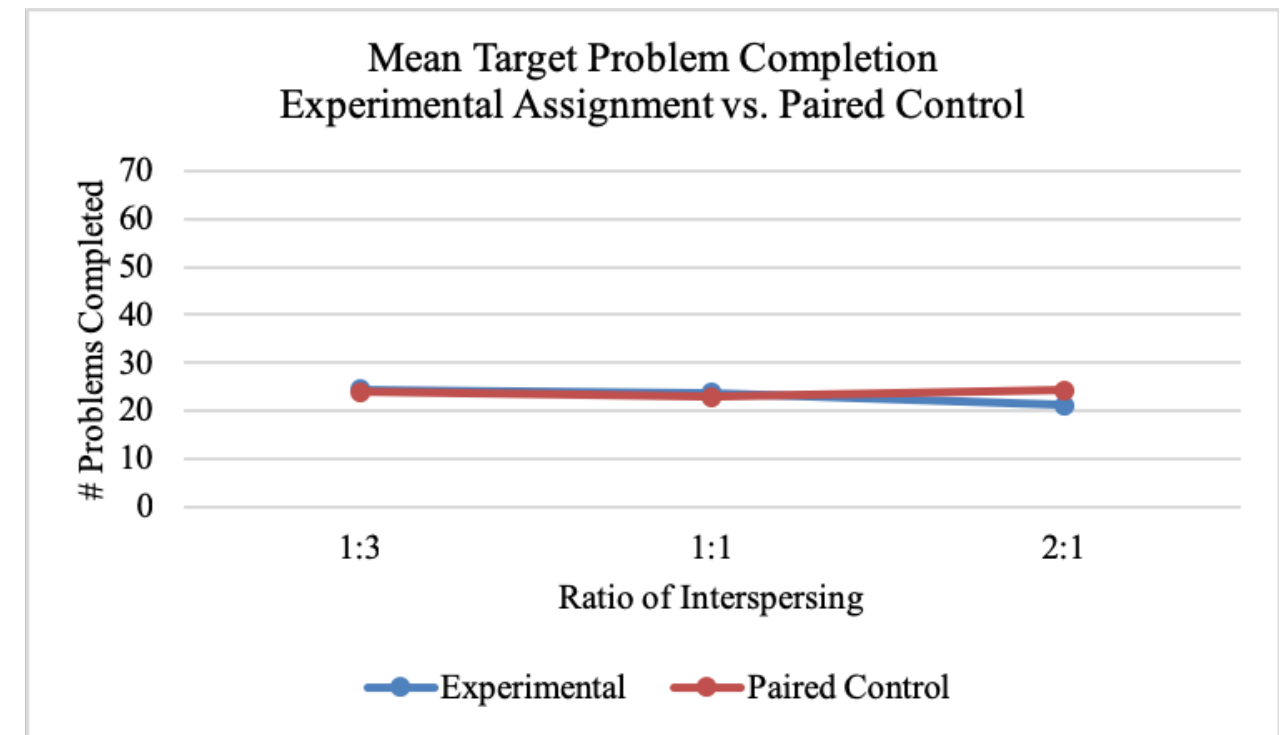

Figure 18. Results for comparison of mean target problem completion for experimental assignments vs. paired controls.

Additional planned comparisons were completed by conducting a series of paired-sample t-tests to compare differences between the mean number of target problems completed on control and experimental assignments for each assignment type. There were no significant differences between the target number of problems completed on 1:3 Control Instructional and 1:3 
Experimental Instructional assignments, $t(d f=19)=.30, p=.768$, or 1:1 Control Instructional and 1:1 Experimental Instructional assignments, $t(d f=19)=1.98, p=.063$. Statistically significant differences were found between the number of target problems completed on the 2:1 Control Instructional and 2:1 Experimental Instructional assignments, $t(d f=19)=2.99,=.008$, which represented a medium-sized effect, $d=.58$. Specifically, participants completed more target problems on the 2:1 Control Instructional assignment $(M=28.55, S E=.75)$ than the paired 2:1 Experimental Instructional assignment $(M=25.60, S E=1.42)$. On frustration level assignment pairs, there were no significant differences present between the target number of problems completed on 1:3 Control Frustration and 1:3 Experimental Frustration assignments, $t$ $(d f=19)=-1.11, p=.282,1: 1$ Control Frustration and 1:1 Experimental Frustration assignments, $t(d f=19)=-1.95, p=.066$, or 2:1 Control Frustration and 2:1 Experimental Frustration assignments, $t(d f=19)=1.87, p=.077$.

Differences between the mean number of target problems completed on experimental assignment and paired controls for each assignment ratio were also compared. There was a statistically significant difference between the target number of problems completed on 1:3 Experimental Instructional and 1:3 Experimental Frustration assignments, $t(d f=19)=4.19, p=$ .001 , which represented a large-sized effect, $d=1.16$. Specifically, participants completed more target problems on the 1:3 Experimental Instructional $(M=28.95, S E=.96)$ than the 1:3 Experimental Frustration assignment $(M=19.85, S E=2.29)$. Participants also completed more target problems on the 1:1 Experimental Instructional $(M=27.65, S E=1.17)$ than the 1:1 Experimental Frustration assignment $(M=19.95, S E=2.12)$. This difference was statistically significant, $t(d f=19)=3.14, p=.005$, and represented a small effect, $d=.31$. Finally, there was a significant difference in target problems completed between the 2:1 Experimental Instructional 
and 2:1 Experimental Frustration assignments, $t(d f=19)=3.51, p=.002$, which represented a large effect, $d=1.11$. Specifically, participants completed significantly more target problems on the 2:1 Experimental Instruction $(M=25.60, S E=1.42)$ than the 2:1 Experimental Frustration assignment $(M=16.60, S E=2.13)$.

Table 7. Comparison of Target Problems Completed on Control versus Experimental Assignments and Assignments at Instructional versus Frustration Level

\begin{tabular}{|c|c|c|c|c|c|}
\hline Planned Comparison & $t$ & $d f$ & $\begin{array}{c}\text { Sig. } \\
\text { (2-tailed) }\end{array}$ & $M$ & $S D$ \\
\hline \multicolumn{6}{|l|}{$\begin{array}{l}\text { Target Problem Completion - } \\
\text { Experimental vs. Control }\end{array}$} \\
\hline $\begin{array}{l}\text { 1:3 Control Instructional vs. 1:3 } \\
\text { Experimental Instructional }\end{array}$ & .30 & 19 & .768 & .20 & 2.98 \\
\hline $\begin{array}{l}\text { 1:3 Control Frustration vs. 1:3 } \\
\text { Experimental Frustration }\end{array}$ & -1.11 & 19 & .282 & -1.25 & 5.05 \\
\hline $\begin{array}{l}\text { 1:1 Control Instructional vs. 1:1 } \\
\text { Experimental Instructional }\end{array}$ & 1.98 & 19 & .063 & 1.25 & 2.83 \\
\hline $\begin{array}{l}\text { 1:1 Control Frustration vs. 1:1 } \\
\text { Experimental Frustration }\end{array}$ & -1.95 & 19 & .066 & -19.80 & 45.37 \\
\hline $\begin{array}{l}\text { 2:1 Control Instructional vs. 2:1 } \\
\text { Experimental Instructional }\end{array}$ & 2.99 & 19 & .008 & 2.95 & 4.42 \\
\hline $\begin{array}{l}\text { 2:1 Control Frustration vs. 2:1 } \\
\text { Experimental Frustration }\end{array}$ & 1.87 & 19 & .077 & 3.35 & 8.02 \\
\hline $\begin{array}{l}\text { Target Problem Completion - } \\
\text { Instructional vs. Frustration }\end{array}$ & & & & & \\
\hline $\begin{array}{l}\text { 1:3 Experimental Instructional vs. } \\
\text { 1:3 Experimental Frustration }\end{array}$ & 4.19 & 19 & .001 & 9.10 & 9.72 \\
\hline $\begin{array}{l}\text { 1:1 Experimental Instructional vs. } \\
\text { 1:1 Experimental Frustration }\end{array}$ & 3.14 & 19 & .005 & 7.70 & 10.97 \\
\hline $\begin{array}{l}\text { 2:1 Experimental Instructional vs. } \\
\text { 2:1 Experimental Frustration }\end{array}$ & 3.51 & 19 & .002 & 9.00 & 11.49 \\
\hline
\end{tabular}

*denotes statistically significant $p$-value 


\section{Hypothesis 3}

Total problem accuracy. Accuracy was calculated for the number of total problems (i.e., target and brief problems) completed correctly on each control and experimental assignment. Problems that were not completed or did not have a correct final answer were not included in the accuracy scores. Mean accuracy rates were calculated for each assignment type across participants. It was hypothesized that total problem completion would be higher for experimental assignments than control assignments. Data were also expected to show a visible differences between the total problem accuracy on instructional versus frustration level assignments. A visual analysis of mean total problem accuracy across control and experimental assignments, as well as across assignments at different instructional levels, was completed. Figure 19 illustrates that total problem accuracy data were slightly higher on experimental assignments than control assignments and higher on assignments at instructional level than assignments at frustration level.

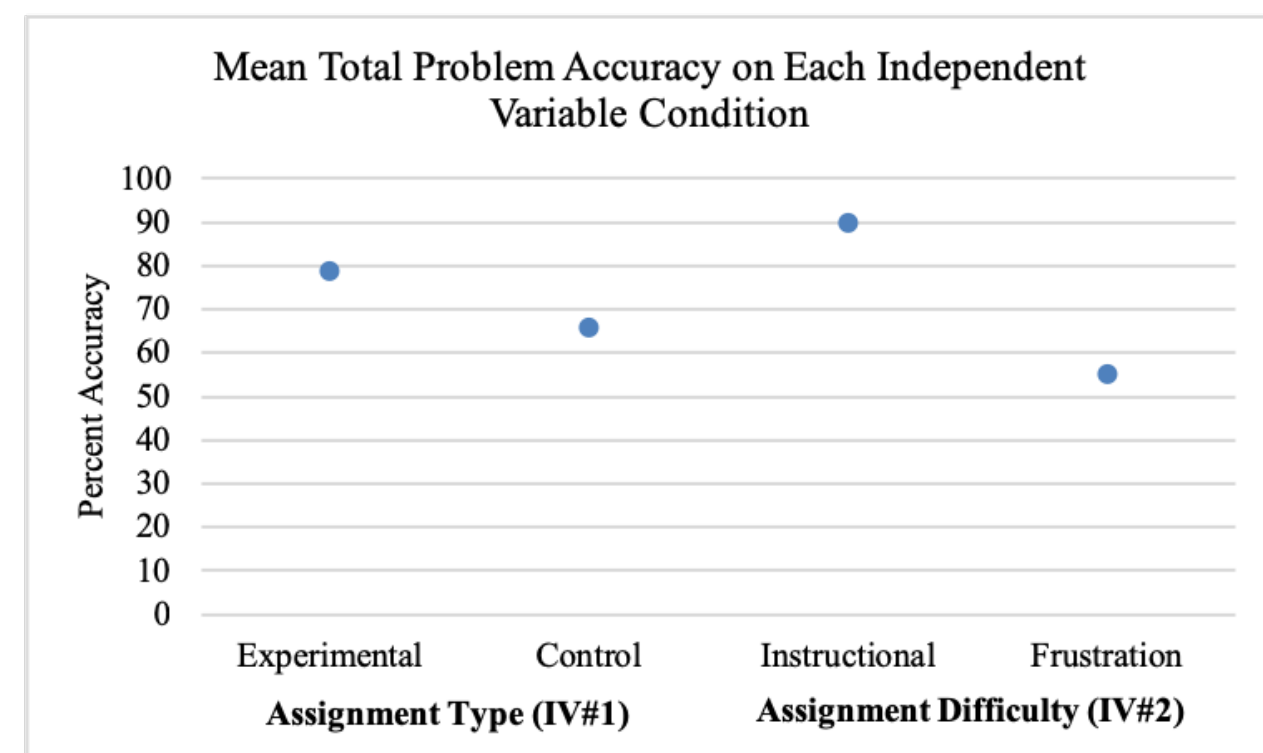

Figure 19. Results for total problem accuracy means across conditions of each independent variable (i.e., experimental vs. control; instructional vs. frustration level). 
As hypothesized, there is a visible difference in level and variability of data points in each comparison group when comparing total problem accuracy across assignment type and difficulty level. The mean total problem accuracy is visibly higher on experimental assignments at instructional level than all other assignment combinations, as well as paired control assignments at instructional level. Further, control assignments at instructional level yielded visibly higher total accuracy means than experimental and paired control assignments at frustration level. This was expected due to assignments at instructional level producing higher levels of productivity and decreasing the likelihood that students become disengaged or frustrated while completing these tasks since they were at an appropriate difficulty level for the participant's current skill level. Figure 20 illustrates the results for the total problem accuracy between assignment type-difficulty level combinations.

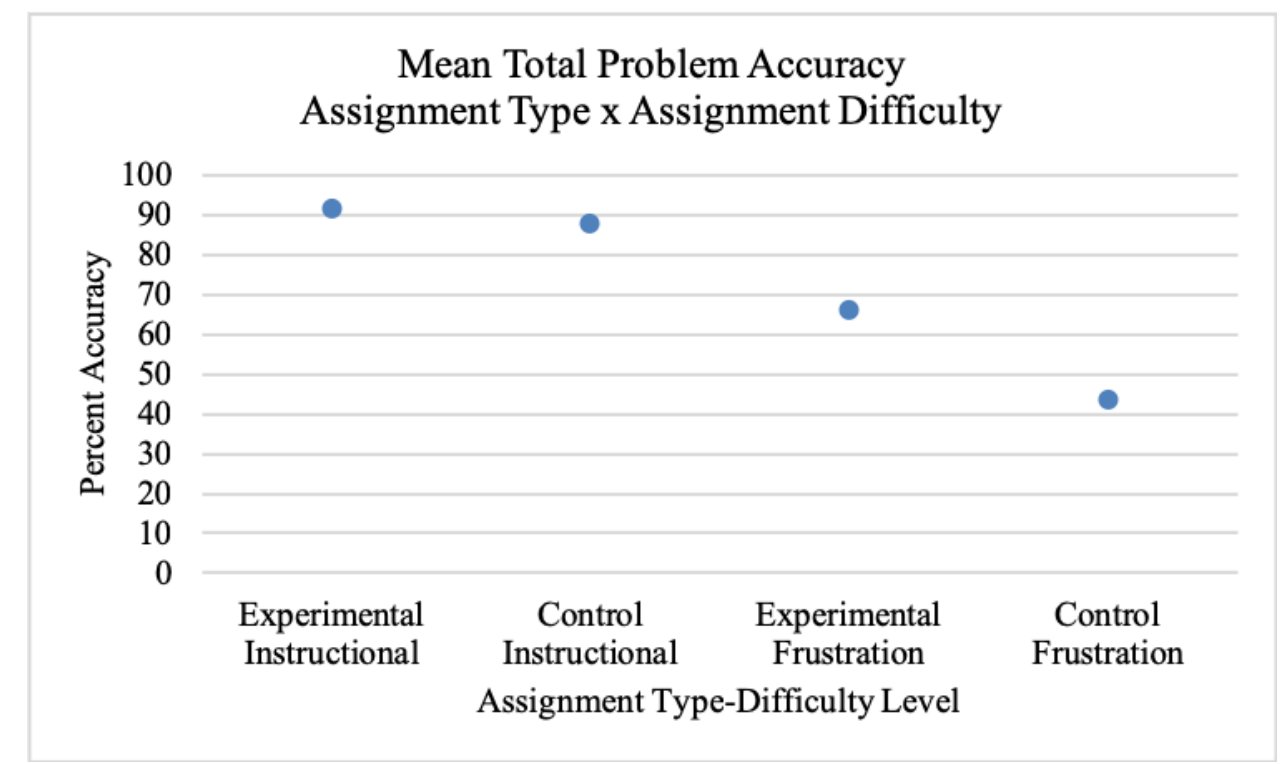

Figure 20. Results for visual analysis of mean total problem accuracy data for assignment type (experimental or control) and assignment difficulty (at instructional level or at frustration level).

Differences between total problem accuracy on assignments at instructional level and at frustration level across each experimental condition (i.e., 1:3; 1:1; 2:1) and differences in total 
problem accuracy between experimental-control assignment pairs were also evaluated. Data were collapsed across participants for each condition and a visual inspection of trend, level, and variability of the data were conducted. As hypothesized, there were slight visible differences on total problem accuracy between experimental assignments at different ratios of interspersing that are at the same instructional level. A slight increasing trend of total problem accuracy on experimental assignments is present when graphed as increasing in density from left to right. In other words, total problem accuracy on experimental assignments at the same instructional level increased as the ratio of interspersing becomes denser due to participants being exposed to more mastery level problems. Data also demonstrated a visible difference in the level of total problem accuracy data between experimental and control assignments at instructional level, with the exception of the 1:3 ratio assignment, and all assignments at frustration level. The level of the data were higher, indicating better total problem accuracy, on experimental and control assignments at instructional level than assignments at frustration level. Figure 21 illustrates the results when comparing mean total problem accuracy across independent variable conditions.

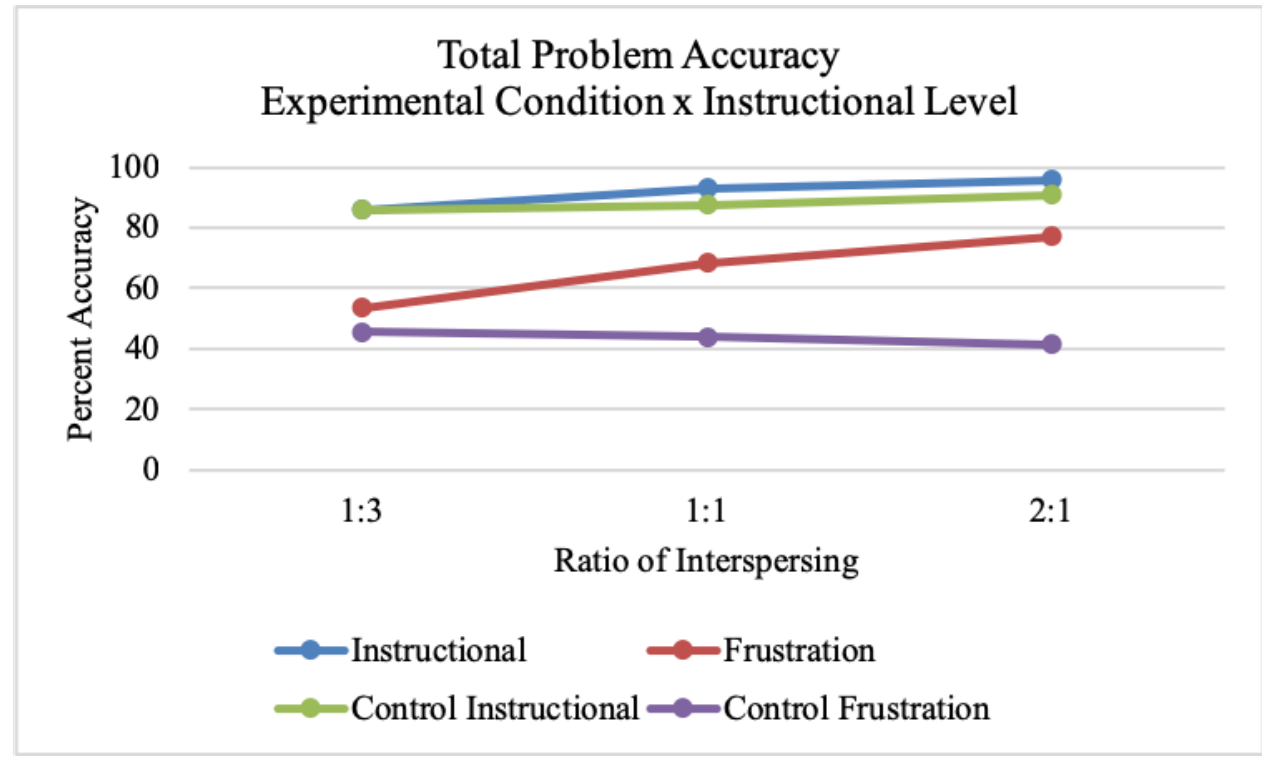

Figure 21. Results for within participant total problem accuracy and across participant mean total problem accuracy across experimental and control assignments at instructional or frustration level. 
Figure 22 illustrates results when total problem accuracy data are collapsed within experimental conditions and paired controls. It was hypothesized that mean total problem accuracy would only slightly increase as the assignments interspersing density increased. As the data demonstrate, mean target problem accuracy slightly increased as the assignments became denser, while the mean total problem accuracy rates remained relatively stable on paired control assignments when difficulty level of the assignment was held constant. Moreover, the level of the data indicates a visible difference between total problem accuracy on all assignments at instructional versus frustration level.

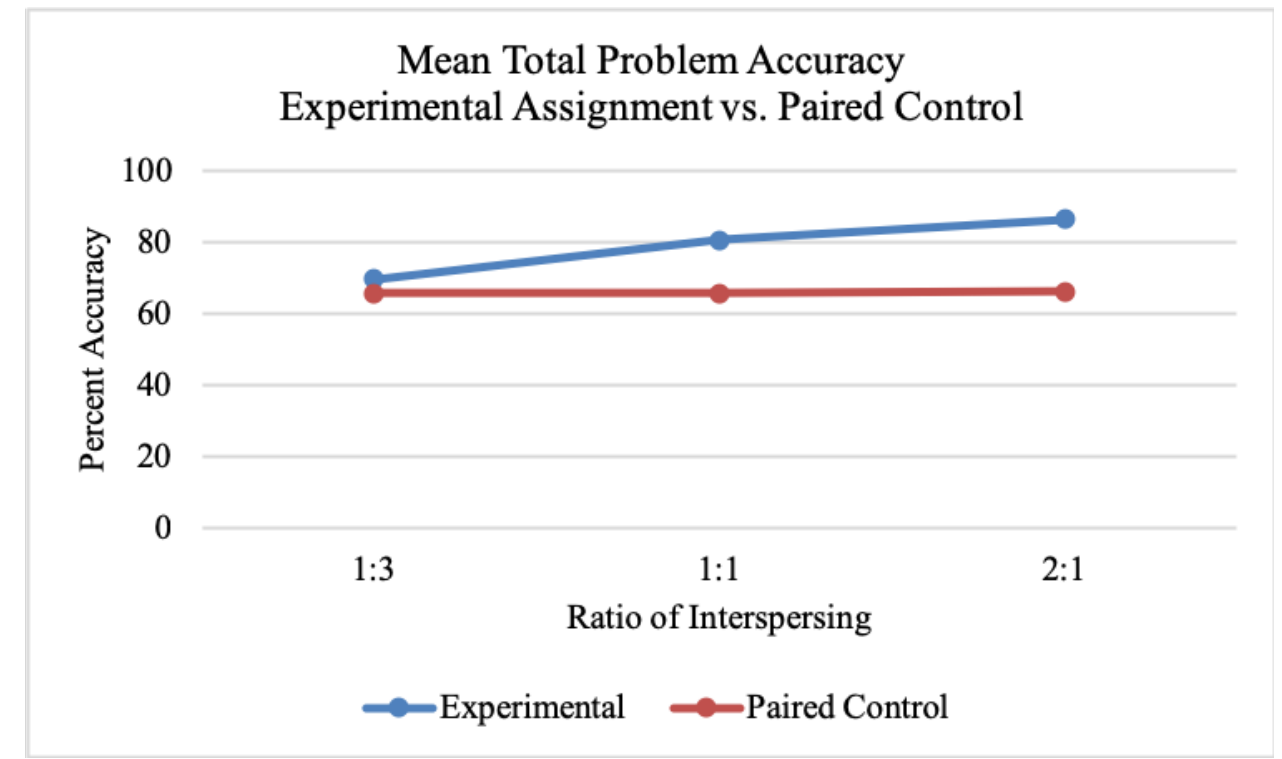

Figure 22. Results for comparison of mean target problem accuracy for experimental assignments vs. paired controls.

Additional planned comparisons were completed by conducting a series of paired-sample t-tests to compare differences between the mean number of total problem accuracy on control and experimental assignments for each assignment type. There was no significant difference between the total problem accuracy on 1:3 Control Instructional and 1:3 Experimental Instructional assignments, $t(d f=19)=-.03, p<.000$. Statistically significant differences were present between the total problem accuracy on 1:1 Control Instructional and 1:1 Experimental 
Instructional assignments, $t(d f=19)=-2.65, p=.016$, and represented a small effect, $d=.37$. At instructional level, participants completed more problems accurately on the 1:1 Experimental Instructional $(M=93.10, S E=2.46)$ than the paired control $(M=87.65, S E=3.94)$. Moreover, participants completed more problem accurately overall on the 2:1 Experimental Instruction assignment $(M=95.90, S E=1.07)$ than the paired control $(M=90.90, S E=2.20)$. This difference was significant, $t(d f=19)=-2.98, p=.008$, and represented a medium to large effect, $d=.65$.

There was no significant difference between total problem accuracy on 1:3 Control Frustration and 1:3 Experimental Frustration assignments, $t(d f=19)=-1.50, p=.151$. However, participants completed more problems accurately on the 1:1 Experimental Frustration $(M=$ 68.25, $S E=4.57)$ than the paired control assignment $(M=43.85, S E=9.40)$. This difference was significant, $t(d f=19)=-4.44, p<.000$, and represented a medium to large effect size, $d=.74$. Participants also completed more problems accurately overall on 2:1 Experimental Frustration $(M=77.20, S E=3.85)$ than the paired control $(M=41.55, S E=8.99)$. This difference was significant, $t(d f=19)=-5.39, p<.000$, and represented a large effect size, $d=1.15$.

Total problem accuracy on instructional and frustration level experimental assignments at each rate of interspersing was compared. There was a statistically significant difference between the total problem accuracy on 1:3 Experimental Instructional and 1:3 Experimental Frustration assignments, $t(d f=19)=4.85, p<.000$, which represented a large-sized effect, $d=1.24$. Specifically, participants problem accuracy was higher on the 1:3 Experimental Instructional ( $M$ $=85.85, S E=3.88)$ than the $1: 3$ Experimental Frustration $(M=53.50, S E=7.31)$ assignment. Participants total problem accuracy was also higher on the 1:1 Experimental Instructional $(M=$ 93.10, $S E=2.46)$ than the 1:1 Experimental Frustration $(M=68.25, S E=4.57)$ assignment. This 
difference was significant, $t(d f=19)=5.97, p<.000$, and represented a large effect, $d=1.51$. Finally, participants’ total problem accuracy was significantly higher overall on the 2:1 Experimental Instruction $(M=95.90, S E=1.07)$ than the 2:1 Experimental Frustration $(M=$ 77.20, $S E=3.85)$ assignment. This difference was significant, $\mathrm{t}(\mathrm{df}=19)=5.63, \mathrm{p}=.000$, and represented a large effect, $d=1.48$. 
Table 8.

Comparison of Total problem Accuracy on Control versus Experimental Assignments and Assignments at Instructional versus Frustration Level

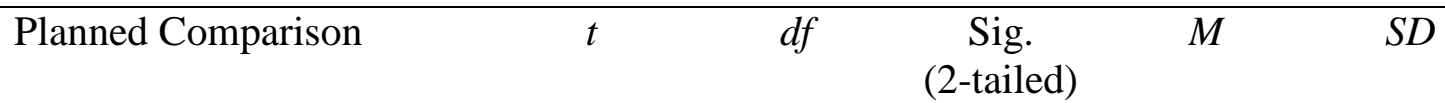

Total Problem Accuracy -

Experimental vs. Control

1:3 Control Instructional vs.

.03

19

.977

.05

7.63

1:3 Experimental Instructional

1:3 Control Frustration vs. 1:3 $\quad-1.50$

19

.151

$-7.95$

23.74

Experimental Frustration

1:1 Control Instructional vs.

19

$.016 *$

$-5.45$

9.21

1:1 Experimental Instructional

1:1 Control Frustration vs. 1:1 $\quad-4.44$

19

$.000 * \quad-24.40$

24.57

Experimental Frustration

2:1 Control Instructional vs.

$-2.98$

19

$.008 *$

$-5.00$

7.51

2:1 Experimental Instructional

2:1 Control Frustration vs. 2:1

19

$.000 *$

$-35.65$

29.60

Experimental Frustration

Total Problem Accuracy -

Instructional vs. Frustration

1:3 Experimental Instructional

4.85

19

$.000 *$

32.35

29.81

vs. 1:3 Experimental

Frustration

1:1 Experimental Instructional

5.97

19

$.000 *$

24.85

18.62

vs. 1:1 Experimental

Frustration

2:1 Experimental Instructional

5.63

19

$.000 *$

18.70

14.85

vs. 2:1 Experimental

Frustration

*denotes statistically significant $p$-value

Target problem accuracy. Target problem accuracy was calculated for the number of target problems, excluding brief interspersed problems, completed correctly on each control and experimental assignment. Problems that were not completed or did not have a correct final 
answer were not included in the accuracy scores. Mean accuracy rates were calculated for each assignment type across participants. It was hypothesized that there would be minimal to no visible difference on target problem accuracy across experimental assignments at different ratios of interspersing that are at the same instructional level. Participants were expected to earn higher target problem accuracy scores on assignments at instructional level than assignments at frustration level. A visual analysis of mean target problem accuracy across control and experimental assignments, as well as across assignments at different instructional levels was completed. As predicted, Figure 23 indicates that target problem accuracy was only slightly lower on experimental assignments than control assignments but much higher on assignments at instructional level than assignments at frustration level.

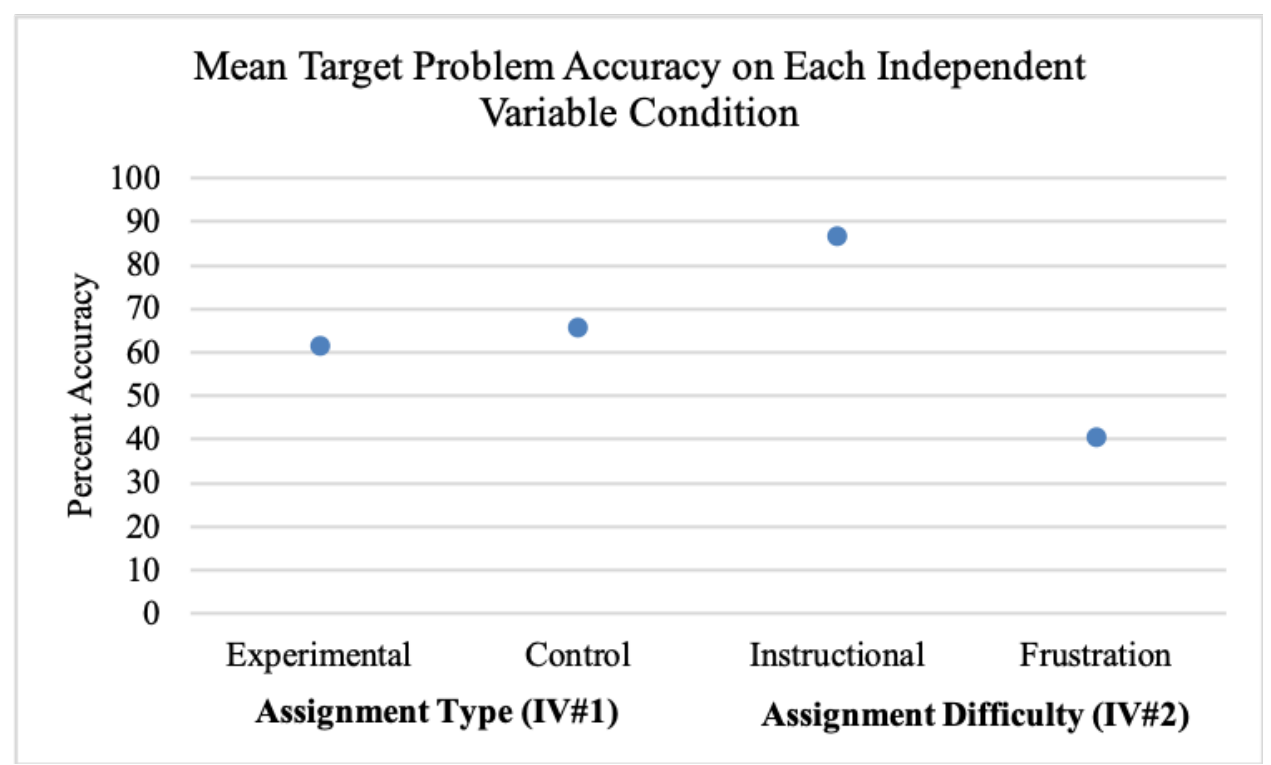

Figure 23. Results for target problem accuracy means across conditions of each independent variable (i.e., experimental vs. control; instructional vs. frustration level).

As predicted, there is only a slight visible difference in the level of data points in each comparison group when comparing target problem accuracy across assignment type and conditions. The mean target problem accuracy is slightly higher on control assignments at instructional than paired experimental assignments at instructional level. Control and 
experimental assignments at instructional level yielded visibly higher target accuracy means than experimental and paired control assignments at frustration level. This was expected due to assignments at instructional level producing higher levels of productivity and decreasing the likelihood that students become disengaged or frustrated while completing these tasks since they were at an appropriate difficulty level for the participant's current skill level. Figure 24 illustrates the results for planned comparisons of target problem accuracy between assignment typedifficulty level combinations.

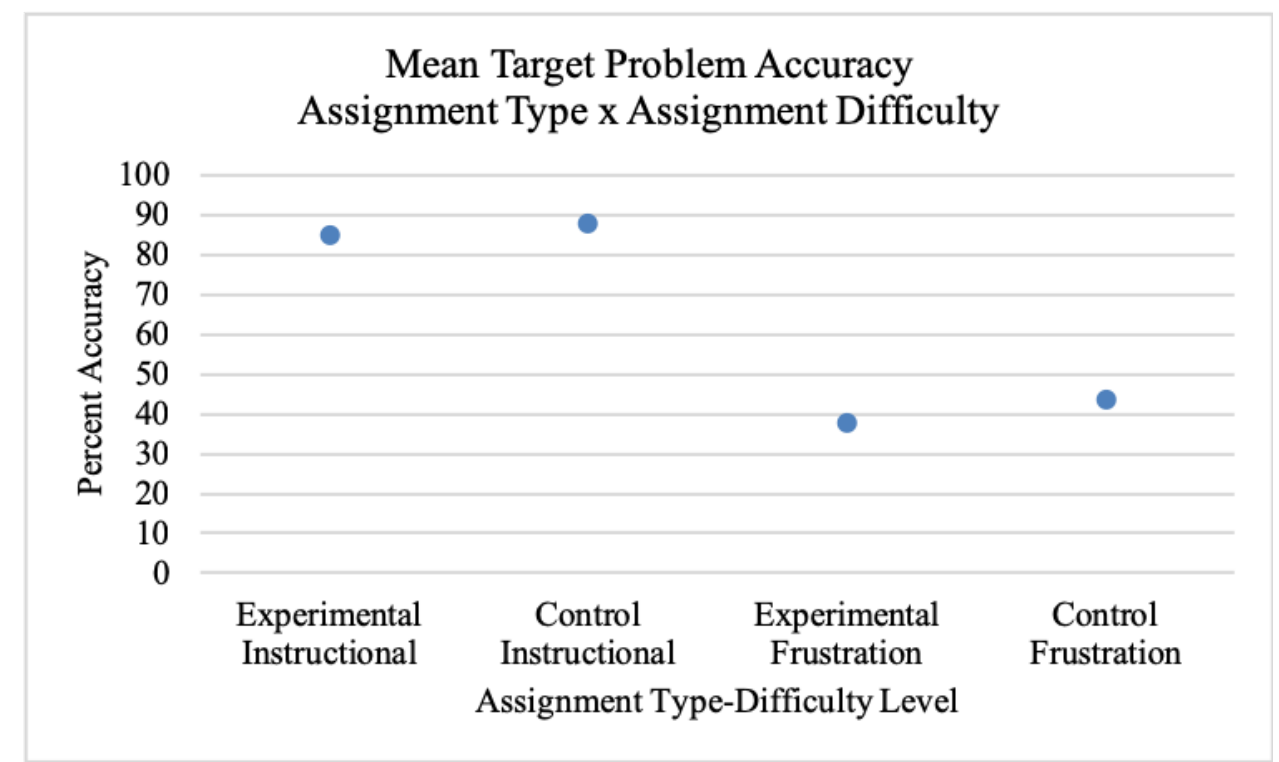

Figure 24. Results for visual analysis of mean target problem accuracy data for assignment type (experimental or control) and assignment difficulty (at instructional level or at frustration level).

As hypothesized, that there were minimal to no visible differences on target problem accuracy across experimental assignments at different ratios of interspersing that are at the same instructional level. Further, participants earned higher target problem accuracy scores on assignments that were at instructional level than assignments that were at frustration level, as demonstrated by the difference in level of data for each assignment type. Figure 25 illustrates results when comparing mean target problem accuracy across independent variable conditions. 


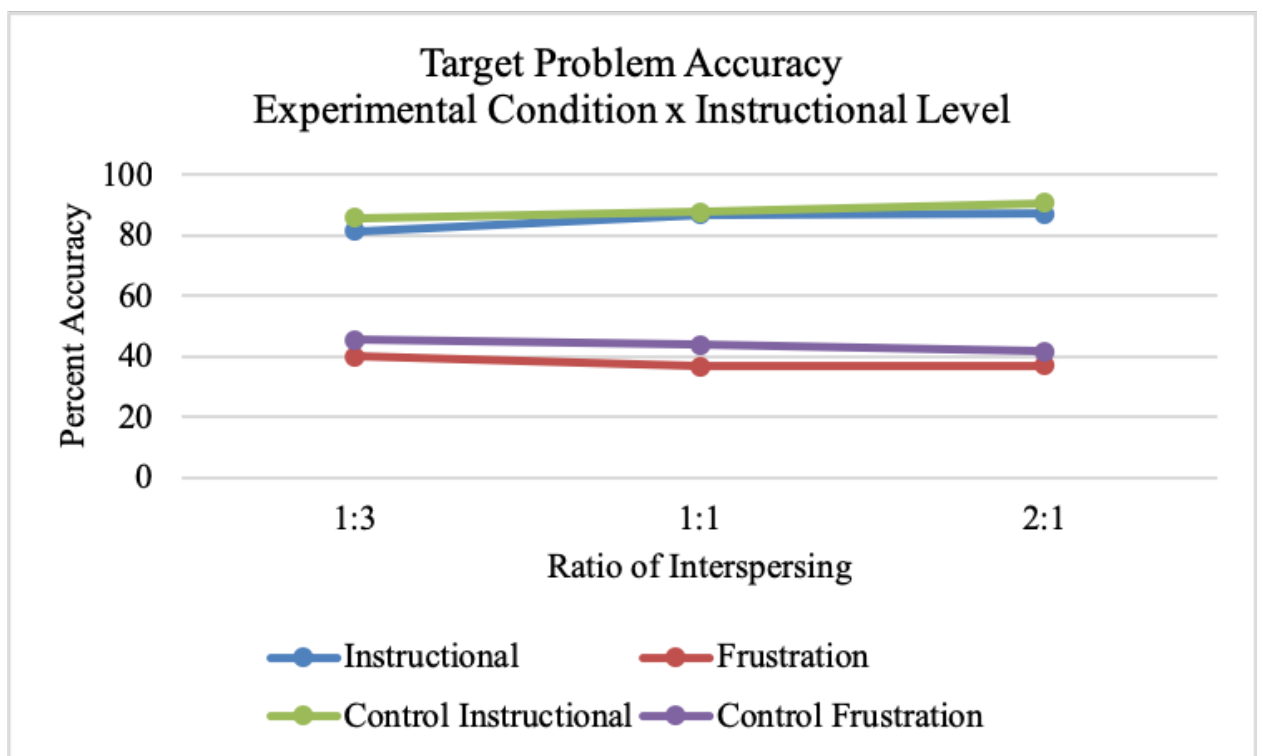

Figure 25. Results for within participant target problem accuracy and across participant mean target problem accuracy across experimental and control assignments at instructional or frustration level.

Figure 26 illustrates results when target problem accuracy data are collapsed within experimental conditions and paired controls. As the data demonstrate, mean target problem accuracy remained stable as the assignments became denser on experimental and paired control assignments when difficulty level of the assignments was held constant. The level of mean target problem accuracy on control assignments was slightly higher than the level of target problem accuracy on paired experimental assignments. 


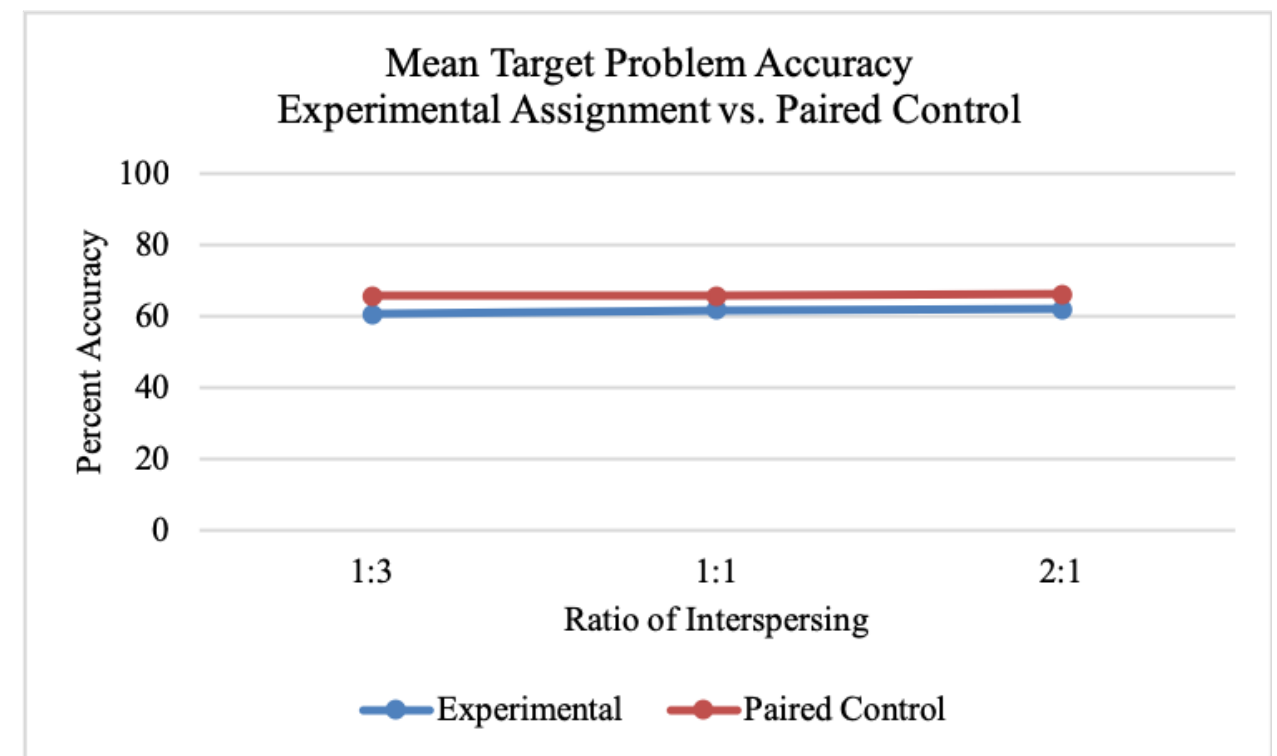

Figure 26. Results for comparison of mean target problem accuracy for experimental assignments vs. paired controls.

Additional planned comparisons were completed by conducting a series of paired-sample t-tests to compare differences between the mean number of target problem accuracy on control and experimental assignments for each assignment type. There was a significant difference between the total problem accuracy on 1:3 Control Instructional and 1:3 Experimental Instructional assignments, $t(d f=19)=3.52, p=.002$, which represented a small effect, $d=.20$. Specifically, participants completed more problems accurately on the 1:3 Experimental Instructional $(M=85.90, S E=4.99)$ than the $1: 3$ Control Instructional assignment $(M=81.45, S E$ =5.05). Statistically significant differences were not present between the target problem accuracy on 1:1 Control Instructional and 1:1 Experimental Instructional assignments, $t(d f=19)=.34, p$ $=.738$, or 2:1 Control Instructional and 2:1 Experimental Instructional assignments, $t(d f=19)$ $=1.52, p=.144$. There was no significant difference between target problem accuracy on 1:3 Control Frustration and 1:3 Experimental Frustration assignments, $t(d f=19)=1.06, p=.301$, 1:1 Control Frustration and 1:1 Experimental Frustration assignments, $t(d f=19)=1.86, p=$ 
.079 , or 2:1 Control Frustration and 2:1 Experimental Frustration assignments, $t(d f=19)=.74$, $p=.467$.

Target problem accuracy on instructional and frustration level experimental assignments at each rate of interspersal was compared. There was a statistically significant difference between the target problem accuracy on 1:3 Experimental Instructional and 1:3 Experimental Frustration assignments, $t(d f=19)=4.80, p<.000$, which represented a large effect, $d=1.23$. Specifically, participants target problem accuracy was higher on the 1:3 Experimental Instructional ( $M=$ 81.45, $S E=5.05)$ than the 1:3 Experimental Frustration $(M=39.95, S E=9.38)$ assignment. Participants target problem accuracy was also higher on the 1:1 Experimental Instructional $(M=$ 87.00, $S E=4.75)$ than the 1:1 Experimental Frustration $(M=36.65, S E=9.06)$ assignment. This difference was significant, $t(d f=19)=6.16, p<.000$, and represented a large effect size, $d=$ 1.56. Finally, participants' target problem accuracy was significantly higher overall on the 2:1 Experimental Instruction $(M=87.15, S E=3.33)$ than the 2:1 Experimental Frustration $(M=$ 36.85, $S E=9.19)$ assignment. This difference was significant, $t(d f=19)=6.25, p<.000$, and represented a large effect size, $d=1.63$. 
Table 9.

Comparison of Target Problem Accuracy on Control versus Experimental Assignments and Assignments at Instructional versus Frustration Level

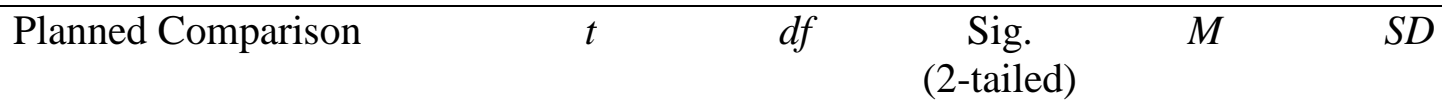

Target Problem Accuracy -

Experimental vs. Control

1:3 Control Instructional vs.

3.52

19

$.002 *$

4.45

5.65

1:3 Experimental Instructional

1:3 Control Frustration vs. 1:3

1.06

19

.301

5.60

23.55

Experimental Frustration

1:1 Control Instructional vs.

.34

19

.738

.65

8.57

1:1 Experimental Instructional

1:1 Control Frustration vs. 1:1

1.86

19

.079

7.20

17.35

Experimental Frustration

2:1 Control Instructional vs.

1.52

19

.144

3.75

11.01

2:1 Experimental Instructional

2:1 Control Frustration vs. 2:1

.74

19

.467

4.70

28.29

Experimental Frustration

Target Problem Accuracy -

Instructional vs. Frustration

1:3 Experimental Instructional

4.80

19

$.000 *$

41.50

38.67

vs. 1:3 Experimental

Frustration

1:1 Experimental Instructional

6.16

19

$.000 *$

50.35

36.54

vs. 1:1 Experimental

Frustration

2:1 Experimental Instructional

6.25

19

$.000 * \quad 50.30$

35.99

vs. 2:1 Experimental

Frustration

*denotes statistically significant $p$-value

\section{Hypothesis 4}

Assignment perceptions on continuous scale. Perceptions of assignments were assessed by asking participants to rate each assignment based on time, difficulty, and effort on a 
dichotomous and continuous rating scale. Dichotomous rating scales asked the participants to circle the corresponding letter for which assignment they thought was more difficult and which would take more time or effort to complete from start to finish (e.g., Which assignment is more difficult? Circle one: $\mathrm{M}$ or L). Continuous rating scales were used to measure incremental changes in assignment perceptions across baseline and experimental conditions. Participants were asked to rate the difficulty of, and effort and time to complete, each assignment on a 4point Likert scale (1=a little time, $4=$ a lot of time): (a) On a scale of 1 to 4 , how much time would the (M/L) assignment take to complete from start to finish?; (b) On a scale of 1 to 4, how much effort would the (M/L) assignment take to complete from start to finish?; (c) On a scale of 1 to 4, how difficult is the (M/L) assignment? Changes in participant perceptions were evaluated using visual inspection procedures to determine if preference varies as a function of the rate of interspersing and/or instructional level.

It was hypothesized that participant perceptions of time, effort, and difficulty would vary as the function of the instructional level and the rate of interspersing. Specifically, participants were expected to indicate that the control assignments are more difficult, took more effort to complete, and took more time to complete than the paired experimental assignment, regardless of instructional level. Further, it was hypothesized that participants would rate assignments at instructional level more favorably across perception ratings than assignments at frustration level. Finally, it was expected that perception ratings would be more favorable for assignments with denser rates of interspersing than paired control assignments and assignments with less dense rates of interspersing.

As hypothesized, Figures 27 through 29 demonstrate that there are visible difference between the level of the time, effort, and difficulty perception Likert ratings on assignments at 
instructional and assignments at frustration level. Specifically, frustration level assignments are consistently rated as requiring more time and effort, as well as being more difficulty than instructional level assignments. There is only slight variability in the data across rates of interspersing, which limits confidence that assignment perceptions differed as a function of the rate of interspersing. Although the variability is limited, the level and trend of the data indicate that participants rated control assignments as requiring less time and effort and as being less difficult to complete across instructional level assignments and rates of interspersing. Conversely, participants began rating the experimental frustration level assignments as more slightly more favorable with regard to time at the $1: 1$ and difficulty at the 2:1 interspersing ratio.

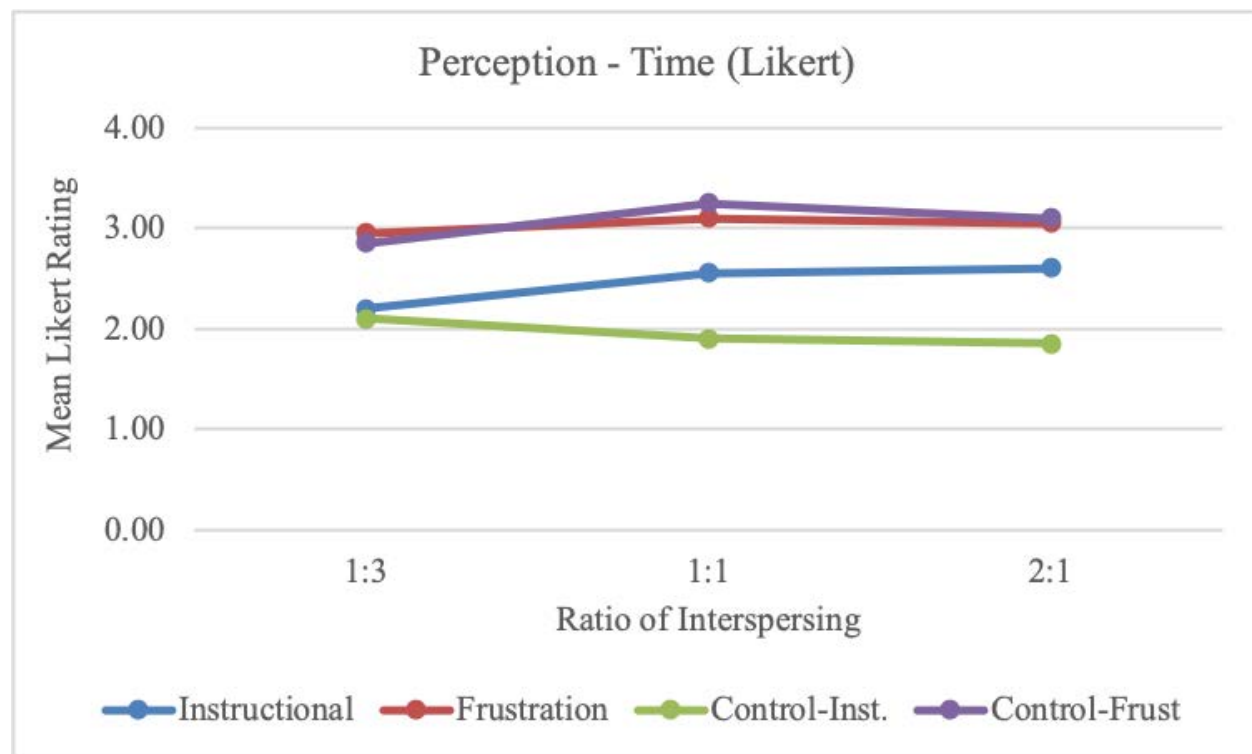

Figure 27. Perception ratings from Likert scale for time across assignment conditions. 


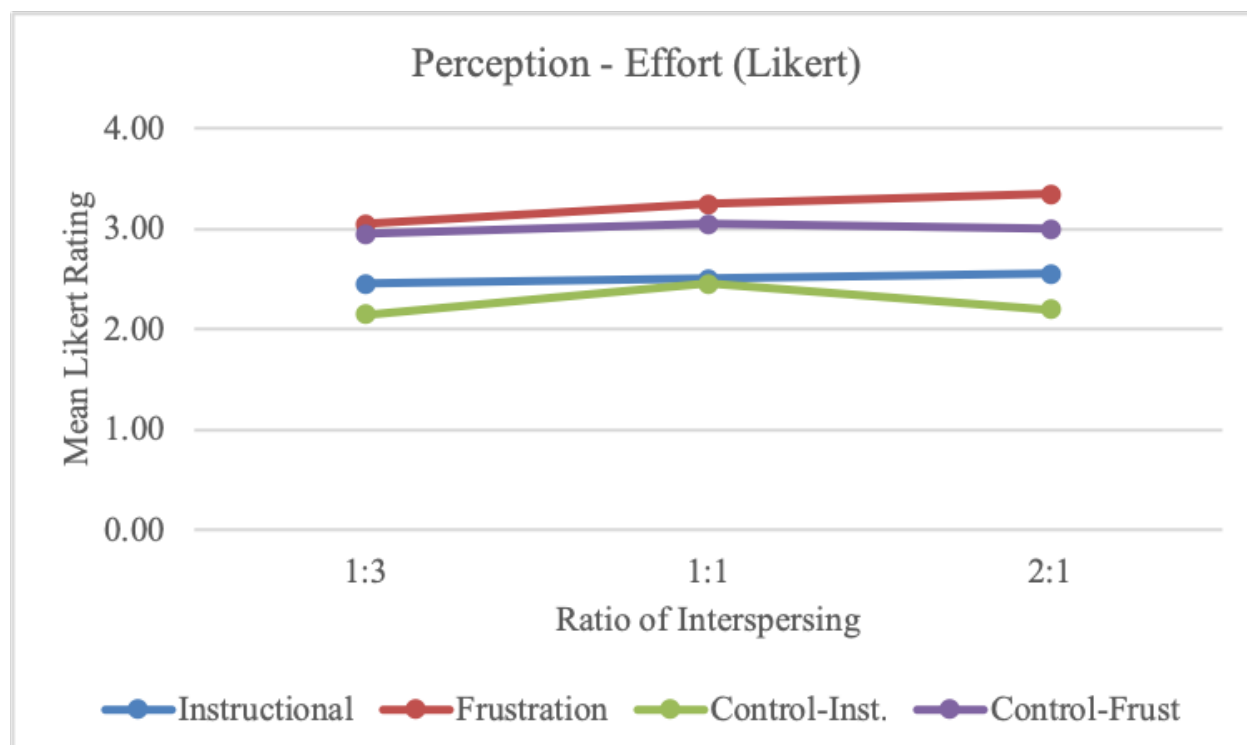

Figure 28. Perception ratings from Likert scale for effort across assignment conditions.

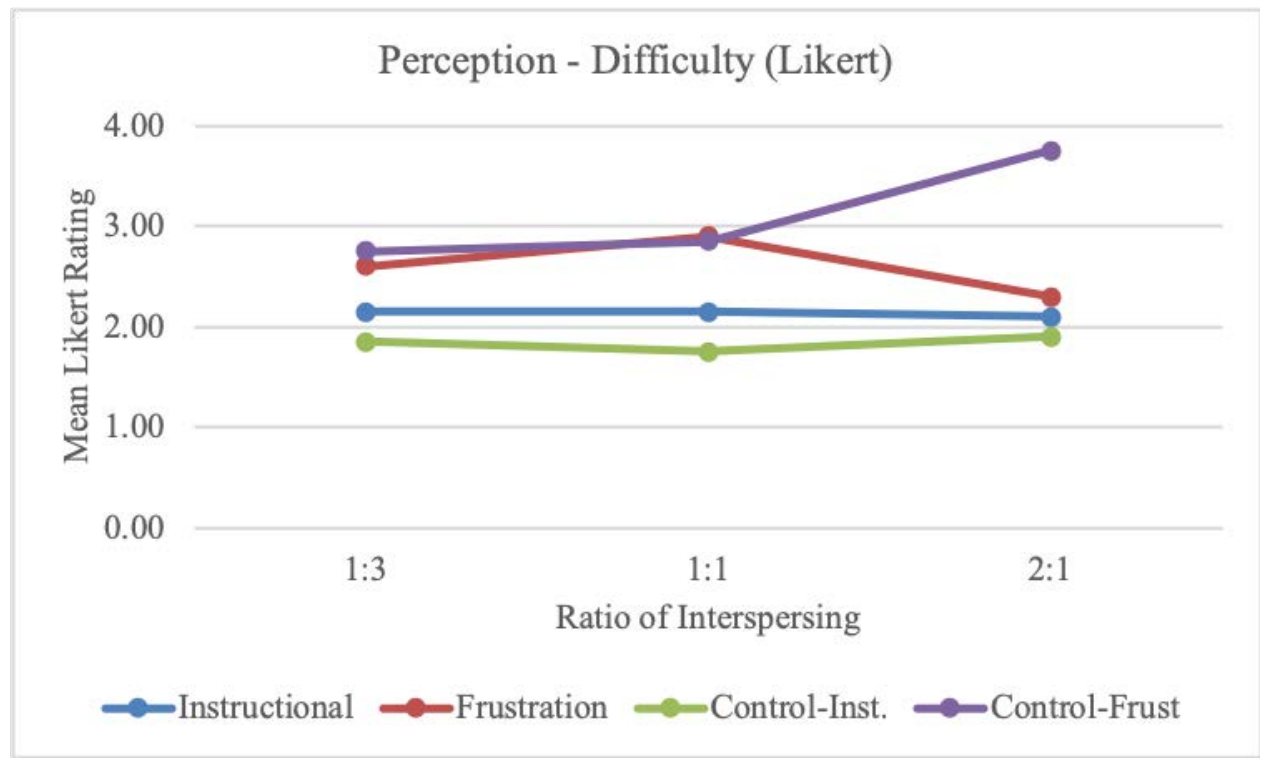

Figure 29. Perception ratings from Likert scale for difficulty across assignment conditions.

Data were collapsed to measure overall perception Likert ratings for experimental and control assignments at instructional level and at frustration level. It was expected that participants would rate experimental assignments as more favorable than control assignments. Further, it was expected that assignments at instructional level would be rated more positively 
than assignments at frustration level. Finally, experimental assignments at instructional level and at frustration level were expected to be rated more favorably than control assignments at similar instructional levels.

Figure 30 illustrates the results when collapsing data within or across participants, with lower ratings being more favorable. Specifically, the level of the data indicate that participants rated assignments at instructional level as more favorable than assignments at frustration level. Further, Participants rating experimental instructional assignments as more favorable than paired controls across time, effort, and difficulty ratings. However, frustration assignment ratings between experimental and controls was much less variable; In fact, frustration level experimental and control assignments were rated similarly for time, and frustration control assignments were rated more favorably than paired controls with regard to difficulty.

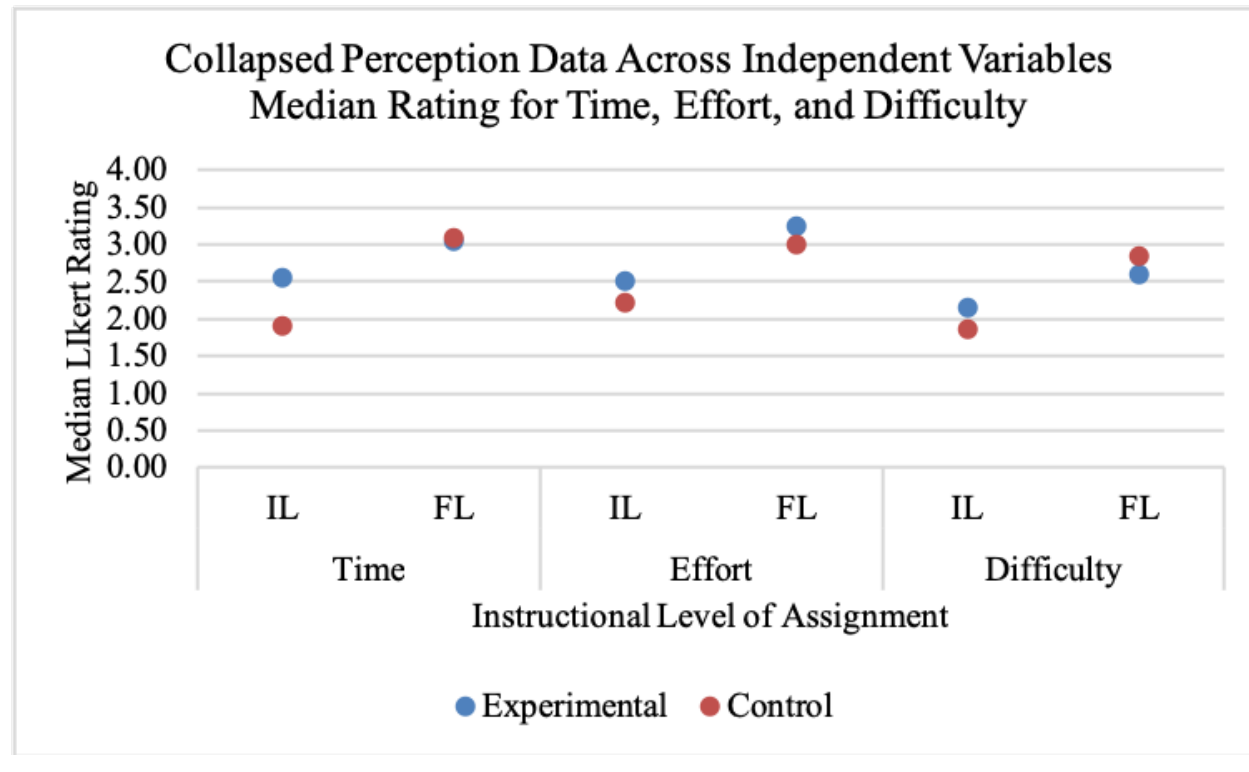

Figure 30. Collapsed perception data within each assignment condition.

Additional planned comparisons were completed by conducting a series of paired-sample t-tests to compare differences between perception ratings on control and experimental 
assignments for each assignment type. There were no significant difference between the perception ratings on paired control assignments and the 1:3 Experimental Instructional assignment for time [ $t(d f=19)=-.57, p=.577]$, effort [ $t(d f=19)=-1.45, p=.163]$, or difficulty $[t(d f=19)=-1.37, p=.186]$ or the $1: 3$ Experimental Frustration assignment for time $[t(d f=19)=-.53, p=.606]$, effort $[t(d f=19)=-.70, p=.494]$, or difficulty $[t(d f=19)=.62, p$ $=.545]$. Further, there were no significant differences present between the perception ratings on paired control assignment and the 1:1 Control Instructional assignment for effort $[t(d f=19)=$ $.24, p=.815]$, or difficulty [ $t(d f=19)=-1.63, p=.119]$ or $1: 1$ Frustration assignment for time $[t$ $(d f=19)=.72, p=.481]$, effort $[t(d f=19)=-.78, p=.447]$, or difficulty $[t(d f=19)=-.17, p=$ .867]. There was a statistically significant difference between the time perception ratings on the 1:1 Experimental Instructional assignment and the paired control $t(d f=19)=-.24, p=.004$, which represented a medium to large-sized effect, $d=.70$. Specifically, participants rated the control assignment as requiring less time to complete $(M=1.90, S E=.19)$ than the paired 1:1 experimental assignment $(M=2.55, S E=.22)$.

There were no statistically significant differences present between the perception ratings on paired control assignment and the 2:1 Control Instructional assignment for effort $[t(d f=19)=$ $-1.51, p=.149]$, or difficulty [ $t(d f=19)=-1.07, p=.297]$ or 2:1 Frustration assignment for time, $t(d f=19)=.25, p=.804$. There was a statistically significant difference between the time perception ratings on the 2:1 Experimental Instructional assignment and the paired control [ $t$ ( $d f$ $=19)=-3.29, p=.004$, which represented a large effect size, $d=.83$. Specifically, participants rated the 2:1 Experimental Instructional assignment $(M=2.60, S E=.25)$ as requiring more time to complete than the paired control $(M=1.85, S E=.15)$. There was also a significant difference between the time perception ratings on the 2:1 Experimental Frustration assignment and the 
paired control for effort, $t(d f=19)=-2.10, p=.049$, which represented a small- to mediumsized effect, $d=.45$. Specifically, participants rated the 2:1 experimental assignment ( $M=3.35$, $S E=.20)$ as requiring more effort to complete than the paired control $(M=3.00, S E=.15)$.

Further, participants rated the 2:1 Control Frustration assignment $(M=2.85, S E=.21)$ as being more difficult to complete than the paired 2:1 Experimental Frustration assignment $(M=2.30$, $S E=.21)$. This difference was significant, $t(d f=19)=2,77, p=.012$, and represented a mediumsized effect, $d=.59$.

Table 10.

Comparison of Likert Scale Ratings on Control versus Experimental Assignments and Assignments at Instructional versus Frustration Level

\begin{tabular}{|c|c|c|c|c|c|}
\hline Planned Comparison & $t$ & $d f$ & $\begin{array}{c}\text { Sig. } \\
\text { (2-tailed) }\end{array}$ & $M$ & $S D$ \\
\hline \multicolumn{6}{|l|}{ Time } \\
\hline $\begin{array}{l}\text { 1:3 Control Instructional vs. } \\
\text { 1:3 Experimental Instructional }\end{array}$ & -.57 & 19 & .577 & -.10 & .79 \\
\hline $\begin{array}{l}\text { 1:3 Control Frustration vs. 1:3 } \\
\text { Experimental Frustration }\end{array}$ & -.53 & 19 & .606 & -.10 & .85 \\
\hline $\begin{array}{l}\text { 1:1 Control Instructional vs. } \\
\text { 1:1 Experimental Instructional }\end{array}$ & -3.32 & 19 & $.004 *$ & -.65 & .88 \\
\hline $\begin{array}{l}\text { 1:1 Control Frustration vs. 1:1 } \\
\text { Experimental Frustration }\end{array}$ & .72 & 19 & .481 & .15 & .93 \\
\hline $\begin{array}{l}\text { 2:1 Control Instructional vs. } \\
\text { 2:1 Experimental Instructional }\end{array}$ & -3.29 & 19 & $.004 *$ & -.75 & 1.02 \\
\hline $\begin{array}{l}\text { 2:1 Control Frustration vs. 2:1 } \\
\text { Experimental Frustration }\end{array}$ & .25 & 19 & .804 & .05 & .89 \\
\hline \multicolumn{6}{|l|}{ Effort } \\
\hline $\begin{array}{l}\text { 1:3 Control Instructional vs. } \\
\text { 1:3 Experimental Instructional }\end{array}$ & -1.45 & 19 & .163 & -.30 & .92 \\
\hline $\begin{array}{l}\text { 1:3 Control Frustration vs. 1:3 } \\
\text { Experimental Frustration }\end{array}$ & -.70 & 19 & .494 & -.10 & .64 \\
\hline
\end{tabular}




\begin{tabular}{|c|c|c|c|c|c|}
\hline Planned Comparison & $t$ & $d f$ & $\begin{array}{c}\text { Sig. } \\
\text { (2-tailed) }\end{array}$ & $M$ & $S D$ \\
\hline $\begin{array}{l}\text { 1:1 Control Instructional vs. } \\
\text { 1:1 Experimental Instructional }\end{array}$ & -.24 & 19 & 815 & -.05 & .95 \\
\hline $\begin{array}{l}\text { 1:1 Control Frustration vs. 1:1 } \\
\text { Experimental Frustration }\end{array}$ & -.78 & 19 & .447 & -.20 & 1.15 \\
\hline $\begin{array}{l}\text { 2:1 Control Instructional vs. } \\
\text { 2:1 Experimental Instructional }\end{array}$ & -1.51 & 19 & .149 & -.35 & 1.04 \\
\hline $\begin{array}{l}\text { 2:1 Control Frustration vs. 2:1 } \\
\text { Experimental Frustration }\end{array}$ & -2.10 & 19 & $.049 *$ & -.35 & .75 \\
\hline \multicolumn{6}{|l|}{ Difficulty } \\
\hline $\begin{array}{l}\text { 1:3 Control Instructional vs. } \\
\text { 1:3 Experimental Instructional }\end{array}$ & -1.37 & 19 & .186 & -.30 & .98 \\
\hline $\begin{array}{l}\text { 1:3 Control Frustration vs. 1:3 } \\
\text { Experimental Frustration }\end{array}$ & .62 & 19 & .545 & .15 & 1.09 \\
\hline $\begin{array}{l}\text { 1:1 Control Instructional vs. } \\
\text { 1:1 Experimental Instructional }\end{array}$ & -1.63 & 19 & .119 & -.40 & 1.10 \\
\hline $\begin{array}{l}\text { 1:1 Control Frustration vs. 1:1 } \\
\text { Experimental Frustration }\end{array}$ & -.17 & 19 & .867 & -.05 & 1.32 \\
\hline $\begin{array}{l}\text { 2:1 Control Instructional vs. } \\
\text { 2:1 Experimental Instructional }\end{array}$ & -1.07 & 19 & .297 & -.20 & .83 \\
\hline $\begin{array}{l}\text { 2:1 Control Frustration vs. 2:1 } \\
\text { Experimental Frustration }\end{array}$ & 2.77 & 19 & $.012 *$ & .55 & .89 \\
\hline
\end{tabular}

*denotes statistically significant $p$-value

Assignment perceptions on forced-choice ratings. Figures 31 through 33 illustrate the graphs for visual analysis when comparing the differences between forced-choice perception responses across assignment types at ratios of interspersing. Overall, the level of the data indicate that more participants chose the experimental instructional assignment as requiring more time and effort to complete than the paired instructional control assignment. Conversely, more 
participants indicated that the frustration control assignment would require more time and effort to complete than the paired experimental frustration assignment. At the densest rate of interspersing, 2:1 ratio, there is a larger difference between the percent of participants who chose the experimental assignments at frustration and instructional levels as requiring more time to complete than the paired control.

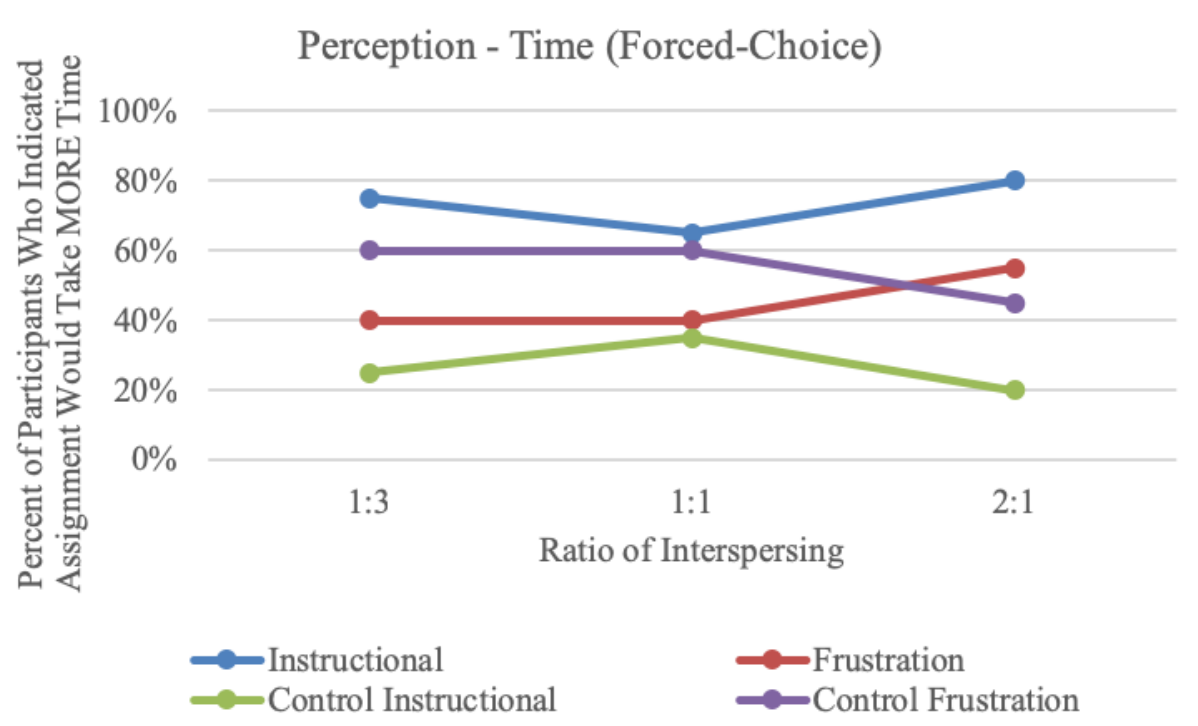

Figure 31. Forced-choice perception ratings for time. Data indicates that percentage of participants who indicated that the experimental assignment for a given condition would take more time than the paired control assignment. 


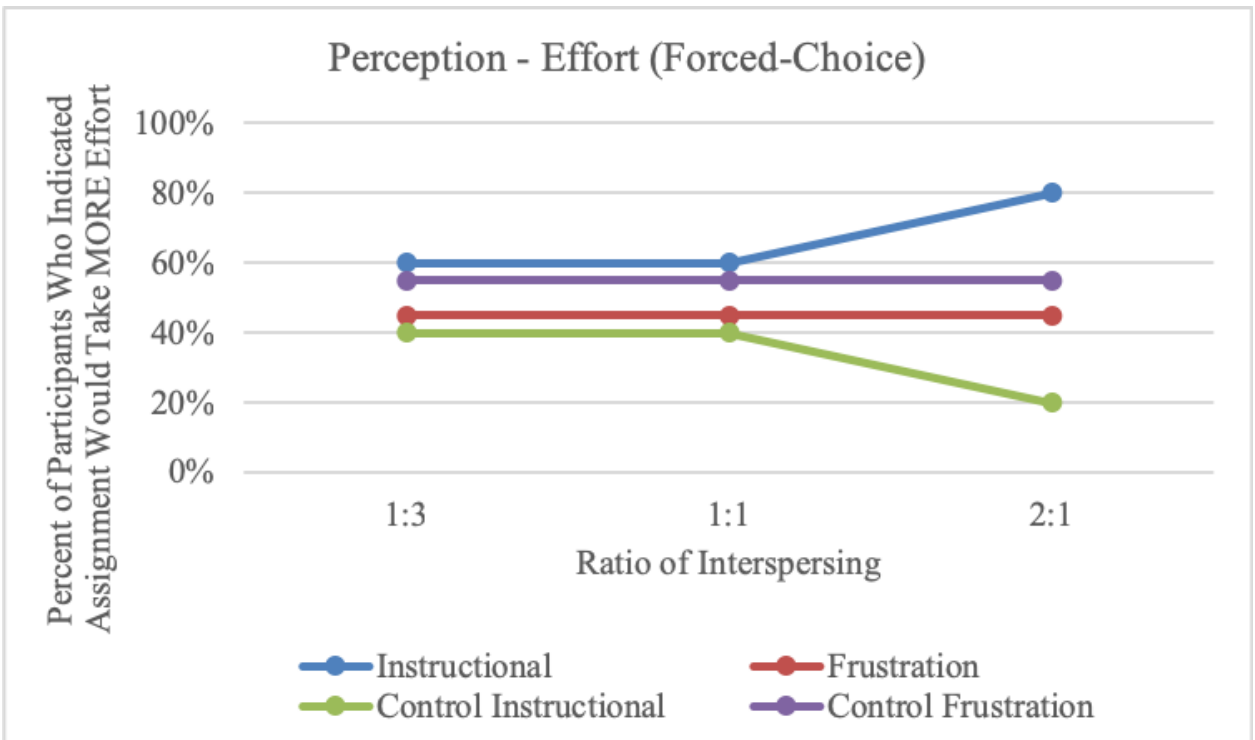

Figure 32. Forced-choice perception ratings for effort. Data indicates that percentage of participants who indicated that the experimental assignment for a given condition would take more effort than the paired control assignment.

With regard to perceived difficulty level of the assignment (See Figure 33), participants indicated that control instructional assignments would be more difficult to completed than the paired experimental assignment at the 1:3 ratio; however, perceptions altered at denser rates of interspersing, such that participants began to perceive the control assignment as being less difficult or just as difficult as the paired control assignment. At frustration level, participants indicated that the 1:3 frustration level assignments were equal in terms of difficulty to complete the assignments. Conversely, control frustration assignments were perceived as being more difficult than the paired experimental frustration assignment, as indicated by the difference in the level of the data. 


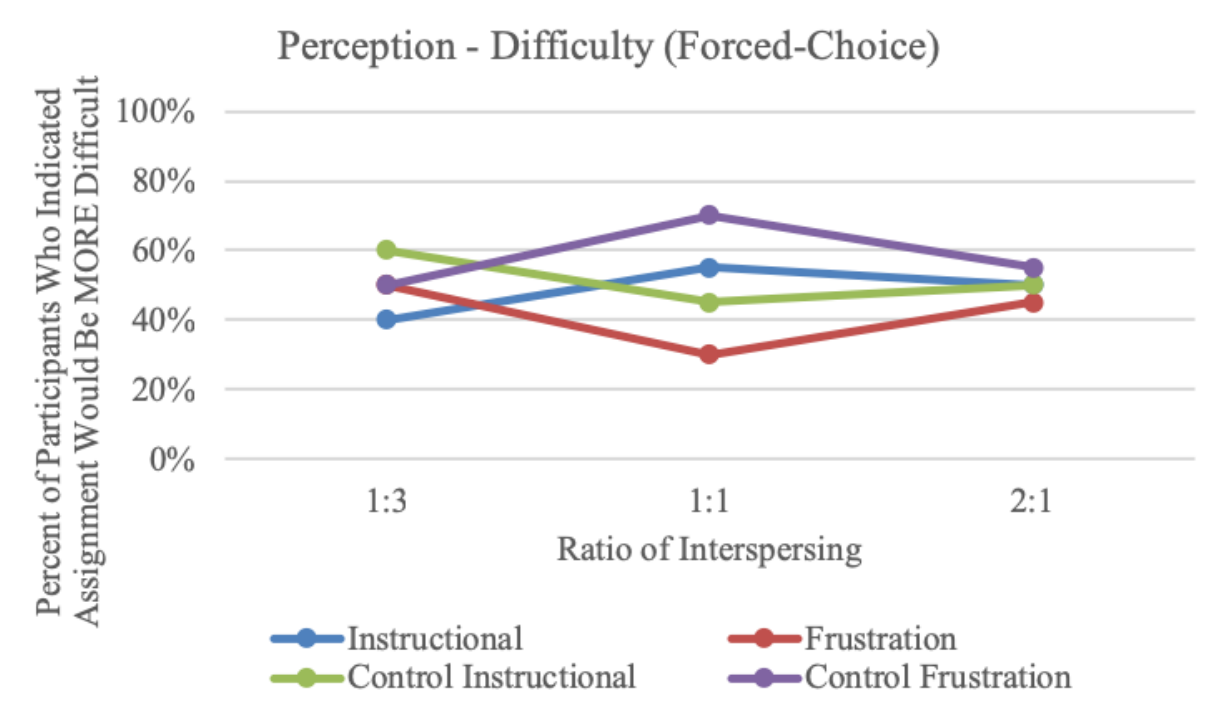

Figure 33. Forced-choice perception ratings for difficulty. Data indicates that percentage of participants who indicated that the experimental assignment for a given condition would be more difficulty to completed than the paired control assignment.

\section{Hypothesis 5}

Assignment preference. Participant preference was measured by asking participants to answer a forced-choice question to indicate which assignment he or she would like to take home for homework. The question was as follows: "Which assignment would you choose for homework? Choose one: I or F.” Changes in participant preference was evaluated using visual inspection procedures to determine if preference varies as a function of the rate of interspersing and/or instructional level. It was hypothesized that participants would consistently choose the experimental assignments over the paired control assignments. Further, Participants were also expected to consistently prefer experimental assignments at instructional level regardless of the ratio of interspersing. Finally, the percentage of participant who chose the experimental assignment over the control assignment was expected to increase as the density of interspersing became increased. 
Figure 34 provides the graphed results for the percentage of participants who preferred or indicated they would choose an assignment for homework. Participants consistently choose the experimental assignments over the paired control assignments. The percentage of participants who the experimental assignment was relatively stable across conditions; however, there was a visibly larger difference between the percentage of participants who chose experimental assignments at the frustration level rather than paired frustration controls. There was a slight decreasing trend for preference for the frustration level experimental assignments when the density of interspersing increased from left to right. This indicates that participants were slightly less likely to choose the experimental assignment for homework as the density of interspersing increased. The level of instructional level preference data indicates that slightly more participants preferred experimental instructional assignments at a 1:1 interspersing ratio than assignments at the 1:3 and 2:1 interspersing ratio.

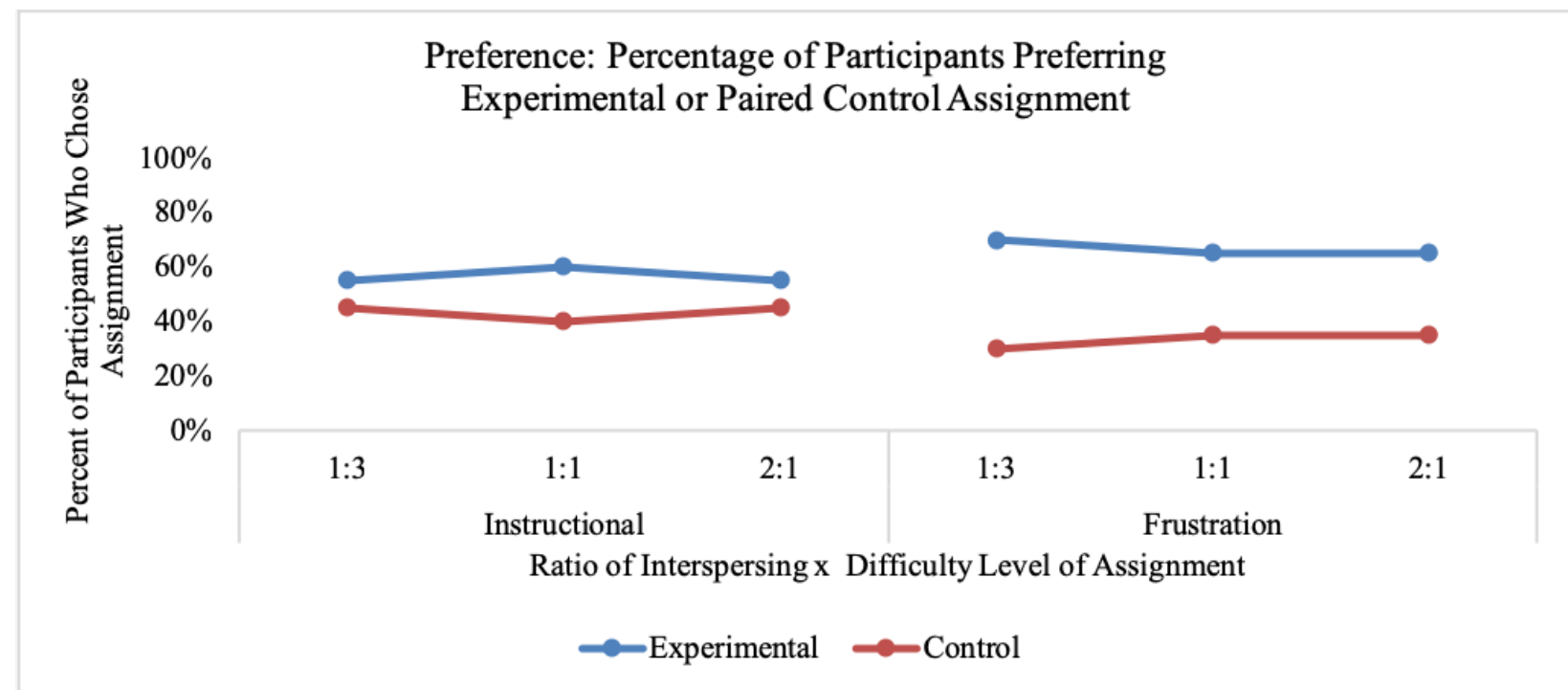

Figure 34. Preference results for experimental and control assignments at each instructional level and ratio of interspersing.

Figure 35 provides the results for the percentage of participants who preferred or indicated they would choose an assignment for homework along with the results for relative 
problem completion rate. It was hypothesized that assignment preference would change as a function of the relative problem completion rates on math assignments. Figure 36 provides the results for the percentage of participants who preferred or indicated they would choose an assignment for homework along with the results for total problem completion rates. It was hypothesized that assignment preference would change as a function of the total problem completion rates, such that as the problem completion rate increased on experimental assignments so would the percentage of participants who preferred that assignment over the paired control. The figures indicate that preference did not appear to change as a function of relative problem completion rates or total problem completion rate.

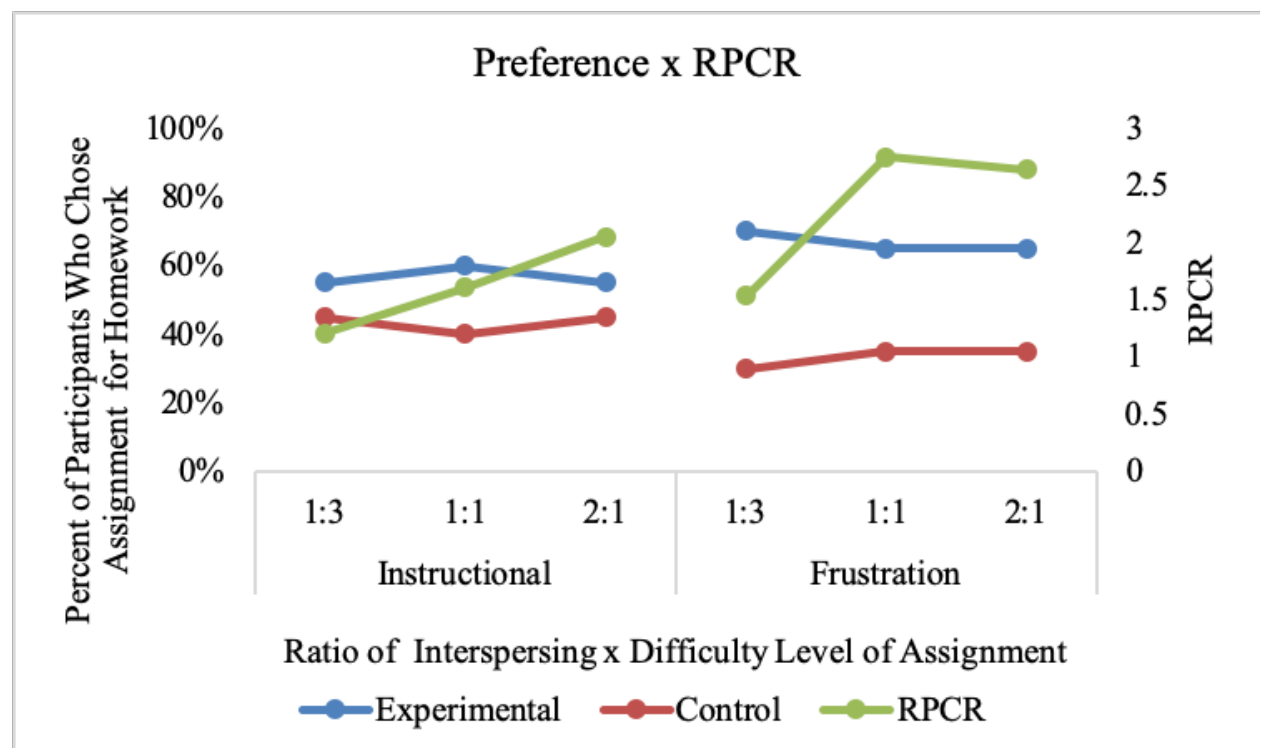

Figure 35. Preference results for experimental and control assignments with overlay of Relative Problem Completion Rate results for each instructional level and ratio of interspersing. 


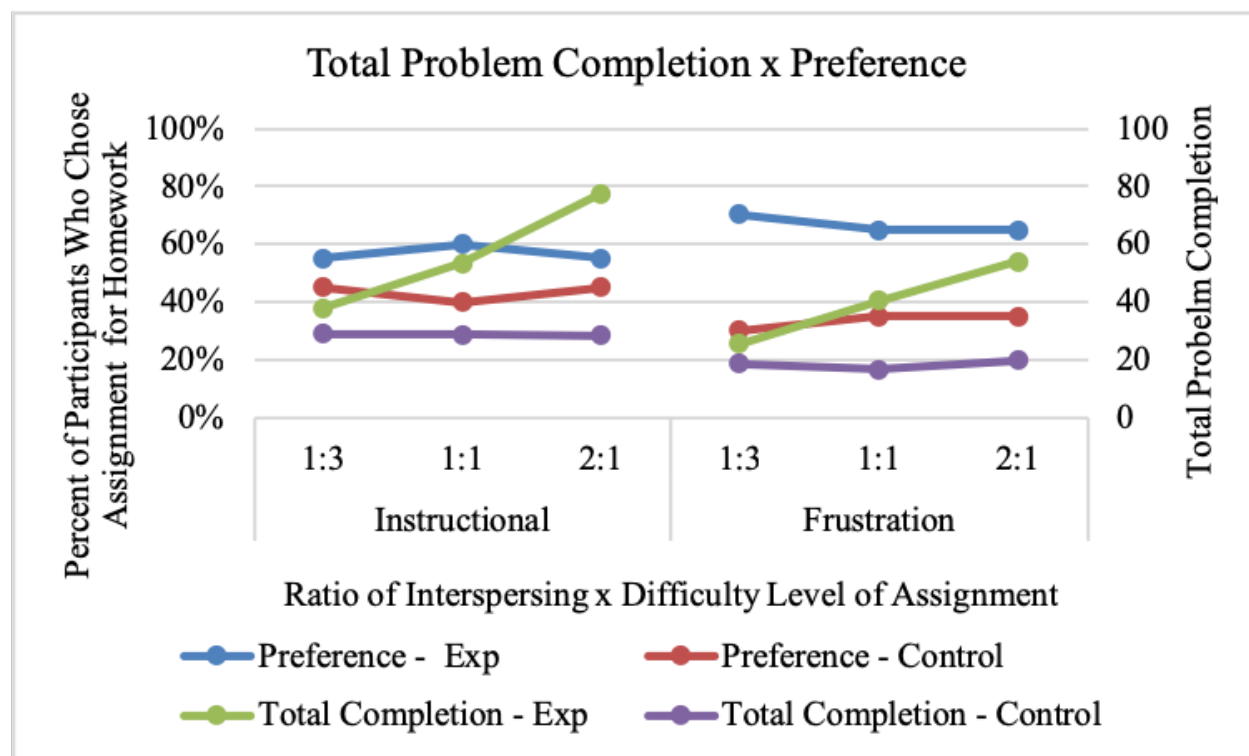

Figure 36. Preference results for experimental and control assignments with overlay of Total Problem Completion Rates results for each instructional level and ratio of interspersing. 


\section{CHAPTER V: DISCUSSION}

\section{Discussion}

\section{General Findings}

As outlined above, a student's learning rate and academic achievement are strongly influenced by the number of opportunities to respond during academic tasks and rate of academic engagement (Shapiro, 2011). Mathematics interspersing can be used to modify tasks by distributing brief math problems among a set of target problems. Studies have demonstrated that students are more actively engaged in these assignments and are more likely to choose them to complete for homework due to the rate at which the student accesses reinforcement (i.e., discrete task completion) for engaging in the task (Cates \& Dalenberg, 2005; Skinner et al., 2002). However, if task demands are too great for a student in comparison with his or her skills, the task is said to be at a frustration level and academic engagement and learning may be compromised (Gravois \& Gickling, 2008). Thus, the current study examined the effects of varying rates of interspersing as a form of reinforcement on students' math performance, assignment perceptions of time, difficulty and effort, and choice behavior (i.e., assignment preference). The effect of students' instructional level and the rate of interspersing threshold for influencing assignment preference was also explored.

Social applications of the matching law suggests that the time allocated to a specific behavior matches the ratio at which they received some form of reinforcement. When considered in the context of academic engagement, it is implied by the matching law that a student's choice to be academically engaged versus off-task can be manipulated by altering the rate at which they are reinforced. The discrete task completion hypothesis suggests that such reinforcement can come from completing a single problem on an assignment (Skinner, 2002). Moreover, students 
can be expected to choose assignments for homework and have more favorable perceptions of assignments with interspersing than those without interspersing. Thus, this research examined whether altering the rate of interspersing influenced relative problem completion rates, performance, perceptions, and preference.

\section{Consistency With Previous Research}

Performance. Research supporting the use of interspersing procedures to improve assignment perceptions and preference has been plentiful (Cates, 2005; Cates \& Skinner, 2000; Dunlap et al., 1994; Logan \& Skinner, 1998; Skinner et al., 2005). However, support for using this procedure to improve performance is limited. The results of the current study are consistent with previous research (Cates et al., 1999; Cates \& Dalenberg, 2005; Cates \& Erkfritz, 2007; Cates \& Skinner, 2000; Hawkins et al., 2005; Skinner et al., 1999; Skinner, Fletcher, et al., 1996;

Wildmon et al., 2004; Skinner, Robinson et al., 1996) that indicates total problem completion rates increase as the rate of interspersing increases, but problem accuracy remains relatively stable. This is likely due to participants accessing brief, easy, problems more frequently, thus, increasing their problem completion rates. However, there is no feedback provided to students on how to improve their math performance; thus, students are likely to continue making the same errors regardless of the rate of interspersing. Although target problem completion did not consistently vary as a function of the rate of interspersing within assignments at the same difficulty level, there was a significant difference between the number of total and target problems completed on instructional versus frustration level assignments. Specifically, participants completed more problems on the instructional assignment than frustration level assignments. 
Relative problem completion rates. As hypothesized, a visual analysis revealed that relative problem completion rates increased as the rate of interspersing increased for assignments at instructional level. A similar pattern was observed for relative problem completion rates on assignments at frustration level with a dip in rates at the highest rate of interspersing. It is likely that exposure to a significantly extended assignment at frustration level induced poorer perceptions of that assignment despite the rate at which brief, mastery-level, problems were interspersed throughout. Although the level of the data indicates a visible difference between relative problem completion rates on all assignments at instructional versus frustration level, statistical analyses revealed that a significant interaction did not exist between interspersing rate, relative problem completion rate, and instructional level.

Assignment perceptions and preference. As noted in previous research, participants perceptions of assignments varied as the rate of interspersing increased. Previous studies provided forced choice response options when assessing for participant perceptions of time, difficulty, and effort. The current study assessed incremental changes in perceptions by using a 4-point rating scale in addition to the forced-choice response. Overall, participants viewed assignments without interspersing as requiring more effort and as being less difficult than paired experimental assignments. At the densest rates of interspersing on assignments at frustration level, participants rate the experimental assignment as being less difficult but as requiring more time to complete. Forced-choice ratings reflected similar results. Moreover, visibly more participants consistently chose the experimental assignment for homework over the control assignment. These results may be related to participants being able to visually notice the difference in the number of problems on control versus experimental assignments. Further, there 
were clocks in many of the rooms that could not be hidden; this may have results in students implicitly timing themselves and adjusting their ratings accordingly.

\section{Extension of Literature on Interspersing}

Adjusting instructional level. Student's must be engaged in or motivated to complete an assignment in order to get access to more learning trials in a particular subject area. Studies have shown that student acceptability of an assignment plays an important role in their willingness to participate in the task and with learning in general. Furthermore, matching the instructional load of a task to the student's current skill level is imperative to target student's learning and to reduce frustration and disengagement from a task (Bramlett et al., 2010; Burns et al., 2014; Gickling \& Armstrong, 1978; Ysseldyke et al., 2003). McDonald and Ardoin (2007) examined the influence of adjusting the instructional level of the assignment when interspersing procedures were used; however, participants were placed into groups based arbitrary math fluency criteria.

The current study addressed this limitation by conducting an assessment phase to identify each participant's individual instructional and frustration level based on evidence-based criteria. Further, students completed a series of baseline control assignments at frustration and instructional level to ensure that the level of the assignments matched with their performance on and perceptions of each assignment level. Overall, results indicate that students had more favorable perceptions of instructional level assignments than frustration level assignments.

Participants total problem completion rate significantly varied, as hypothesized, across assignments at different rates of interspersing and instructional levels. However, target problem completion rates remained relatively stable across rates of interspersing. These results are similar to the results of other studies that explored the influence of interspersing procedures on target and total problem completion rates. This study also examined whether significant differences 
were present between assignments at instructional versus frustration level. Results revealed that participants completed significantly more target problems and total problems on instructional level assignments than assignments at frustration level. These results provide further support for the importance of matching assignments to the remedial math students’ instructional level. Further, target problem accuracy did not vary as a function of the rate of interspersing; however, participants’ accuracy was significantly better on assignments at instructional than frustration level. The current study further supports the importance of matching assignments to the student's skill level to improve assignment perceptions, accuracy, and, problem completion rate.

\section{Study Strengths}

This study encompassed many strengths, particularly in terms of the procedures implemented. With regard to the sample, the number of males and females who participated was balanced; thus, it is not likely that the sample's gender composition affected the results. With regard to methodology, this study used more than one method for measuring assignment perceptions. Additionally, a systematic procedure grounded in research was used to identify participants' instructional and frustration level and modify assignment pairs used throughout the study. The influence of modifying assignment instructional level on performance and perception variables was assessed prior to implementing experimental conditions. Further, any participants whose performance during the assessment phase did not align with performance on instructional level assignments were eliminated from the study. Finally, the order in which participants received assignment pairs was counterbalanced for each participant to ensure that order of assignment presentation did not affect the results. Counterbalancing allowed participants within a testing group to be completing a variety of assignments, thus limiting the opportunity for 
students to look at a peer's assignment for answers and reducing frustration or boredom with the assignment type.

\section{Limitations and Future Directions for Research}

There are also important limitations to note that may have affected the results of the current study. There were a limited number of fourth grade students who returned the consent form, which result in a significant difference in the number of fifth grade student and fourth grade student who participated in the study. Thus, generalizations to fourth grade students is cautioned. Furthermore, the racial composition of the sample was primarily European American; therefore, results are not reflective of the racial diversity of the general population. Information on socioeconomic status or other demographic factors were not obtained as a part of this study. Studies have shown that students from low socioeconomic backgrounds or racially diverse (Pajares \& Kranzler, 1995; Stevens, Olivarez, Lan, \& Tallent-Runnels, 2004) backgrounds hold less favorable perceptions of math and/or have low self-efficacy which influences their motivation to engage in math tasks and math performance. Future research may want to explore the influence, if any, of cultural and/or socioeconomic differences on perceptions on academic tasks using an interspersing procedure.

Another limitation includes the repeated use of self-report measures to assess perceptions. Self-report of assignment perceptions could have been influenced by other environmental factors, such as a clock being present and students timing themselves without the examiner's knowledge, time of day the condition was presented, and the peer group participants completed the assignment with and whether there was competition to speed through the assignment. Further, having the researcher, rather than the classroom teacher or math interventionist, implement the conditions may have affected the student's effort on, engagement in, and 
perceptions of math assignments throughout the study. There was also external reinforcement provided to students after reach condition was presented, which may have positively influenced the student's perception of and engagement in the tasks. Researchers examining the use of interspersing procedures or other academic interventions or assignment modification may consider having the teacher or school-based interventionists that the students are familiar with administer each phase. This may increase generalizability to school settings and decrease the influence of behavioral factors associated with having an unfamiliar adult implement the procedures. Although environmental factors were not consistent throughout the implementation of each phase, all phases of a study were administered in rooms within the school that were familiar to the students. To gain more control over environmental factors, future researchers should consider identifying a single room within the school to implement the procedures. However, this may pose as a challenge due to many schools being limited on space and resources.

There were notable differences between instructional and frustration level assignments with regard to problem completion, problem accuracy, and assignment perceptions. Thus, future researchers and practitioners should consider adjusting assignments to match the student's instructional level to provide the student more opportunities to practice completing target problems and reducing frustration while completing the assignment. If an assignment is too difficult for the student, it is likely that they will not be able to complete as many problems in a timely manner and will begin to reduce their motivation to engage in and complete their work. Differences between instructional and frustration level assignment preference were not gathered due to these two assignment types not being paired together. Thus, it would be beneficial to have additional research on the difference between student assignment preference, perception, and 
performance on instructional versus frustration level assignment pairs. Further, this study, much like many others, did not consider problem accuracy when calculating the number of problems completed; thus, it is likely that participants made similar mistakes as there was no additional instruction or feedback provided. Researchers are encouraged to explore whether integrating a feedback component to interspersed assignments at instructional level would improve target problem accuracy.

\section{Conclusions}

This study provides results that demonstrate the usefulness of interspersing procedures and altering assignments to meet a student's instructional level to improve perceptions of and preference for an assignment, as well as overall problem completion. This study can be used to demonstrate that when students are asked to complete work that is at their frustration level, their

perceptions and motivation to complete the assignment diminishes along with their productivity. Although an interspersing procedure coupled with matching the student's instructional level to the level of problems that make up the assignment may improve perceptions of, preference for and productivity when completing assignments, results of this study, as well as others, do not support the use of these procedures to improve accuracy. Further, if assignment length is increased too much, students may begin to prefer the assignment less. Therefore, additional supports may have to be put into place to target and promote further skill development. 


\section{REFERENCES}

Anderson, K. G., Velkey, A. J., \& Woolverton, W. L. (2002). The generalized matching law as a predictor of choice between cocaine and food in rhesus monkeys. Psychopharmacology, 163(3-4), 319-326.

Ardoin, S. P., Witt, J. C., Connell, J. E., \& Koenig, J. L. (2005). Application of a three-tiered response to intervention model for instructional planning, decision making, and the identification of children in need of services. Journal of Psychoeducational Assessment, 23(4), 362-380.

Bambara, L. M., Ager, C., \& Koger, F. (1994). The effects of choice and task preference on the work performance of adults with severe disabilities. Journal of Applied Behavior Analysis, 27(3), 555-556.

Baum, W. M. (1974a). Choice in free-ranging wild pigeons. Science, 185(4145), 78-79.

Baum, W. M. (1974b). On two types of deviation from the matching law: Bias and undermatching. Journal of the Experimental Analysis of Behavior, 22(1), 231-242.

Baum, W. M. (1975). Time allocation in human vigilance. Journal of the Experimental Analysis of Behavior, 23(1), 45-53.

Baum, W. M. (1979). Matching, undermatching, and overmatching in studies of choice. Journal of the Experimental Analysis of Behavior, 32(2), 269-281.

Baum, W. M., \& Rachlin, H. C. (1969). Choice as time allocation. Journal of the Experimental Analysis of Behavior, 12(6), 861-874.

Billington, E. J., \& DiTommaso, N. M. (2003). Demonstrations and applications of the matching law in education. Journal of Behavioral Education, 12(2), 91-104. 
Billington, E. J., \& Skinner, C. H. (2002). Getting students to choose to do more work: Evidence of the effectiveness of the interspersal procedure. Journal of Behavioral Education, 11(2), 105-116.

Billington, E. J., \& Skinner, C. H. (2006). Reducing perceptions of time required to complete math assignments by adding problems to assignments: A synthesis of the additive interspersal research. Journal of Behavioral Education, 15(3), 181-188.

Billington, E. J., Skinner, C. H., \& Cruchon, N. M. (2004). Improving sixth-grade students’ perceptions of high-effort assignments by assigning more work: Interaction of additive interspersal and assignment effort on assignment choice. Journal of School Psychology, 42(6), 477-490.

Billington, E. J., Skinner, C. H., Hutchins, H. M., \& Malone, J. C. (2004). Varying problem effort and choice: Using the interspersal technique to influence choice towards more effortful assignments. Journal of Behavioral Education, 13(3), 193-207.

Borrero, C., Vollmer, T. R., Borrero, J. C., Bourret, J. C., Sloman, K. N., Samaha, A. L., \& Dallery, J. (2010). Concurrent reinforcement schedules for problem behavior and appropriate behavior: Experimental applications of the matching law. Journal of the Experimental Analysis of Behavior, 93(3), 455-469.

Borrero, J. C., \& Vollmer, T. R. (2002). An application of the matching law to severe problem behavior. Journal of Applied Behavior Analysis, 35(1), 13-27.

Bradley, R., Danielson, L., \& Doolittle, J. (2005). Response to intervention. Journal of Learning Disabilities, 38(6), 485-486. 
Bradshaw, C. M., Szabadi, E., \& Bevan, P. (1976). Behavior of humans in variable-interval schedules of reinforcement. Journal of the Experimental Analysis of Behavior, 26(2), 135-141.

Bramlett, R., Cates, G. L., Savina, E., \& Lauinger, B. (2010). Assessing effectiveness and efficiency of academic interventions in school psychology journals: 1995-2005. Psychology in the Schools, 47(2), 113-125.

Bryant, D. P., Bryant, B R., \& Hammill, D. D. (2000). Characteristic Behaviors of Students with LD Who Have Teacher-Identified Math Weaknesses. Journal of Learning Disabilities, 33(2), 168-177.

Burns, M. K., Codding, R. S., Boice, C. H., \& Lukito, G. (2010). Meta-analysis of acquisition and fluency math interventions with instructional and frustration level skills: Evidence for a skill-by-treatment interaction. School Psychology Review, 39(1), 69-83.

Burns, M. K., VanDerHeyden, A. M., \& Jiban, C. L. (2006). Assessing the instructional level for mathematics: A comparison of methods. School Psychology Review, 35(3), 401.

Burns, M. K., VanDerHeyden, A. M., \& Zaslofsky, A. F. (2014). Best practices in delivering intensive academic interventions with a skill-by-treatment interaction. In Best Practices in School Psychology: Student Level Services (6th ed., pp. 139-142). Bethesda, MA: National Association of School Psychologists.

Calderhead, W. J., Filter, K. J., \& Albin, R. W. (2006). An investigation of incremental effects of interspersing math items on task-related behavior. Journal of Behavioral Education, 15(1), 51-65.

Catania, A. C. (1963a). Concurrent performances: A baseline for the study of reinforcement magnitude. Journal of the Experimental Analysis of Behavior, 6(2), 299-300. 
Catania, A. C. (1963b). Concurrent performances: Reinforcement interaction and response independence. Journal of the Experimental Analysis of Behavior, 6(2), 253-263.

Cates, G. L. (2005). A review of the effects of interspersing procedures on the stages of academic skill development. Journal of Behavioral Education, 14(4), 305-325.

Cates, G. L., Blum, C., \& Swerdlik, M. E. (2011). Effective RtI training and practices: Helping school and district teams improve academic performance and social behavior. Research Press Publishers.

Cates, G. L., \& Dalenberg, A. E. (2005). Effects of interspersing rate on student preferences for mathematics assignments. Journal of Behavioral Education, 14(2), 89-103. -y

Cates, G. L., \& Erkfritz, K. N. (2007). Effects of interspersing rates on students’ performance on and preferences for mathematics assignments: Testing the discrete task completion hypothesis. Psychology in the Schools, 44(6), 615-625.

Cates, G. L., \& Skinner, C. H. (2000). Getting remedial mathematics students to prefer homework with $20 \%$ and $40 \%$ more problems: An investigation of the strength of the interspersing procedure. Psychology in the Schools, 37(4), 339-347.

Cates, G. L., Skinner, C. H., Watkins, C. E., Rhymer, K. N., McNeill, S. L., \& McCurdy, M. (1999). Effects of interspersing additional brief math problems on student performance and perception of math assignments: Getting students to prefer to do more work. Journal of Behavioral Education, 9(3/4), 177-192.

Cates, G. L., Skinner, C. H., Watson, T. S., Meadows, T. J., Weaver, A., \& Jackson, B. (2003). Instructional effectiveness and instructional efficiency as considerations for data-based decision making: An evaluation of interspersing procedures. School Psychology Review, 32(4), 601-616. 
Chang, L. (1994). A psychometric evaluation of 4-point and 6-point Likert-type scales in relation to reliability and validity. Applied Psychological Measurement, 18(3), 205-215.

Chung, S. H., \& Herrnstein, R. J. (1967). Choice and delay of reinforcement. Journal of the Experimental Analysis of Behavior, 10(1), 67-74.

Clark, S. L., \& Rhymer, K. N. (2003). Student preference for explicit timing and interspersal procedures as a function of math problem completion rates: Testing the discrete task completion hypothesis. Journal of Behavioral Education, 12(4), 275-286.

Clarke, S., Dunlap, G., Foster-Johnson, L., Childs, K. E., Wilson, D., White, R., \& Vera, A. (1995). Improving the conduct of students with behavioral disorders by incorporating student interests into curricular activities. Behavioral Disorders, 20(4), 221-237.

Conger, R., \& Killeen, P. (1974). Use of concurrent operants in small group research: A demonstration. Pacific Sociological Review, 17(4), 399-416.

Cronbach, L. J. (1957). The two disciplines of scientific psychology. American Psychologist, 12(11), 671-684.

Cronbach, L. J., \& Snow, R. E. (1977). Aptitudes and instructional methods: A handbook for research on interactions. Irvington. Retrieved from http://psycnet.apa.org/psycinfo/197811462-000

de Villiers, P. A., \& Herrnstein, R. J. (1976). Toward a law of response strength. Psychological Bulletin, 83(6), 1131.

Denton, C. A. (2012). Response to intervention for reading difficulties in the primary grades: Some answers and lingering questions. Journal of Learning Disabilities, 45, 232-243.

Deno, S. L. (1985). Curriculum-based measurement: The emerging alternative. Exceptional Children, 52(3), 219-232. 
Deno, S. L., \& Mirkin, P. K. (1977). Data-Based Program Modification: A Manual. Retrieved from http://eric.ed.gov/?id=ED144270

DiPerna, J. C., \& Elliott, S. N. (2002). Promoting academic enablers to improve student achievement: An introduction to the mini-series. School Psychology Review, 31(3), 293.

DiPerna, J. C., Volpe, R. J., \& Elliott, S. N. (2005). A model of academic enablers and mathematics achievement in the elementary grades. Journal of School Psychology, 43(5), 379-392.

Dougan, J. D., \& McSweeney, F. K. (1985). Variation in Herrnstein’s ro as a function of alternative reinforcement rate. Journal of the Experimental Analysis of Behavior, 43(2), $215-223$.

Dunlap, G. (1984). The influence of task variation and maintenance tasks on the learning and affect of autistic children. Journal of Experimental Child Psychology, 37(1), 41-64.

Dunlap, G., DePerczel, M., Clarke, S., Wilson, D., Wright, S., White, R., \& Gomez, A. (1994). Choice making to promote adaptive behavior for students with emotional and behavioral challenges. Journal of Applied Behavior Analysis, 27(3), 505-518.

Dunlap, G., \& Egel, A. L. (1982). Motivational techniques. Educating and understanding autistic children, 106-126.

Dunlap, G., \& Kern, L. (1996). Modifying instructional activities to promote desirable behavior: A conceptual and practical framework. School Psychology Quarterly, 11(4), 297.

Dunlap, G., Kern-Dunlap, L., Clarke, S., \& Robbins, F. R. (1991). Functional assessment, curricular revision, and severe behavior problems. Journal of Applied Behavior Analysis, 24(2), 387-397. 
Dunlap, G., \& Koegel, R. L. (1980). Motivating autistic children through stimulus variation. Journal of Applied Behavior Analysis, 13(4), 619-627.

Dunlap, L. K., \& Dunlap, G. (1987). Using task variation to motivate handicapped students. Teaching Exceptional Children, 19(3), 16-19.

Dyer, K., Dunlap, G., \& Winterling, V. (1990). Effects of choice making on the serious problem behaviors of students with severe handicaps. Journal of Applied Behavior Analysis, 23(4), 515-524.

Fisher, W. W., Thompson, R. H., Piazza, C. C., Crosland, K., \& Gotjen, D. (1997). On the relative reinforcing effects of choice and differential consequences. Journal of Applied Behavior Analysis, 30(3), 423-438.

Fuchs, L. S., \& Fuchs, D. (1998). Treatment validity: A unifying concept for reconceptualizing the identification of learning disabilities. Learning Disabilities Research \& Practice, 13(4), 204-219.

Fuchs, L. S., Fuchs, D., Prentice, K., Hamlett, C. L., Finelli, R., Courey, S. J. (2004). Enhancing mathematical problem solving among third-grade students with schema-based instruction. Journal of Educational Psychology, 96, 635-647.

Fuchs, D., Mock, D., Morgan, P. L., \& Young, C. L. (2003). Responsiveness-to-intervention: Definitions, evidence, and implications for the learning disabilities construct. Learning Disabilities Research \& Practice (Wiley-Blackwell), 18(3), 157-171.

Garland, R. (1991). The mid-point on a rating scale: Is it desirable. Marketing Bulletin, 2(1), 6670. 
Gettinger, M., \& Miller, K. (2014). Best practices in increasing academic engaged time. In Best Practices in School Psychology: Student Level Services (6th ed., pp. 19-36). Bethesda, MA: National Association of School Psychologists.

Gettinger, M., \& Stoiber, K. C. (2012). Curriculum-based early literacy assessment and differentiated instruction with high-risk preschoolers. Reading Psychology, 33, 11-36.

Gickling, E. E., \& Armstrong, D. L. (1978). Levels of instructional difficulty as related to ontask behavior, task completion, and comprehension. Journal of Learning Disabilities, 11(9), 559-566.

Gickling, E. E., \& Thompson, V. P. (1985). A personal view of curriculum-based assessment. Exceptional Children, 52(3), 205-218.

Gottfried, A. E. (1982). Relationships between academic intrinsic motivation and anxiety in children and young adolescents. Journal of School Psychology, 20(3), 205-215.

Gravois, T. A., \& Gickling, E. E. (2008). Best practices in instructional assessment. Best Practices in School Psychology V, 2, 503-518.

Greenwood, C. (1991). Longitudinal analysis of time engagement, and achievement in at-risk versus non-risk students. Exceptional Children, 57, 521-535.

Greenwood, C. R., Delquadri, J., \& Hall, R. V. (1984). Opportunity to respond and student academic performance. Focus on Behavior Analysis in Education, 58-88.

Gresham, F. M. (2006). Response to intervention. In Children’s Needs III: Development, Prevention, and Intervention (3rd ed., pp. 525-540). Bethesda, MA: National Association of School Psychologists. 
Hawkins, J., Skinner, C. H., \& Oliver, R. (2005). The effects of task demands and additive interspersal ratios on fifth-grade students’ mathematics accuracy. School Psychology Review, 34(4), 543.

Hawthorn-Embree, M. L., Skinner, C. H., Parkhurst, J., \& Conley, E. (2011). An investigation of the partial-assignment completion effect on students’ assignment choice behavior. Journal of School Psychology, 49(4), 433-442.

Hawthorn-Embree, M. L., Skinner, C. H., Parkhurst, J., O’Neil, M., \& Conley, E. (2010). Assignment choice: Do students choose briefer assignments or finishing what they started? School Psychology Quarterly, 25(3), 143-151.

Herrnstein, R. J. (1961). Relative and absolute strength of response as a function of frequency of reinforcement. Journal of the Experimental Analysis of Behavior, 4(3), 267-272.

Herrnstein, R. J. (1970). On the law of effect. Journal of the Experimental Analysis of Behavior, 13(2), 243-266.

Herrnstein, R. J. (1974). Formal properties of the matching law. Journal of the Experimental Analysis of Behavior, 21(1), 159-164.

Hollard, V., \& Davison, M. C. (1971). Preference for qualitatively different reinforcers. Journal of the Experimental Analysis of Behavior, 16(3), 375-380.

Horner, R. H., \& Day, H. M. (1991). The effects of response efficiency on functionally equivalent competing behaviors. Journal of Applied Behavior Analysis, 24(4), 719-732.

Howell, K. W., \& Hosp, J. L. (2014). Best practices in curriculum-based evaluation. In Best Practices in School Psychology: Data-Based and Collaborative Decision Making (6th ed., pp. 159-170). Bethesda, MA: National Association of School Psychologists. 
Jaspers, K. E., Skinner, C. H., Williams, R. L., \& Saecker, L. B. (2007). Effects of problem order on accuracy, preference, and choice of multiplication assignments. The Behavior Analyst Today, 8(3), 347.

Johns, G. A., Skinner, C. H., \& Nail, G. L. (2000). Effects of interspersing briefer mathematics problems on assignment choice in students with learning disabilities. Journal of Behavioral Education, 10(2/3), 95-106.

Kelley, B., Hosp, J. L., \& Howell, K. W. (2008). Curriculum-based evaluation and math: An overview. Assessment for Effective Intervention, 33(4), 250-256.

Kenna, G., Hussar, W., McFarland, J., de Brey, C., Musu-Gillette, L., Wang, X., ... Dunlop Velez, E. (2016). The conditions of education, 2016 (NCES 2016-144). U.S. Department of Education, National Center for Education Statistics: Washington, DC. Retrieved from http://nces.ed.gov/pubsearch

Kern, L., Delaney, B., Clarke, S., Dunlap, G., \& Childs, K. (2001). Improving the classroom behavior of students with emotional and behavioral disorders using individualized curricular modifications. Journal of Emotional and Behavioral Disorders, 9(4), 239-247.

Kern, L., Mantegna, M. E., Vorndran, C. M., Bailin, D., \& Hilt, A. (2001). Choice of task sequence to reduce problem behaviors. Journal of Positive Behavior Interventions, 3(1), $3-10$.

Kern, L., Vorndran, C. M., Hilt, A., Ringdahl, J. E., Adelman, B. E., \& Dunlap, G. (1998). Choice as an intervention to improve behavior: A review of the literature. Journal of Behavioral Education, 8(2), 151-169. 
Kratochwill, T. R., Hitchcock, J. H., Horner, R. H., Levin, J. R., Odom, S. L., Rindskopf, D. M., \& Shadish, W. R. (2013). Single-case intervention research design standards. Remedial and Special Education, 34(1), 26-38.

Kratochwill, T. R., Hitchcock, J., Horner, R. H., Levin, J. R., Odom, S. L., Rindskopf, D. M., \& Shadish, W. R. (2010). Single-case designs technical documentation. What Works Clearinghouse. Retrieved from http://eric.ed.gov/?id=ED510743

Lane, K. L., Oakes, W. P., \& Menzies, H. M. (2014). Comprehensive, integrated, three-tiered models of prevention: Why does my school and district need an integrated approach to meet students’ academic, behavioral, and social needs? Preventing School Failure: Alternative Education for Children and Youth, 58(3), 121-128.

Lichtenstein, R. (2014). Best practices in identification of learning disabilities. In Best Practices in School Psychology: Data-Based and Collaborative Decision Making (6th ed., pp. 331354). Bethesda, MA: National Association of School Psychologists.

Logan, P., \& Skinner, C. H. (1998). Improving students’ perceptions of a mathematics assignment by increasing problem completion rates: Is problem completion a reinforcing event? School Psychology Quarterly, 13(4), 322.

Mace, F. C., McCurdy, B., \& Quigley, E. A. (1990). A collateral effect of reward predicted by matching theory. Journal of Applied Behavior Analysis, 23(2), 197-205.

Mace, F. C., Neef, N. A., Shade, D., \& Mauro, B. C. (1994). Limited matching on concurrentschedule reinforcement of academic behavior. Journal of Applied Behavior Analysis, 27(4), 585-596. 
Mace, F. C., Neef, N. A., Shade, D., \& Mauro, B. C. (1996). Effects of problem difficulty and reinforcer quality on time allocated to concurrent arithmetic problems. Journal of Applied Behavior Analysis, 29(1), 11-24.

Martens, B. K., Halperin, S., Rummel, J. E., \& Kilpatrick, D. (1990). Matching theory applied to contingent teacher attention. Behavioral Assessment. Retrieved from http://psycnet.apa.org/psycinfo/1991-02711-001

Martens, B. K., \& Houk, J. L. (1989). The application of Herrnstein’s law of effect to disruptive and on-task behavior of a retarded adolescent girl. Journal of the Experimental Analysis of Behavior, 51(1), 17-27.

Martens, B. K., Lochner, D. G., \& Kelly, S. Q. (1992). The effects of variable-interval reinforcement on academic engagement: A demonstration of matching theory. Journal of Applied Behavior Analysis, 25(1), 143-151.

Matell, M. S., \& Jacoby, J. (1971). Is there an optimal number of alternatives for Likert scale items? Study I: Reliability and validity. Educational and Psychological Measurement, 31(3), 657-674.

McCurdy, M., Skinner, C. H., Grantham, K., Watson, T. S., \& Hindman, P. M. (2001). Increasing on-task behavior in an elementary student during mathematics seatwork by interspersing additional brief problems. School Psychology Review, 30(1), 23-32.

McDonald, E., \& Ardoin, S. P. (2007). Interspersing easy math problems among challenging problems: Detection of interspersal effects in whole-class applications. Journal of Behavioral Education, 16(4), 342-354.

McDowell, J. J. (1988). Matching theory in natural human environments. The Behavior Analyst, 11(2), 95. 
McDowell, J. J. (1989). Two modern developments in matching theory. The Behavior Analyst, 12(2), 153.

Monahan, S., Kratochwill, T., \& Lipscomb, S. (2011). What Works Clearinghouse (WWC) Standards for Evaluating Single Case Designs (SCDs). Society for Research on Educational Effectiveness. Retrieved from http://eric.ed.gov/?id=ED519806

Montarello, S., \& Martens, B. K. (2005). Effects of interspersed brief problems on students' endurance at completing math work. Journal of Behavioral Education, 14(4), 249-266.

Moors, A., Weisenburgh-Snyder, A., \& Robbins, J. (2010). Integrating frequency-based mathematics instruction with a multi-level assessment system to enhance response to intervention frameworks. The Behavior Analyst Today, 11(4), 226.

Neef, N. A., Iwata, B. A., \& Page, T. J. (1980). The effects of interspersal training versus highdensity reinforcement on spelling acquisition and retention. Journal of Applied Behavior Analysis, 13(1), 153-158.

Neef, N. A., \& Lutz, M. N. (2001). Assessment of variables affecting choice and application to classroom interventions. School Psychology Quarterly, 16(3), 239.

Neef, N. A., Mace, F. C., \& Shade, D. (1993). Impulsivity in students with serious emotional disturbance: The interactive effects of reinforcer rate, delay, and quality. Journal of Applied Behavior Analysis, 26(1), 37-52.

Neef, N. A., Mace, F. C., Shea, M. C., \& Shade, D. (1992). Effects of reinforcer rate and reinforcer quality on time allocation: Extensions of matching theory to educational settings. Journal of Applied Behavior Analysis, 25(3), 691-699. 
Neef, N. A., Shade, D., \& Miller, M. S. (1994). Assessing influential dimensions of reinforcers on choice in students with serious emotional disturbance. Journal of Applied Behavior Analysis, 27(4), 575-583.

Neuringer, A. J. (1967). Effects of reinforcement magnitude on choice and rate of responding. Journal of the Experimental Analysis of Behavior, 10(5), 417-424.

Organization for Economic Cooperation and Development (OECD), Program for International Student Assessment (PISA), 2015.

Pajares, F., \& Kranzler, J. (1995). Self-efficacy beliefs and general mental ability in mathematical problem-solving. Contemporary Educational Psychology, 20(4), 426-443.

Reschly, A. L., Appleton, J. J., \& Pohl, A. (2014). Best practices in fostering student engagement. In Best Practices in School Psychology: Student Level Services (6th ed., pp. 37-50). Bethesda, MA: National Association of School Psychologists.

Reynolds, G. S. (1963). On some determinants of choice in pigeons. Journal of the Experimental Analysis of Behavior, 6(1), 53-59.

Rhymer, K. N., \& Cates, G. L. (2006). Student performance on and preferences for mathematics word problems: An investigation of the effects of explicit timing and interspersing procedures. School Psychology Quarterly, 21(1), 34.

Rhymer, K. N., \& Morgan, S. K. (2005). Comparison of the explicit timing and interspersal interventions: Analysis of problem completion rates, student preference, and teacher acceptability. Journal of Behavioral Education, 14(4), 283-303.

Roberts, M. L., Turco, T. L., \& Shapiro, E. S. (1991). Differential effects of fixed instructional ratios on students’ progress in reading. Journal of Psychoeducational Assessment, 9(4), 308-318. 
Robinson, S. L., \& Skinner, C. H. (2002). Interspersing additional easier items to enhance mathematics performance on subtests requiring different task demands. School Psychology Quarterly, 17(2), 191.

Schroeder, S. R., \& Holland, J. G. (1969). Reinforcement of eye movement with concurrent schedules. Journal of the Experimental Analysis of Behavior, 12(6), 897-903.

Shapiro, E. S. (2011). Academic skills problems: Direct assessment and intervention (4th ed.). New York, NY: The Guilford Press.

Shriver, M. D., \& Kramer, J. J. (1997). Application of the generalized matching law for description of student behavior in the classroom. Journal of Behavioral Education, 7(2), 131-149.

Shull, R. L., \& Pliskoff, S. S. (1967). Changeover delay and concurrent schedules: Some effects on relative performance measures. Journal of the Experimental Analysis of Behavior, 10(6), 517-527.

Skinner, C. H. (2002). An empirical analysis of interspersal research evidence, implications, and applications of the discrete task completion hypothesis. Journal of School Psychology, 40(4), 347-368.

Skinner, C. H. (2004). Single-subject designs: Procedures that allow school psychologists to contribute to the intervention evaluation and validation process. Journal of Applied School Psychology, 20(2), 1-10.

Skinner, C. H., Fletcher, P. A., Wildmon, M., \& Belfiore, P. J. (1996). Improving assignment preference through interspersing additional problems: Brief versus easy problems. Journal of Behavioral Education, 6(4), 427-436. 
Skinner, C. H., Hall-Johnson, K., Skinner, A. L., Cates, G., Weber, J., \& Johns, G. A. (1999). Enhancing perceptions of mathematics assignments by increasing relative problem completion rates through the interspersal technique. The Journal of Experimental Education, 68(1), 43-59.

Skinner, C. H., Hurst, K. L., Teeple, D. F., \& Meadows, S. O. (2002). Increasing on-task behavior during mathematics independent seat-work in students with emotional disturbance by interspersing additional brief problems. Psychology in the Schools, 39(6), $647-659$.

Skinner, C. H., Pappas, D. N., \& Davis, K. A. (2005). Enhancing academic engagement: Providing opportunities for responding and influencing students to choose to respond. Psychology in the Schools, 42(4), 389-403.

Skinner, C. H., Robinson, S. L., Johns, G. A., Logan, P., \& Belfiore, P. J. (1996). Applying Herrnstein's matching law to influence students' choice to complete difficult academic tasks. The Journal of Experimental Education, 65(1), 5-17.

Skinner, C. H., Wallace, M. A., \& Neddenriep, C. E. (2002). Academic remediation: Educational applications of research on assignment preference and choice. Child \& Family Behavior Therapy, 24(1-2), 51-65.

Stevens, T., Olivarez, A., Lan, W.Y., \& Tallent-Runnels, M.K. (2004). Role of mathematics selfefficacy and motivation in mathematics performance across ethnicity. Journal of Educational Research, 97(4), 208-222. 
Stoiber, K. C. (2014). A comprehensive framework for multitiered systems of support in school psychology. In Best Practices in School Psychology: Data-Based and Collaborative Decision Making (6th ed., pp. 41-70). Bethesda, MA: National Association of School Psychologists.

Stoiber, K. C., \& Gettinger, M. (2016). Multi-tiered systems of support and evidence-based practices. In S. R. Jimerson, M. K. Burns, \& A. M. VanDerHeyden (Eds.), Handbook of Response to Intervention (pp. 121-141). Boston, MA: Springer US. Retrieved from http://link.springer.com/10.1007/978-1-4899-7568-3_9

Sugai, G., \& Horner, R. H. (2009). Responsiveness-to-intervention and school-wide positive behavior supports: Integration of multi-tiered system approaches. Exceptionality, 17(4), 223-237.

U.S. Department of Education, Institute of Education Sciences, National Center for Education Statistics, National Assessment of Educational Progress (NAEP), various years, 1990— 2017 Mathematics Assessments.

Vaughn, S., \& Chard, D. (2006, Winter). Three-tier intervention research studies: Descriptions of two related projects. Perspectives, 29-34.

Wallace, M. A., Cox, E. A., \& Skinner, C. H. (2003). Increasing independent seatwork: Breaking large assignments into smaller assignments and teaching a student with retardation to recruit reinforcement. School Psychology Review, 32(1), 132-142.

Wildmon, M. E., Skinner, C. H., McCurdy, M., \& Sims, S. (1999). Improving secondary students' perception of the “dreaded mathematics word problem assignment” by giving them more word problems. Psychology in the Schools, 36, 4. 
Wildmon, M. E., Skinner, C. H., \& McDade, A. (1998). Interspersing additional brief, easy problems to increase assignment preference on mathematics reading problems. Journal of Behavioral Education, 8(3), 337-346.

Wildmon, M. E., Skinner, C. H., Watson, T. S., \& Garrett, L. S. (2004). Enhancing assignment perceptions in students with mathematics learning disabilities by including more work: An extension of interspersal research. School Psychology Quarterly, 19(2), 106.

Winterling, V., Dunlap, G., \& O’Neill, R. E. (1987). The influence of task variation on the aberrant behaviors of autistic students. Education and Treatment of Children, 105-119.

Ysseldyke, J., Spicuzza, R., Kosciolek, S., Teelucksingh, E., Boys, C., \& Lemkuil, A. (2003). Using a curriculum-based instructional management system to enhance math achievement in urban schools. Journal of Education for Students Placed at Risk, 8(2), 247-265. 


\title{
APPENDIX A: PARENT CONSENT
}

\author{
Department of Psychology, Illinois State University \\ Informed Consent Form \\ Principal Investigator: Dr. Gary Cates
}

Dear Parent/Guardian,

This letter is to obtain your consent for your child to participate in a research study in mathematics completed by a graduate student in the School Psychology Doctoral Program at Illinois State University. From this study, we expect to gain information about how the structure of mathematics assignments affect students' performance, assignment acceptability, and perceptions about the assignment. Participation in this study is unlikely to result in any risk to your child beyond that of working on several mathematics worksheets. You are free to withdraw your child, or your child can withdraw him/herself, from participation at any time. The Institutional Review Board at Illinois State University has already approved this study before asking you to participate.

Your child will be asked to work on mathematics assignments and answer questions about what he/she thought of the assignments. Your child's performance and answers will be kept strictly confidential. To ensure this, your child's name will not be attached with his/her performance. Further, all data will be kept on a password protected flash-drive that will be locked in a university office.

The study will be made up of 10,15-20-minute, sessions over the course of two to three weeks. Your child will be described the study and will choose whether he/she would like to participate or not participate prior to the completion of any study component. Your child is free to withdraw from participation at any time without any kind of penalty. For your child's participation in each phase of the study he/she will be allowed to choose a small prize out of a prize box (e.g., pencils, erasers, notebooks, etc.).

If you have questions regarding this study, please contact Gary L. Cates, Ph.D. at (309) 483-3123 or glcates@ilstu.edu. You may also contact the Research Ethics \& Compliance Office via phone (309) 438-2529 or email rec@ilstu.edu to learn about the protection of human participants in university research. (A copy of this consent form has been provided for you to keep for your records).

I agree to allow my child to participate in this research. I understand that my child will be provided the opportunity to decline participation and/or withdraw from the research at any time. I understand that I am permitted to withdraw my child's participation at any time.

Yes

Parent/Legal Guardian’s Signature

Signature of Researcher
No

\section{Date}

Date 


\section{APPENDIX B: PARTICIPANT ASSENT FORM}

Participant \#

Remove at dotted line

\section{Dear Student,}

My name is Samantha DeHaan and I am a college student at Illinois State University. I've brought you here to ask you to participate in a research study about math. If you agree to participate, you will be asked to complete math assignments every day for 10 days. We will ask you to complete the assignments the best that you can and you are not expected to get all the problems correct. This will take about 20-minutes each day we meet.

If you agree to participate, you will get to choose a small prize out of a prize box at end of each session. There are no big risks to your participation in this study, but you may become tired after completing so many math assignments.

Participation in this study is voluntary and you can quit at any time, without any penalties. No one will know how you did except for the members of my research team. Not even your parents or teachers will learn about how you did on the math assignments.

By signing my name below, I agree to participate in the research study.

Printed Name

Student Signature

Date

Adult Witness Signature

Date 


\section{APPENDIX C: RESEARCHER ASSENT SCRIPT}

The information below is to be read to students verbatim before obtaining assent.

"Hi, my name is Samantha and I am a college student at Illinois State University. You are invited to participate in a research study about math. We want to figure out things that help you complete math problems better.

If you agree to participate, you will be asked to complete a series of math assignments. We will ask you to complete the assignments the best that you can and you are not expected to get all of the problems correct. I will be here to work with you every day for about 10 days and each day should take about 20 minutes.

Your answers will be confidential. This means that your name will not be on the math assignments. Me and my research team will be the only people reading your answers. No one else will be able to read your answers, including your teachers and parents.

This study is not likely to hurt you, but we know that you might get tired of doing the math assignments. So, as a thank you for helping us with this study you will receive a small prize after you complete each day of assignments.

You do not have to participate in this study. If you decide to participate, you can quit at any time. You also have the right not to answer any questions that I ask you. If you do not want to be involved in this study, you will not be punished in any way. Other than me and the people I work at the university, no one will know if you decide that you do not want to participate.

If you have any questions about this study, please ask.” 


\section{APPENDIX D: DEMOGRAPHICS FORM}

Please provide the following information:

Age:

Sex/Gender:

Grade in school:

Race/Ethnicity:

$\square \quad$ American Indian or Alaska Native

$\square \quad$ Asian

$\square \quad$ Black or African American

$\square \quad$ Hispanic-Latino

$\square \quad$ Native Hawaiian - Other Pacific Islander

$\square \quad$ White

$\square \quad$ Other 
APPENDIX E: CONTROL, AT INSTRUCTIONAL LEVEL (WITHOUT CARRYING), ASSIGNMENT EXAMPLE

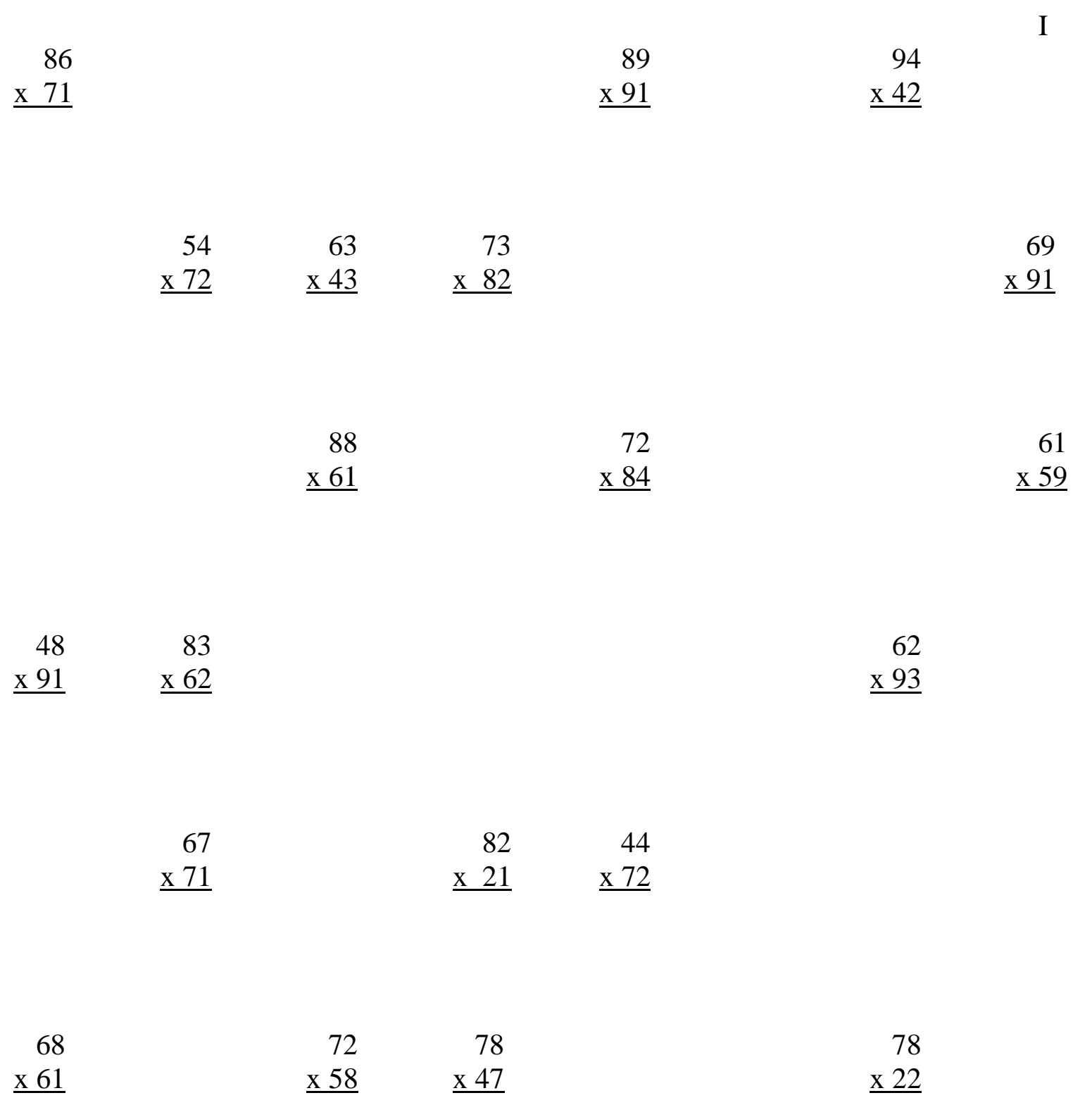


APPENDIX F: CONTROL, AT FRUSTRATION LEVEL, ASSIGNMENT EXAMPLE

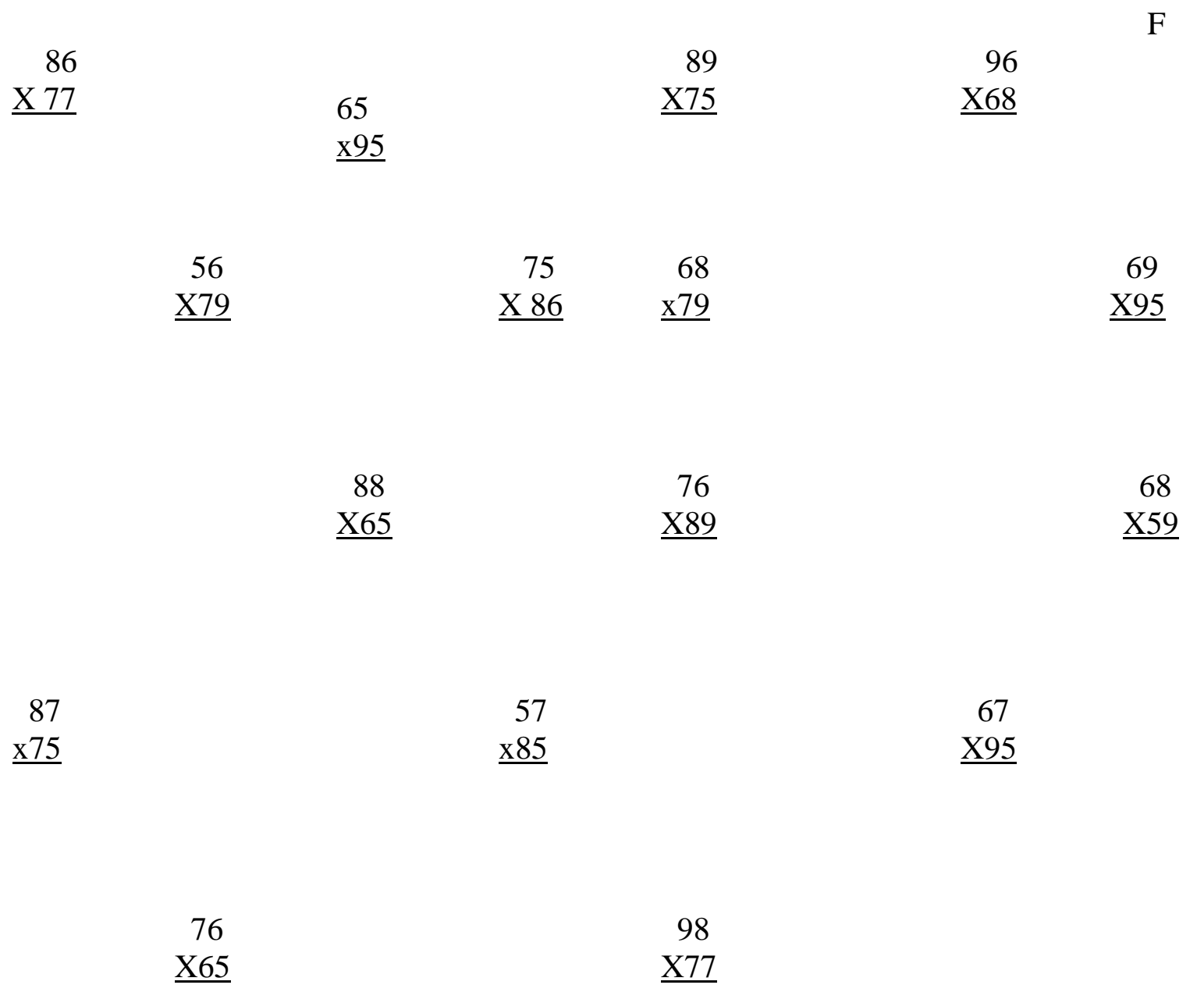

\begin{tabular}{rrr}
76 & 89 & 97 \\
$\times 95$ & $\times 78$ \\
\hline
\end{tabular}




\section{APPENDIX G: 1:3 EXPERIEMNTAL ASSIGNMENT EXAMPLE}

\begin{tabular}{crrr}
99 & 87 & 67 & 4 \\
$\underline{x} 58$ & $\underline{x 75}$ & $\underline{x 68}$ & $\underline{x 2}$ \\
\hline
\end{tabular}

55

65

79

$\underline{\mathrm{x} 89}$

$\underline{\mathrm{x} 95}$

$\underline{\mathrm{x} 86}$

\begin{tabular}{rrrr}
3 & 89 & 97 & 57 \\
$\times 1$ & $\underline{66}$ & $\underline{\times 59}$ & $\underline{85}$ \\
\hline
\end{tabular}

2

97

58

$\underline{x} 2$

$\underline{\mathrm{x} 88} \quad \underline{\mathrm{x} 77}$

$76 \quad 1$

66

$\underline{\mathrm{x} 95} \quad \underline{\mathrm{x}}$

$\underline{\mathrm{x} 57}$

97

68

3

57

$\underline{\times 55}$

×99

$\underline{x} 2$

$\underline{\times 96}$

\begin{tabular}{rrr}
89 & 76 & 1 \\
$\times 78$ & $\underline{x} 95$ & $\underline{x}$ \\
\hline
\end{tabular}


APPENDIX H: 1:1 EXPERIMENTAL ASSIGNMENT EXAMPLE

$\begin{array}{rrrrr}1 & 97 & 2 & 58 & \mathrm{~F} \\ \underline{\mathrm{x} 1} & \underline{\mathrm{x} 55} & \underline{\mathrm{x}} & \underline{\mathrm{x} 77} & \end{array}$

2

\begin{tabular}{rr}
66 & 1 \\
$\times 57$ & $\underline{x}$ \\
\hline
\end{tabular}

\begin{tabular}{rrrr}
68 & 2 & 76 & 1 \\
$\underline{x 99}$ & $\underline{\mathrm{x} 3}$ & $\underline{\mathrm{x} 95}$ & $\underline{\mathrm{x}}$ \\
\hline
\end{tabular}

57

$\underline{\times 85}$

$\begin{array}{rrr}4 & 97 & 3 \\ \mathrm{x} 1 & \underline{\mathrm{x}} & \underline{1}\end{array}$

97

$\begin{array}{rrr}2 & 79 & 3 \\ \times 2 & \underline{x} 86\end{array}$

3

$\begin{array}{rrr}65 & 1 & 89 \\ \times 95 & \times 3\end{array}$

$\underline{\mathrm{x}}$

$\underline{\times 59}$

x95

x66

$\begin{array}{rrrr}1 & 55 & 2 & 87 \\ \underline{x 1} & \underline{\mathrm{x} 89} & \underline{\mathrm{x}} & \underline{\mathrm{x} 75} \\ & & & \\ & & & \\ 4 & 67 & \underline{\mathrm{x} 3} & \underline{\mathrm{x} 58} \\ \underline{\mathrm{x} 2} & \underline{ } & & \end{array}$




\begin{tabular}{|c|c|c|c|c|c|}
\hline 3 & 77 & 2 & & 57 & \\
\hline$\underline{x 2}$ & $\underline{\mathrm{X} 55}$ & $\underline{x 4}$ & & $\underline{\mathrm{x} 95}$ & \\
\hline 1 & & & 66 & 3 & 59 \\
\hline$\underline{x 1}$ & & & x57 & $x 4$ & $\underline{x 86}$ \\
\hline & & 1 & 75 & & \\
\hline & & $\underline{x 2}$ & $\underline{x} 87$ & & \\
\hline
\end{tabular}


APPENDIX I: 2:1 EXPEIRMENTAL ASSIGNMENT EXAMPLE

$\begin{array}{rrrrr}1 & 3 & 97 & 2 & \mathrm{~F} \\ \underline{\mathrm{x} 1} & \underline{\mathrm{x}} & \underline{\mathrm{x} 55} & \underline{\mathrm{x}} & \end{array}$

$\begin{array}{r}2 \\ \underline{2} \\ \hline\end{array}$

\begin{tabular}{rr}
58 & 1 \\
$\times 77$ & $\underline{x}$ \\
\hline
\end{tabular}

68

$\underline{\times 99}$

$\begin{array}{rrrr}2 & 66 & 3 & 1 \\ \underline{\mathrm{X}} & \underline{\mathrm{5} 57} & \underline{\mathrm{x}} & \underline{\mathrm{x}}\end{array}$

2

3

57

3

$\underline{x} 2$

$\underline{x}$

X85

$\underline{\mathrm{x}}$

3

x3

\section{7 \\ $\times 188$}

\begin{tabular}{rr}
4 & 1 \\
$\times 1$ & $\underline{1}$ \\
\hline
\end{tabular}

97

×59

1

2

79

$\underline{\mathrm{x}} \quad \underline{\mathrm{x} 86}$

$\begin{array}{r}4 \\ \times 2 \\ \hline\end{array}$

2

65

$\underline{\mathrm{x}} \quad \underline{\mathrm{x} 95}$

4

2

$\underline{\mathrm{x}} \quad \underline{\mathrm{x}}$ 


\begin{tabular}{|c|c|c|c|}
\hline $\begin{array}{ll}89 & 3\end{array}$ & 2 & & 55 \\
\hline$\underline{x 66} \quad \underline{x}$ & $\underline{\mathrm{x} 4}$ & & $\underline{x 89}$ \\
\hline 1 & & 3 & 87 \\
\hline$\underline{\mathrm{x} 1}$ & & $\underline{\mathrm{x}}$ & $\underline{\mathrm{X} 75}$ \\
\hline & 1 & 67 & 2 \\
\hline & $\underline{x 2}$ & $\underline{x 68}$ & $\underline{x 2}$ \\
\hline 2 & 99 & & \\
\hline$\underline{\mathrm{x} 3}$ & $\underline{\mathrm{X} 58}$ & & \\
\hline
\end{tabular}


Researchers: Please follow each step as indicated in the protocol and be sure to have all materials prior to meeting with students for data collection.

Materials Required for Session 1:

- Participant assent form

- Participant assent script

- Procedural protocol

- Procedural script

- Demographic form

- Intervention Central Single-Skill probes (x4)

- Intervention Central Multiple Skill probes (x2)

- Intervention Central CBM directions

- Stopwatch/Timer

- Accordion file folder to collect data

- List of participant numbers

Materials Required for Sessions 2 through 9:

- List of participant names and numbers

- Assignment packets for the appropriate session

- Procedural protocol

- Procedural script

- Sharpened pencils with erasers

- Stopwatch/Timer

- Appropriate session packet for each student - located in accordion file

Materials Required for Session 10:

- List of student names and protocol numbers

- Assignment packets for the appropriate session

- Procedural protocol

- Procedural script

- Sharpened pencils with erasers

- Stopwatch/Timer

- Appropriate session packet for each student - located in accordion file

- Debriefing script

Session 1 Procedural Protocol

1.) Pass out assent forms and pencils to all prospective participants.

2.) Read Assent Script.

$\square$ 3.) Pass out Session 1 packet to all those who choose to participate.

**Make sure that participant numbers on each form/probe they complete matches their assigned number on the assent script**

4.) Instruct students to complete the first page of the packet (i.e., demographic page). 
"Please complete page 1 of your packet. After you have completed page 1 do not turn the page until you are instructed to do so.

4.) Instruct students to turn to next page (i.e., Cover page for first CBM probe).

5.) Read Intervention Central CBM probe directions verbatim. After reading directions say.

"Turn the page. (Wait 1 second) Begin."

6.) Time for 1-minute, as indicated in CBM directions.

7.) Collect CBM probes

8.) Read CBM instructions for each of the following CBM probes and time for 1 minute each, as indicated in directions.

79.) Collect Session 1 packets

$\square 10$.) Dismiss students to the classroom and say:

"Thank you for participating everyone. We will see you later this week."

$\square 11$.$) Allow students to choose a prize.$

$\square$ 12.) When returning to University, open the password protected file named "Participant List" and enter the student's names with his/her respective participant number. Then remove the slip with the assigned number from the assent form at the dotted line.

\section{Sessions 2-9 Procedural Protocol}

1.) Open the file named "Participant List" on the password protected flash drive.

2.) Greet students and say, "Hi everyone, we are going to do some math today."

3.) Pass out pencils and each student's respective assignment packet.

**Make sure that participant numbers on each packet match their assigned number in the "Participant List" **

4.) Instruct students to not open the packets, say:

"I am passing out some math assignments and pencils. Please do not open your packets until I provide instructions and say begin."

5.) Read instructions:

"I will ask you to complete as many problems as you can on some math assignments.

Please work all of the problems on each page in order from left to right (demonstrate with random packet) as quickly as possible, without skipping problems or making errors, starting with the first problem on the top left (point). When you have finished all of the problems on the first line, begin working on the next problem on the next line. If you finish the assignment before we tell you to stop, please put your pencil down and sit quietly without looking ahead in your packet. Any questions? (wait for response) Ready, Begin.”

6.) Begin stopwatch and time for 5 minutes.

7.) When 5 minutes has lapsed, say:

"Stop working and please put your pencils down. When we tell you to turn to the next page, please work all of the problems in order from left to right as quickly as possible, without skipping problems or making errors, starting with the first problem on the top left. When you finish all of the problems on the first line, begin working on the next problems on the next line. If you finish the assignment before we tell you to stop, please put your pencil down and sit quietly without looking ahead in your packet. Any questions? (wait for response) Ready, Begin." 
8.) Begin stopwatch and time for 5 minutes.

$\square$ 9.) When 5 minutes has lapsed, say:

"Stop and please put your pencils down. Turn to the next page in your packet. You will see nine questions regarding the two assignments you just completed. Please read each question carefully and answer by circling the number or letter corresponding to the answer you wish to choose. When you finish, please remain seated and put your pencil down."

10.) When students have finished, begin collecting packets.

$\square$ 11.) Dismiss students to the classroom and say:

"Thank you for participating everyone. You can choose a prize out of the prize box We will see you again later this week."

Session 10 Procedural Protocol

1.) Open the file named "Participant List" on the password protected flash drive.

2.) Greet students and say, "Hi everyone, we are going to do some math today."

3.) Pass out pencils and each student's respective assignment packet.

**Make sure that participant numbers on each packet match their assigned number in the "Participant List" **

4.) Instruct students to not open the packets, say:

"I am passing out some math assignments and pencils. Please do not open your packets until I provide instructions and say begin."

5.) Read instructions:

"I will ask you to complete as many problems as you can on some math assignments.

Please work all of the problems on each page in order from left to right (demonstrate with random packet) as quickly as possible, without skipping problems or making errors, starting with the first problem on the top left (point). When you have finished all of the problems on the first line, begin working on the next problem on the next line. If you finish the assignment before we tell you to stop, please put your pencil down and sit quietly without looking ahead in your packet. Any questions? (wait for response) Ready, Begin."

6.) Begin stopwatch and time for 5 minutes.

7.) When 5 minutes has lapsed, say:

"Stop working and please put your pencils down. When we tell you to turn to the next page, please work all of the problems in order from left to right as quickly as possible, without skipping problems or making errors, starting with the first problem on the top left. When you finish all of the problems on the first line, begin working on the next problems on the next line. If you finish the assignment before we tell you to stop, please put your pencil down and sit quietly without looking ahead in your packet. Any questions? (wait for response) Ready, Begin.”

8.) Begin stopwatch and time for 5 minutes.

9.) When 5 minutes has lapsed, say:

"Stop and please put your pencils down. Turn to the next page in your packet. You will see nine questions regarding the two assignments you just completed. Please read each question carefully and answer by circling the number or letter corresponding to the 
answer you wish to choose. When you finish, please remain seated and put your pencil down."

$\square$ 10.) When students have finished, begin collecting packets.

11.) Pass out debriefing slips.

12.) Read debriefing script.

13.) Dismiss students to the classroom and say:

"Thank you for participating everyone. Please line up if you wish to choose a prize from the prize box for participating." 


\section{APPENDIX K: PREFERENCE AND PERCEPTION RATINGS WORKSHEET}

1.) On a scale of 1 to 4 , how much time would assignment I take to complete from start to finish?
1
2
3
4

Little time

A lot of time

2.) On a scale of 1 to 4 , how much time would assignment $F$ take to complete from start to finish?
1
2
3
4
Little time
A lot of time

3.) On a scale of 1 to 4 , how much effort would assignment I take to complete from start to finish?
1
2
3
4
Little effort A lot of effort

4.) On a scale of 1 to 4 , how much time would assignment $\mathrm{F}$ take to complete from start to finish?
1
2
3
4
Little effort
A lot of effort

5.) On a scale of 1 to 4 , how difficult is assignment I?

$\begin{array}{cccc}1 & 2 & 3 & 4 \\ \text { Not Difficult } & & & \text { Very Difficult }\end{array}$

6.) On a scale of 1 to 4 , how difficult is assignment F?

$\begin{array}{cccc}1 & 2 & 3 & 4 \\ \text { Not Difficult } & & & \text { Very Difficult }\end{array}$

7.) Which assignment would take the most time to complete from start to finish:

I $\mathrm{F}$

8.) Which assignment would take the most effort to complete from start to finish:

9.) Which assignment was most difficult?

$$
\text { I } \quad \mathrm{F}
$$

I F

10.) Which assignment would you choose for homework?

I $\mathrm{F}$




\section{APPENDIX L: PARTICIPANT DEBRIEFING SCRIPT}

We want to thank you for your participation in this study about math. The purpose was to look at the types of assignments that students like to complete. We were trying to find out if students prefer completing math assignments with short, easier, problems mixed in. We also want to know if students prefer completing math assignments that do not include problems that are too difficult or frustrating to complete. We have given you a copy of what this study was about for you and your parents to review. Anonymous results for all students as a group can be obtained from Gary L. Cates, PhD. Your individual performance will not be made public in a manner that will jeopardize anonymity. Data will be kept for no more than 5 years and then shredded. For further information please contact Dr. Cates by calling (309) 438-3123 or e-mail glcates@ilstu.edu.

Thank you for your participation,

Gary L. Cates, Ph.D., NCSP, BCBA

Associate Professor of Psychology

School Psychology

Illinois State University

Samantha DeHaan, M.S.

Advanced Doctoral Student

School Psychology

Illinois State University 


\section{APPENDIX M: INTERVENTION FIDELITY CHECKLIST}

Session \#

Researcher Name

Observer Name
Date

Time

Score

Session 1 Procedural Protocol Checklist

\begin{tabular}{|c|c|c|}
\hline 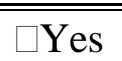 & 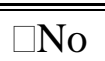 & Passed out assent forms and pencils to all prospective participants. \\
\hline$\square$ Yes & $\square$ No & Read assent script verbatim \\
\hline$\square$ Yes & $\square$ No & Correctly passed out Session 1 packet to those who chose to participate. \\
\hline$\square$ Yes & $\square$ No & Instructed students to complete the demographic page (i.e., first page) \\
\hline$\square$ Yes & $\square$ No & Read CBM directions verbatim. \\
\hline$\square$ Yes & $\square$ No & $\begin{array}{ll}\text { Accurately timed CBM probes (i.e., 1-minutes) } & \text { Stop: } \\
\text { 1.) Start: } & \text { Stop: } \\
\text { 2.) Start:- } & \text { Stop: } \\
\text { 3.) Start:- Stop: } & \text { Stop: } \\
\text { 4.) Start: } & \text { Stop: } \\
\text { 5.) Start:- } & \text { Start: }\end{array}$ \\
\hline$\square$ Yes & $\square$ No & Dismissed students as outlined in protocol \\
\hline
\end{tabular}

Sessions 2-9 Procedural Protocol Checklist

\begin{tabular}{|l|l|l|}
\hline \hline$\square$ Yes & $\square$ No & Greeted students \\
\hline$\square$ Yes & $\square$ No & Passed out pencils and correctly passed out assignment packets \\
\hline$\square$ Yes & $\square$ No & Correctly passed out Session 1 packet to those who chose to participate. \\
\hline$\square$ Yes & $\square$ No & Provided instruction for students to not open packets until “begin” \\
\hline$\square$ Yes & $\square$ No & Read directions for intervention verbatim \\
\hline$\square$ Yes & $\square$ No & $\begin{array}{l}\text { Accurately timed assignment 1 (i.e., 5-minutes) } \\
\text { Start: }\end{array}$ \\
\hline$\square$ Yes & $\square$ So & Read directions for intervention verbatim \\
\hline$\square$ Yes & $\square$ No & $\begin{array}{l}\text { Accurately timed assignment 2 (i.e., 5-minutes) } \\
\text { Start: }\end{array}$ \\
\hline$\square$ Yes & $\square$ No & Instructed students to complete preference/perception ratings (verbatim) \\
\hline$\square$ Yes & $\square$ No & Collected packets \\
\hline$\square$ Yes & $\square$ No & Dismissed students \\
\hline
\end{tabular}


Session 10 Procedural Protocol Checklist

\begin{tabular}{|l|l|l|}
\hline \hline$\square$ Yes & $\square$ No & Greeted students \\
\hline$\square$ Yes & $\square$ No & Passed out pencils and correctly passed out assignment packets \\
\hline$\square$ Yes & $\square$ No & Correctly passed out Session 1 packet to those who chose to participate. \\
\hline$\square$ Yes & $\square$ No & Provided instruction for students to not open packets until "begin” \\
\hline$\square$ Yes & $\square$ No & Read directions for intervention verbatim \\
\hline$\square$ Yes & $\square$ No & $\begin{array}{l}\text { Accurately timed assignment 1 (i.e., 5-minutes) } \\
\text { Start: }\end{array}$ \\
\hline$\square$ Yes & $\square$ No & Read directions for intervention verbatim \\
\hline$\square$ Yes & $\square$ No & $\begin{array}{l}\text { Accurately timed assignment 2 (i.e., 5-minutes) } \\
\text { Start: }\end{array}$ \\
\hline$\square$ Yes & $\square$ No & Instructed students to complete preference/perception ratings (verbatim) \\
\hline$\square$ Yes & $\square$ No & Collected packets \\
\hline$\square$ Yes & $\square$ No & Passed out debriefing slips \\
\hline$\square$ Yes & $\square$ No & Read debriefing script verbatim to students \\
\hline$\square$ Yes & $\square$ No & Allowed students to choose a prize \\
\hline
\end{tabular}

